\title{
Sovereign Credit Risk, Liquidity, and ECB Intervention: Deus ex Machina? *
}

\author{
Loriana Pelizzon \\ Marti G Subrahmanyam \\ Davide Tomio \\ Jun Uno
}

This draft: November 2013.

\begin{abstract}
We explore the interaction between credit risk and liquidity, during the Euro-zone crisis, in the Italian sovereign bond market, using a unique tick-by-tick dataset, from the period June 2011-December 2012. We document a strong, dynamic relationship between changes in sovereign credit risk and market liquidity, conditional on the credit default swap (CDS) spread: When the CDS is above 500 basis points (bp), market liquidity adjusts more rapidly and significantly to changes in the credit risk. Other global systemic factors also affect market liquidity, while, surprisingly, the specific credit risk of primary dealers plays only a modest role, especially under conditions of stress. Further, the Long-Term Refinancing Operations (LTRO) by the European Central Bank (ECB) on December 8, 2012, clearly attenuated the relationship between credit risk and liquidity.
\end{abstract}

Keywords: Liquidity, government bonds, financial crisis, MTS bond market

JEL Classification: G01, G12, G14.

\footnotetext{
${ }^{*}$ Ca' Foscari University of Venice and Goethe University Frankfurt, Stern School of Business at New York University, Copenhagen Business School, and Waseda University, respectively. We thank Einaudi Institute of Economics and Finance, the NYU Stern Center for Global Economy and Business, and the NYU-Salomon Center for financial Support. We thank Monica Billio, Rohit Deo, Rama Cont, Clara Vega and participants at the CREDIT 2013 Conference, Venice, for their insightful comments on a previous draft of this paper. We thank Stefano Bellani, Mitja Blazincic, Alberto Campari, Alfonso Dufour, Carlo Draghi, Peter Eggleston, Sven Gerhardt, and Davide Menini for sharing their thorough understanding of market practice with us. We also thank the MTS group for providing us with access to their tick-by-tick trade and quote database and, in particular, Simon Linwood and Christine Sheeka, for their assistance in interpreting the data. The views expressed in the paper are those of the authors and are not necessarily reflective of the views of the MTS group. We are responsible for all remaining errors. Corresponding author: Loriana Pelizzon, loriana.pelizzon@unive.it.
} 


\section{Introduction}

The challenges facing the governments of the GIIPS countries (Greece, Ireland, Italy, Portugal and Spain) in refinancing their debt marked the genesis of the Euro-zone sovereign debt crisis. Following a series of credit rating downgrades of three countries on the Euro-zone periphery, Greece, Ireland and Portugal, in the spring of 2010, the crisis spread throughout the Euro-zone, and even beyond. The instability in the Euro-zone sovereign bond market reached its apogee during the summer of 2011, when the credit ratings of two of the larger countries in the Euro-zone periphery, Italy and Spain, were downgraded. This culminated in the serious hurdles faced by several Euro-zone countries in placing their new sovereign bond issues, causing their bond yields to spike to unsustainable levels. The contagion soon spread into the European banking system through the sovereign debt holdings of the major European banks, converting the sovereign debt crisis into a full-fledged banking crisis. It even threatened countries at the core of the Euro-zone, such as France and Germany, due to the close linkages between their major banks and the sovereign debt of countries on the periphery. The crisis has abated to some extent, due in part to fiscal measures by the European Union (EU) and the International Monetary Fund (IMF), but, as we will show in this paper, mostly thanks to the intervention by the European Central Bank (ECB) through a series of policy actions, including the Long-Term Refinancing Operations (LTRO) and Outright Monetary Transactions (OMT) programs, starting in December 2011. Even so, the Euro-zone sovereign debt crisis remains a drag on the economic recovery of the global economy, leaving open the questions of whether the crisis will resurface.

The discussion in the academic and policy-making literatures on the Euro-zone crisis has mainly focused on market aggregates such as bond yields, relative spreads, and credit default swap (CDS) spreads, at various points during the crisis, and the reaction of the market to intervention by the troika: the ECB, the EU and the IMF. Although the analysis of yields and spreads is useful, it is equally relevant for policy makers and market participants to understand the dynamics of market liquidity in the European sovereign debt markets, i.e., the drivers of market liquidity, particularly given the impact market liquidity has on bond yields, as documented in the previous literature on asset prices. In particular, it is important to analyze the inter-relationship between market liquidity and credit risk, as well as the effect of the funding liquidity of the market-makers and how this inter-relationship has changed thanks to the ECB interventions. An improvement in market liquidity moderates bond yields, and a deeper understanding of the determinants of market liquidity could help policy makers in their efforts to improve it. Consequently, it will allow policy makers to assess the efficacy of their interventions in these markets in terms of diminished risk perceptions.

Why is the linkage between credit risk and market liquidity of considerable interest to monetary economists and policy markets, such as central bankers and public debt managers? First, market liquidity and liquidity risk have an important influence on interest rates, variables that monetary policy actions, such as quantitative easing, attempt to control. Second, the major central banks of the world, including the Federal Reserve System, the Bank of Japan and the ECB, have employed unusually strong quantitative easing measures, which would ultimately have to be unwound, and a sound knowledge of the mechanisms affecting market liquidity in the sovereign bond market would be of paramount importance, when this occurs. Third, monetary policy has a direct impact, not only on the level of short term (and perhaps, long term) interest rates, but also market liquidity and liquidity risk, as we demonstrate in this paper. Fourth, again as we show in this paper, monetary policy has an impact on market sentiment, and hence, on credit risk, as well as the interplay between credit risk and market liquidity. 
The Euro-zone sovereign crisis provides us with an unusual laboratory in which to study how the interaction between credit risk and illiquidity played out, in a more comprehensive framework, compared to previous studies of corporate or other sovereign bond markets. Compared to corporate bonds, which are generally traded over-the-counter, we have the advantage of investigating an exchange-traded market, using a unique, tick-by-tick data set obtained from the Mercato dei Titoli di Stato (MTS), the world's largest electronic trading platform for sovereign bonds. With respect to the US Treasury or other sovereign bonds markets, the presence of a common currency for sovereign issuers with different credit standings allows for the separate identification of the risk free rate and the credit spread dynamics. Further, unlike prior analyses that presume sovereign debt to be free of credit risk, our analysis addresses the issue of sovereign credit risk head on, in a setting where differential monetary policies and exchange rate dynamics do not confound the identification of sovereign credit risk. In fact, we are able to investigate the dynamic relationship between credit risk and market liquidity, measured by proxies constructed with intra-day data, on a daily basis. We also analyze other risk factors, such as those measuring global systemic risk, the counter-party risk of the primary dealers, and funding liquidity risk, during a period when several macro-economic shocks affected the sovereign risk of many countries in the Euro-zone. On top of this, we have also been able to directly investigate how the ECB programs affected both credit risk perceptions and market liquidity. It is difficult to imagine another setting where the confluence of these issues could be studied with such detailed data as are available in the context of the Euro-zone crisis.

Ours is the first paper to empirically investigate the dynamic relationship between market liquidity and credit risk in the sovereign bond market, particularly during a period of crisis. The existing literature has highlighted the theoretical relationship between credit risk and market liquidity, as well as that between funding liquidity and market liquidity (see Brunnermeier and Pedersen (2009)) in a generic sense. We focus here on such an analysis in the Italian sovereign bond market, particularly since the inception of the Euro-zone crisis in July 2011. Italy has the largest sovereign bond market in the Euro-zone (and the third largest in the world after the US and Japan), and is also a market that experienced substantial stress during the recent crisis. In addition, it has a large number of bond issues with a wide variety of characteristics. Hence, the Italian sovereign bond market is best suited to an in-depth analysis of the liquidity effects of the crisis, both in terms of the inter-linkages between sovereign credit risk and liquidity, and the credit risk and funding constraints of the market-makers.

We perform our analysis focusing on the MTS Global Market bond trading system. Our data set, obtained from MTS, is unique for several reasons. First, this market is the largest interdealer trading system for Euro-zone government bonds, largely based on electronic transactions, and hence one of the most important financial markets in the world. ${ }^{1}$ Second, Italy has the largest number of sovereign bonds outstanding and the largest trading volumes on the MTS trading platform, which permits an examination of the link between credit risk and liquidity. Third, similar to other countries in the Euro-zone, Italy is distinctive in that its central bank, the ECB, is completely independent of its government. Hence, the central bank's monetary policy has a qualitatively different impact on its sovereign credit risk, as well as on the market liquidity of its sovereign bonds, compared to countries whose central banks are somewhat within the control of the sovereign.

The main focus of our research in this paper is to determine the dynamic relationship between market liquidity and credit risk, as well as other risk factors such as global systemic risks, primary dealers' credit risk, and the funding liquidity risk of market-makers. We study the effects of the ECB

\footnotetext{
${ }^{1}$ While it is difficult to precisely quantify the market share of the MTS in terms of trading in Italian sovereign bonds, estimates provided to us by leading market participants range between $80 \%$ and $85 \%$ of interdealer transactions.
} 
measures in the context of this dynamic relationship. We employ a range of liquidity metrics, from simple measures of volume to more complex measures incorporating the bid-ask spread and the price impact, as well as the time series of CDS spreads, to analyze the liquidity of Italian sovereign bonds during the period from June 1, 2011 to December 31, 2012. We allow the data help us uncover how the relationship between credit risk and liquidity depends on the endogenous level of the CDS spread, with the changes in the latter depending on particular break points in calendar time. In addition, we examine how these relationships were influenced by the interventions by the ECB, and whether those interventions were successful in ameliorating credit risk and illiquidity.

First, we explore the hypothesis that an increase in the credit risk, as measured by changes in the Italian CDS spread, adversely affects market liquidity. Given the data we have available, we are able to investigate this relationship on a daily basis to determine the quantitative impact of changes in credit risk on market liquidity. We find that market liquidity, measured by several alternative measures, follows a mean-reverting process with a lag of a day, which is largely significant at the $1 \%$ level, and accounts for about $10 \%$ of the changes in market liquidity. Further, the coefficients of both contemporaneous changes in the CDS spread, and lagged changes in the CDS, are statistically and economically significant, after controlling for the lagged liquidity variable. While the mean-reverting process is important in explaining the changes in market liquidity, the credit risk variable exhibits even stronger effects in terms of economic impact. In particular, a change in the credit spread by 10bp induces an increase in the bid-ask spread of the average bond by $8 \mathrm{bp}$ on the same day and another $11 \mathrm{bp}$ on the next day.

Second, we examine whether the relationship between credit risk and market liquidity is structurally altered when the CDS spread crosses a certain threshold. We let the data help us uncover how the relationship between credit risk and liquidity depends on the endogenous level of the CDS spread, and find that the relationship between market liquidity and credit liquidity is rather different below and above $500 \mathrm{bp}$ ! We find not only that a change in the CDS spread has a larger impact on market liquidity when the CDS spread is above $500 \mathrm{bp}$, but that the lead-lag relationship between credit risk and liquidity disappears; thus, above the threshold, only the contemporaneous relationship between the market liquidity and CDS spreads, with no lagged effects, obtains. This dual relationship is present only until December 8, 2011. In fact, our test for a structural break indicates that, on December 8, 2011 (when the ECB formally announced the implementation of the LTRO program), the relationship changes significantly. Thereafter, changes in market liquidity still respond to changes in credit risk, but with a lagged effect, albeit with a significantly lower intensity.

Third, we investigate other factors that may affect market liquidity and, in particular, whether global systemic risk and funding liquidity factors, or Italian sovereign-specific risk factors per se, affect market liquidity. We perform several additional analyses, and confirm that the dual relationships below and above the threshold in the CDS spread of $500 \mathrm{bp}$ holds before 2011, while market liquidity is largely related to the global systemic risk factor, USVIX, and the market credit risk factor, the Euribor-Eonia spread, as well as the Italian sovereign-specific risk. During 2012, after the LTRO program was initiated, market liquidity responds only to the changes in market liquidity on the previous day, while the only contemporaneous variable that affects market liquidity significantly is the global funding liquidity variable proxied by the Euro-US Dollar cross-currency basis swap spread (CCBSS). ${ }^{2}$ Fourth, we analyze the effect of the credit risk of primary dealers on market liquidity

\footnotetext{
${ }^{2}$ This spread represents the additional premium paid per period for a cross-currency swap between Euribor and US Dollar Libor. Market participants view it as a measure of the liquidity imbalances in currency flows between the Euro and the US Dollar, the global reserve currency.
} 
through the potential funding liquidity channel, strictly related to their own credit risk. We analyze the effects of changes in the CDS spreads of Italian, European and non-European primary dealers on changes in market liquidity, but find that market-makers' own credit risk has an impact on the Italian government bonds market liquidity only in periods of severe stress. Finally, we perform a Granger causality test using changes in the liquidity measures and the changes in the CDS spreads to investigate whether illiquidity drives credit risk or vice versa. The results show that it is largely credit risk that affects market liquidity and not the other way around.

In Section II of the paper, we survey the literature on sovereign bonds, particularly the papers relating to liquidity issues. In the following section, Section III, we discuss the hypotheses to be tested in the paper and their economic motivation. In Section IV, we provide a description of the MTS market architecture, the features of our database, our data filtering procedures and our liquidity measures. In Section V, we present our descriptive statistics. Our analysis and results are presented in Section VI. Section VII concludes.

\section{Literature Survey}

Thus far, no other papers have investigated the dynamic relationship between credit risk and the market liquidity of sovereign bond markets. The existing literature on bond market liquidity seldom focuses on sovereign bond markets. One exception is the US Treasury bond market; yet, even in this case, most papers cover periods before the current financial crisis and address issues related to the pricing of liquidity, in bond yields. Indeed, the relation between sovereign risk and market liquidity has not been investigated, thus far, in the US Treasury market, possibly because US sovereign risk was not an issue up until the recent credit downgrade by Standard \& Poor's. Similarly, there is a handful of papers on the European sovereign bond markets, and again, these papers generally examine a limited time period, mostly prior to the global financial crisis and largely focusing on the impact of market liquidity on bond yields. Hence, it is valid to conclude that the existing literature on the sovereign bond markets is fairly limited in depth and scope, in the context of what we study in this paper: the relationship between credit risk and liquidity in the Euro-zone sovereign bond markets during the depths of the recent Euro-zone crisis. Nevertheless, we provide below a short summary of the existing literature so as to place our research in context.

We begin with a brief review of the papers on liquidity in the US Treasury bond market. Fleming and Remolona (1999) study the price and volume responses of the US Treasury markets to unanticipated macro-economic news announcements. Chakravarty and Sarkar (1999) study the determinants of the bid-ask spread in the corporate, municipal and government bond markets in the US during 1995-1997, using data from the National Association of Insurance Commissioners. Fleming (2003) studies the realized (i.e., effective) bid-ask spread using GovPX data from 1996-2000, and finds that it is a better measure of liquidity than the quote size, trade size, on-the-run/off-the-run spread and other competing metrics. Pasquariello and Vega (2006) analyze the announcement effects of macro news using daily data from GovPX on the US Treasury bond market. In a related paper, Pasquariello, Roush and Vega (2011) study the impact of outright (i.e., permanent) open-market operations (POMOs) by the Federal Reserve Bank of New York (FRBNY) on the micro-structure of the secondary US Treasury market. Goyenko, Subrahmanyam and Ukhov (2011) use quoted bid and ask prices for Treasury bonds with standard maturities, obtained from the Center for Research in Security Prices (CRSP) database, for the period from November 1967 to December 2005, to study the determinants 
of liquidity in the US Treasury bond market. They document that order flow surprises are linked to macro-economic news announcements.

There are a few papers in the literature analyzing data from the electronic trading platform similar to MTS known as BrokerTec, which was introduced in 2000. Fleming and Mizrach (2009) provide a detailed description of this market and an analysis of its liquidity, showing the latter to be much greater than has been reported in prior studies using less detailed data from GovPX. Using more recent data from BrokerTec, Engle, Fleming, Ghysels and Nguyen (2011) propose a new class of dynamic order book models based on prior work by Engle (2002). They show that liquidity decreases with price volatility, but increases with liquidity volatility.

There is a vast literature on liquidity effects in the US corporate bond market, examining data from the Trade Reporting and Compliance Engine (TRACE) database maintained by the Financial Industry Regulatory Authority (FINRA) and using liquidity measures for different time periods, including the global financial crisis. This literature is relevant to our research both because it analyzes a variety of liquidity measures and because it deals with a relatively illiquid market with a vast array of securities. For example, Friewald, Jankowitsch and Subrahmanyam (2012a) show that liquidity effects are more pronounced in periods of financial crisis, especially for bonds with high credit risk, based on a sample of over 20,000 bonds and employing several measures including the Amihud measure, the price dispersion measure and the Roll measure, apart from bond characteristics and transaction measures such as the bid-ask spread. ${ }^{3}$

In the context of European sovereign bond markets, Coluzzi, Ginebri and Turco (2008) use various liquidity measures to analyze Italian Treasury bonds, using data from the MTS market during the period 2004-2006. Dufour and Nguyen (2011) analyze data from 2003-2007 for the Euro-zone sovereign bond market to estimate the permanent price response to trades. Beber, Brandt and Kavajecz (2009) analyze the Euro-zone sovereign markets using MTS data between April 2003 and December 2004. They show that most of the yield spread differences are accounted for by differences in credit quality, although liquidity plays a role for the bonds of higher-rated countries. Similar results have been found for a more recent time period by Favero, Pagano and von Thadden (2010). More recently, Bai, Julliard and Yuan (2012) study how liquidity and credit risks have evolved in the Euro-zone sovereign bond markets since 2006. They conclude that bond yield spread variations prior to the recent global financial crisis were mostly due to liquidity concerns but, since late 2009, they have been more attributable to credit risk concerns, exacerbated by contagion effects.

The paper whose analysis is most closely related to ours is by Darbha and Dufour (2012), who use a range of liquidity proxies to analyze the liquidity component of Euro area sovereign bond yield spreads prior to the global financial crisis (2004-2007), and during the crisis period (2007-2010). They find that liquidity, particularly measured by the bid-ask spread of non-AAA bonds, explains the dynamics of corresponding yield spreads better during the crisis than prior to the crisis.

There are several important differences between the prior literature and the evidence we present in this paper. First, we are the first to focus on sovereign credit risk, which is a relatively recent concern among the G8 countries. Second, we focus on liquidity (rather than yield spreads), measured by a range of liquidity metrics, and investigate the relationship between market liquidity in the cash bond market and credit risk measured by changes in the CDS spread on the Italian sovereign debt.

\footnotetext{
${ }^{3}$ Similar results have been obtained by Dick-Nielsen, Feldhütter and Lando (2012), who investigate the effect of credit risk (credit ratings) on the market liquidity of corporate bonds. Other recent papers quantifying liquidity in this market provide related evidence. See, for example, Mahanti, Nashikkar, Subrahmanyam, Chacko and Mallik (2008), Ronen and Zhou (2009), Jankowitsch, Nashikkar and Subrahmanyam (2011), Bao, Pan and Wang (2011), Nashikkar, Subrahmanyam and Mahanti (2011), Lin, Wang and Wu (2011), and Feldhütter (2012).
} 
We also examine the credit risk of the primary dealers, measured by their CDS spreads. Third, while most of the previous literature spans the past, and thus more normal, time periods in the US and Euro-zone markets, the sample period we consider includes the most relevant period of the Euro-zone sovereign crisis, the period since mid-2011, when both Italy and Spain experienced a series of rating downgrades that spread instability both to other European countries (including France, and later on, even Germany) and to many European banks. Fourth, our focus is on the interaction between credit risk and liquidity, i.e., how credit risk affects illiquidity and vice versa, which has been of particular interest since the onset of the Euro-zone crisis. In particular, we examine the dynamics of the interaction between credit and liquidity, tracing these effects over time. We also explore how the effect of a macro-credit shock on liquidity is affected by the level of the credit risk. This is in contrast to the prior literature on both corporate bonds and, to a lesser extent, sovereign bonds, which focuses only on the static cross-sectional relationship between credit quality and liquidity. Last but not least, we define global macro-economic variables relating to credit, market liquidity and funding liquidity, which are important determinants of credit risk and liquidity in sovereign debt markets.

\section{Hypothesis Development}

In this section, we provide an overview of the questions we pose and the hypotheses we test in our research. Our approach is to examine the validity of specific arguments regarding the relationship between credit risk and liquidity risk in the Italian sovereign bond market. We draw upon the results from the broad micro-structure literature in constructing these hypotheses.

H1: The dynamics of credit risk are an important factor in the determination of the dynamics of liquidity in the Italian sovereign bond market: Changes in credit risk have an important bearing on changes in liquidity.

The micro-structure literature has extensively investigated the impact of liquidity on the price of corporate bonds, and to some extent sovereign bonds. However, to our knowledge, there is no empirical evidence of the dynamic relationship between credit risk and changes in market liquidity. The motivation for this hypothesis comes from the literature pioneered by Bagehot (1971), Glosten and Milgrom (1985), Kyle (1985), and Easley and O'Hara (1987), which argues that asymmetry of information about the value of an asset has a positive impact on liquidity, in particular the bid-ask spread. The intuition is that, if the market-marker anticipates that there is a higher probability of trading with a market participant with superior information, she will raise her bid-ask spread for all participants to compensate for this possibility. As argued by Kyle, this effect translates into other proxies for liquidity, such as volume, market breadth, depth and price impact. This prediction is similar to the one implied by inventory models of micro-structure (such as Garbade and Silber (1976), Garman (1976), Amihud and Mendelson (1980) and Ho and Stoll (1980)), which suggest that the greater the risk of an asset, the greater the aversion of market-makers to hold the asset (long or short), due to its opportunity costs, and hence the higher the bid-ask spread they will post. To the extent that the asymmetry of information about an asset is correlated with its underlying risk, the two strands of the literature lead to the same conclusion: an increase in the risk of an asset adversely affects its liquidity.

A similar conclusion follows from risk management practices based on the calculations of the value-at-risk (VaR) used by market participants, particularly market-makers. A portfolio with an 
excessively large VaR erodes a dealer's buffer capacity, thus implying a greater aversion of the dealer towards holding the asset, which results in the dealer setting higher bid-ask spreads (lowering market liquidity). ${ }^{4}$ The connection to the practice of risk-management based on the VaR has also implications for the dynamics of the relationship between credit risk and market liquidity: risk constraints are based on the agent's exposure to credit risk on the previous day, that is day $t$ liquidity depends on the VaR calculated at the end of day $t-1$. In periods of market stress, however, the VaR is often calculated at an intraday frequency, thus implying that day $t$ liquidity will depend on day $t$ credit risk. We address this practice-based prediction in the analysis of the dynamic relation between Italian credit risk and market liquidity.

Based on this theoretical background, we should expect the change in credit risk to be a relevant variable in characterizing the dynamics of liquidity in the market. It is important, therefore, to investigate whether there is any lead-lag relationship between credit risk and illiquidity as well as whether there is any persistence in the adjustment of the liquidity component. Several alternative specifications of this relationship are possible, and our empirical tests are designed to be flexible enough to cover a range of these possibilities. Specifically, our aim is to identify the dynamic relationship between changes in the CDS spread and changes in market liquidity, measured by several alternative metrics.

H2: The relationship between credit risk and liquidity risk is altered when credit risk is high, in particular when the CDS spread on the obligor crosses a certain threshold.

This hypothesis is an elaboration of the first one, and deals with the structural shift in the relationship between changes in credit risk and changes in liquidity when the level of credit risk is high, especially when the CDS spread breaches a certain threshold level, accompanied by sharply higher illiquidity. It is also motivated by observations from market makers and policy pronouncements, which have suggested that the credit risk-liquidity relationship shifted as the credit quality of the Italian sovereign was eroded. In the period under consideration, several economic and political events occurred that caused the level of credit risk to increase more than threefold (the CDS spread shot up from $145 \mathrm{bp}$ to $592 \mathrm{bp}$ ).

Several conceptual arguments can be advanced for such a structural shift in the relationship. First, the adverse change in credit quality was generally accompanied by downgrades in the credit rating, changing the clientele of investors who would want to hold Italian sovereign bonds. Second, margins in the repo market are generally increased as a consequence of the decline in credit quality, making it more expensive to hold Italian sovereign bonds. Third, in the presence of a sharp decline in credit quality, internal (and external) models of risk-weighting and illiquidity used by banks, a major investor segment, would necessarily predict an increase in the capital required to support the higher level of risk. (A similar argument arises for the accounting classification of assets by liquidity into Levels 1, 2 , and 3, the latter calling for more provisions.) This structural break is likely to be particularly important when the credit rating is downgraded below investment grade (Standard \& Poor's or Fitch BBB- (or Moody's Baa3) or better), when the clientele effects are exacerbated. The rule of thumb for traders is that this occurs when the CDS spread goes above $500 \mathrm{bp}$, when the structural shift is likely to fundamentally alter the relationship between credit risk and market liquidity. ${ }^{5}$

\footnotetext{
${ }^{4}$ Reiss and Werner (1998) show that market makers engage in interdealer trading on the London Stock Exchange to actively mitigate their inventory risk, and that dealers who have the most extreme positions are those most likely to trade with each other, in order to share their inventory risk.

${ }^{5}$ This threshold of $500 \mathrm{bp}$ is also used by clearing houses, such as the Depository Trust and Clearing Corporation
} 
Parallel arguments for these effects have been proposed in the literature based on the behavior of agents in a crisis. For example, Duffie, Garleanu and Pedersen (2007) argue that liquidity is more important in crisis periods, when inventory holding costs and search costs are higher, and asymmetric information is more significant. ${ }^{6}$ Moreover, a greater proportion of investors could have shorter horizons in a period of crisis. For example, bond mutual funds and hedge funds could face the possibility of redemptions or be forced to meet value-at-risk requirements and margin calls and, therefore, would wish to hold more liquid assets to address these eventualities (see, e.g., Sadka (2010)). Individual investors could shift more of their portfolios from illiquid to liquid assets as they turn more risk averse. Market-makers may also face more severe funding constraints based on accentuated risk aversion as well as a reduction in risk limits in a crisis.

We investigate this hypothesis, leaving the data to tell us whether there is a level of CDS above which there is a statistically significant change in the relationship between changes in CDS spreads and changes in market liquidity variables. ${ }^{7}$

H3: Monetary policy interventions made by the central bank affect the relationship between credit risk and market liquidity.

Several significant economic and political events occurred in the Euro-zone during our sample period. Apart from jawboning by political leaders and policy makers about potential changes in their behavior, there were announcements of several important policy actions: fiscal measures, including bail-outs by the EU and the IMF, and monetary intervention by the ECB, including the LTRO and OMT programs, which started in December 2011 and continued until July 2012. A significant event, in the judgment of several market observers we spoke to, was the speech by Mario Draghi, the ECB President, who unveiled the potential for new tools to ease the European sovereign debt crisis. ${ }^{8}$ Therefore, the third research question of this paper is whether there are any structural breaks in the estimated relationship around the dates of significant policy interventions, particularly by the ECB. Again, we allow the data to inform us of the presence of any structural breaks over the time period. ${ }^{9}$

H4: Market liquidity is driven by both global systemic factors and macro-economic factors specific to Italy.

We investigate the key mechanisms through which sovereign bond market liquidity is affected. Specifically, we focus on the role played by global systemic factors that may potentially affect market liquidity through the inventory channel, the increase in the risk aversion of market-makers and traders in general, as well as obligor-specific uncertainty and asymmetry of information. This hypothesis relates to the effect of risk factors on the market liquidity of the Italian sovereign bond market: global uncertainty and appetite for risk, as measured by the US volatility index, USVIX; the increase in the cost of funding due to the banking crisis, measured by the Euribor-Eonia spread; the lack of funding liquidity, measured by the Eonia-German T-Bill spread (as suggested by Brunnermeier and Pedersen

(DTCC) and LCH.Clearnet, to switch between quotation of CDS contracts from a yield basis to a price basis, leading to more stringent margining.

${ }^{6}$ There is empirical support for this hypothesis in the context of the US corporate bond market in the work of Friewald, Jankowitsch and Subrahmanyam (2012(a)), Bao, Pan and Wang (2011), Feldhütter (2012), and Dick-Nielsen, Feldhütter and Lando (2012).

${ }^{7}$ We use the threshold test proposed by Hansen (2000), as discussed in Appendix C.

${ }^{8}$ In his speech on July 26, 2012, at the Global Investment Conference in London, Mario Draghi stated: "The ECB is ready to do whatever it takes to preserve the euro. And believe me, it will be enough."

${ }^{9}$ We perform a Chow test (Chow (1960)) to investigate this issue (see Appendix C for the details of the procedure). 
(2009) and others); versus the specific increase in the credit risk of Italian sovereign bonds, that largely causes a decline in liquidity in this market. We also use an alternative proxy, the CCBSS, as a global funding liquidity cost proxy.

H5: The level of financial distress of the primary dealers (market makers) adversely affects market liquidity.

Brunnermeier and Pedersen (2009) present a framework to distinguish between (asset) market liquidity (the ease and cost at which assets can be bought and sold) and funding liquidity (the ability of market-makers to fund their positions). Their model identifies a channel whereby traders become reluctant to take positions when funding liquidity is tight, especially when their positions are capital intensive, calling for higher margins; in turn, such a constraint applying to several market-makers lowers market liquidity. In their model, an adverse shock to primary dealer funding liquidity (the availability of funding) forces market-makers to reduce their inventories and provide less liquidity to the markets, which, in turn, reduces market liquidity. When the impact of the funding liquidity shock on asset market liquidity is strong enough, the decrease in asset liquidity makes funding even tighter for market-makers, causing a self-reinforcing liquidity spiral, in which both funding liquidity and asset liquidity continue to deteriorate. An important driver of the willingness of market-makers to take positions is their ability to raise funds in the market to finance their positions; this, in turn, depends on their credit quality, proxied by their CDS spreads. Hence, we use the average CDS spread of the group of market-makers in the MTS market, who are all primary dealers in the Italian sovereign bond market, as a determinant of market liquidity. The structure of the market is ideal to investigate the issue of the relationship between funding liquidity and market liquidity, which, to our knowledge, has not yet been investigated empirically. The funding liquidity channel shows another potential route through which bank credit risk may affect sovereign risk (well before the bank bailout channel investigated by Acharya, Drechsler and Schnabl (2011) could apply).

\section{H6: Over time, the change in credit risk leads changes in market liquidity and vice versa.}

The prior literature has focused on the distinction between the two components of the bond yield spread: the liquidity component and the credit risk component (see Acharya and Pedersen (2005), for the general argument in the context of equity markets, and Friewald, Jankowitsch and Subrahmanyam (2012a), in the context of corporate bonds). However, for the reasons we have stressed above, it is easy to argue that market liquidity (and therefore liquidity risk) is closely related to credit risk too. The market's perception of credit risk could itself be strictly related to market liquidity, though, especially under conditions of market stress. ${ }^{10}$ In fact, the actions of the ECB could have a direct impact on market liquidity, while indirectly affecting credit risk perceptions: as soon it is easy to buy or sell bonds, credit risk falls sharply; as bonds mature, new bonds can be issued to finance their repayment! However, this mechanism could be implemented by the ECB only for a short period in their LTRO and OMT programs. Therefore, we expect that the ECB could affect the Granger-causality between credit risk and market risk only for a short period.

The related question we investigate is whether the increase in credit risk drove the reduction of liquidity in the bond market or vice versa, i.e., whether the low liquidity in the bond market increased

\footnotetext{
${ }^{10}$ This argument is conceptually similar to the framework of He and Milbrandt (2013) in the context of corporate bonds, where a default-liquidity loop arises in an illiquid secondary bond market in default: earlier endogenous default worsens a bond's market liquidity, which in turn leads to earlier endogenous default.
} 
the CDS spread or the other way around. Which of the two economic variables contributes most to the other is a question that we attempt to resolve with a lead-lag analysis using a simple Granger causality test, a statistical notion of causality based on the relative forecasting power of two time-series.

\section{MTS Market Structure and Data Description}

Our data consists of all quotes, orders, and transactions that took place on the MTS European government bond market, and are provided by the MTS Group. These high-frequency data cover trades and quotes for the fixed income securities issued by twelve national treasuries and their local equivalents: Austria, Belgium, Finland, France, Germany, Greece, Ireland, Italy, the Netherlands, Portugal, Slovenia and Spain. The MTS system is the largest interdealer market for Euro-denominated government bonds and is made up of many markets, including the EuroMTS (the "European market"), EuroCredit MTS, and several domestic MTS markets. In this study, we will focus on the liquidity of Italian government bonds, regardless whether the trading or quoting activity took place on the domestic or European market. The liquidity measures used later on in this paper do not depend on the market where the order placement and trading activity takes place. ${ }^{11}$

The MTS trading system is an automated quote-driven electronic limit order inter-dealer market, in which market-makers' quotes can be "hit" or "lifted" by other market participants via market orders. EuroMTS is the reference electronic market for European benchmark bonds, which are bonds with an outstanding value higher than 5 billion Euro. ${ }^{12}$ Appendix A provides details of the market architecture, trading protocol and data released for the MTS market.

The sample period of our study is from June 1, 2011 to December 31, 2012. ${ }^{13}$ The time period we analyze provides a good window through which to study the behavior of European government bond markets during the most recent part of the Euro-zone sovereign debt crisis and the period leading up to it. Our data set consists of 152 Italian government bonds. Table1 presents the distribution of these bonds in terms of maturity and coupon rate, between maturity groups as well as bond types. The maturity groups chosen were determined by looking at the time distance between each bond maturity and the closest whole year. As Table 1 shows, the large majority (in numbers) of the bonds analyzed have short maturities (from 0 to 5 years). All bonds considered in this analysis belong to one of the following types: Buoni Ordinari del Tesoro (BOT) or Treasury Bills, Certificato del Tesoro Zerocoupon (CTZ) or Zero coupon bonds, Certificati di Credito del Tesoro (CCT) or Floating notes, or Buoni del Tesoro Poliennali (BTP) or Fixed-income Treasury Bonds. The vast majority of the bonds in our sample belong to the BOT and BTP types. We exclude inflation and index-linked securities from our analysis.

\section{INSERT TABLE 1 HERE}

\footnotetext{
${ }^{11}$ Three notable exceptions are the Quoted Spread, the Quoted Quantity, and the Lambda, as defined in Section IV.I. The domestic market is chosen as the reference for a liquidity measure, when the measure differs between the European and the Italian domestic market.

${ }^{12}$ See also Dufour and Skinner (2004).

${ }^{13}$ The start date of this sample is dictated by the availability of detailed tick-by-tick, second-by-second, data from MTS. Prior to June 1, 2011, the MTS data on quotes and quote revisions were not quite as detailed. The end date is dictated by a major change in the market structure that was implemented in December 2012, and that changed the role of market-makers acting in the European section of the MTS market. Fortuitously, the period we consider covers a large part of the Euro-zone crisis.
} 
In order to control for and characterize the effect of global credit and liquidity risk, we employ several macro-economic indicators, most of which are common in the academic literature. The EuriborEonia spread captures the (global) market credit risk, through an increase in the cost of funding, and is measured as the difference between the 3-month Euro Area Inter-Bank Offered Rate (Euribor) for the Euro, covering dealings from 57 prime banks, and the 3-month Euro OverNight Index Average (Eonia), or the effective swap rate against the overnight rate computed as a weighted average of all overnight interbank unsecured lending transactions reported by 44 banks in the Euro area. The Eonia-German T-Bill spread is a measure of funding liquidity (macro liquidity risk) and is the difference between the 3 -month Eonia and the yield of the 3-month German Treasury bill. The USVIX, measuring global systemic risk, is the implied volatility index of S\&P 500 index options, calculated by the Chicago Board Options Exchange (CBOE) and is used widely as a market sentiment indicator. The Euro Stoxx 50 is a blue-chip index for the Euro-zone and covers 50 stocks from 12 Euro-zone countries. The CCBSS represents the additional premium paid per period for a cross-currency swap between Euribor and US Dollar Libor, and serves as a proxy for funding liquidity. ${ }^{14}$ Finally, the Italian Government-specific credit risk is measured by the spread of a senior 5-year dollar-denominated CDS contract obtained from Bloomberg. The choice of this proxy for sovereign credit risk is debatable. An alternative potential proxy for Italian sovereign risk could be the BTP-Bund yield spread. We prefer to avoid using the BTP-Bund yield spread, or simply the BTP yield, as an explanatory variable because they are likely to be intimately connected to the bond quote and transaction prices that are also used to calculate our liquidity measures. CDS spreads are obviously related to the BTP yield and the BTP-Bund yield spread (as Figure 1 shows), through arbitrage in the basis between them, but at least are determined in a different market. Moreover, as the figure shows, the CDS spread typically leads the BTP-Bund spread, during much of the sample period, especially during the crisis.

\section{INSERT FIGURE 1] HERE}

\section{IV.I Liquidity measures}

There is no consensus in the academic or policy-making literatures regarding the best metrics for assessing the liquidity of an asset. Thus, although we focus on the quoted bid-ask spread, Quoted Spread, for the exposition, in Section VI.V we report the results for other liquidity measures, which are described in this section. The proxies we employ cover a wide range of metrics that have been used extensively in the literature. ${ }^{15}$ The relationships we investigate allow us to compare the effectiveness of different proxies for estimating liquidity in the MTS market. The proxies we use can be divided into two main categories: quote-based and trade-based measures. Quote-based measures include the (absolute) bid-ask spread (Quoted Spread), total quoted quantity (Quoted Quantity) and the market depth measure, Lambda. Trade-based measures include the actual spread experienced by traders (Effective Spread) and the traded volume (Volume). In addition, we have two liquidity measures that are based on computed values using changes in traded prices, Amihud Measure and Roll Measure, comprehensive metrics that are widely used in the literature.

The Quoted Spread is defined as the difference between the best ask and the best bid, per $100 €$ of face value, proxying for the cost of immediacy that a trader would face when dealing with a small trade. Quoted Quantity, on the other hand, measures the largest amount a trader could buy or sell

\footnotetext{
${ }^{14}$ All global factor data are obtained from Bloomberg.

${ }^{15}$ In a companion paper, Pelizzon, Subrahmanyam, Tomio and Uno (2013), we study these liquidity proxies in a comprehensive manner, in the context of the micro-structure of the Italian sovereign bond market.
} 
at any point in time, if she were not concerned with execution costs. The depth measure Lambda attempts to combine the two previous proxies by measuring by how much a trader would move the best bid (ask) if she were to trade 15 million $€$ of a given bond. ${ }^{16}$ Mathematically, the Lambda on the ask side would be defined as $\lambda^{a}=E\left[\left(P_{t}^{a}-P_{t-1}^{a}\right)\left(Q_{t}\right) \mid Q_{t}=15 M\right]=E\left[\Delta P_{t}^{a}\left(Q_{t}\right) \mid Q_{t}=15 M\right]$, where $P_{t}^{a}$ is the time $t$ ask price following a buy trade of quantity $Q_{t}=15 \mathrm{M}, \lambda^{b}$ would be defined similarly. In order to represent both sides of the market, we consider the mean, $\lambda=\frac{\lambda^{a}+\lambda^{b}}{2}$, in our empirical estimations, as a market depth measure.

As for the trade-based measures, the effective bid-ask spread, Effective Spread is calculated as $Q \cdot(A P-M) \cdot 2$, where $Q=1$ if it is a buy order, and $Q=-1$ if it is a sell order, $A P$ is the face value-weighted trade price, and $M$ is the mid-quote in place at the time the order arrives. Since orders might "walk" the book, once the quantity offered at the best bid and ask price is depleted, effective and quoted spreads are bound to differ, given the endogenous relationship between the quoted spread and the trading decision regarding the quantities bid or offered. Moreover, we consider the traded volume, Volume, as a trade-based liquidity measure.

The Amihud Measure for bond $i$, on day $t$, is calculated in its daily formulation as $\frac{\left\|r_{i t}\right\|}{V_{i t}}$ where $\left\|r_{i t}\right\|$ is the mid-quote return between 9 am and $5 \mathrm{pm}$ (the trading day, minus the first and last halfhours) for bond $i$ on day $t$, and $V_{i t}$ is the bond $i$ day $t$ traded quantity, Volume. The Roll Measure for bond $i$, on day $t$, is calculated as $2 \sqrt{-\operatorname{Cov}\left(\Delta p_{k}, \Delta p_{k-1}\right)}$, where $\Delta p_{k}$ is the price change between transaction $k$ and transaction $k-1$. Following the literature, we calculate the covariances during a 21-day window; we require at least three entries to make this calculation, which means, for example, either three days with three trades each or one day with seven trades in the 21 days preceding the days for which the measure is calculated. ${ }^{17}$

All quote-based measures are calculated at a 5-minute frequency for each bond, then averaged across bonds to calculate a daily market-wide measure. ${ }^{18}$ The effective spread is calculated for our sample of the whole market, volume-weighting the trades of all bonds, while the volume is the sum of the face-value of bonds traded on the MTS on a specific day.

\section{Descriptive Statistics}

Table 2, Panels A and B, presents the summary statistics for the activity and liquidity measures for Italian sovereign bonds traded on the MTS market, between June 2011 and December 2012, spanning the period of the Euro-zone sovereign crisis. The ten columns on the left report time-series averages of the daily statistics. These statistics have been calculated as the time-series averages of the simple averages of the corresponding measure across all bonds that were quoted on the MTS on a given day. ${ }^{19}$

\footnotetext{
${ }^{16}$ This amount was chosen since it is the $90 \mathrm{th}$ percentile of the overall market in terms of trade size. As traders might split up large amounts over several subsequent trades, Lambda captures the price movement caused by a relatively large trade requiring immediacy. It is conceptually equivalent to the concept of market depth defined by Kyle (1985).

${ }^{17}$ This is standard practice in the prior literature, e.g., Dick-Nielsen (2009), and Friewald, Jankowitsch and Subrahmanyam (2012a).

${ }^{18}$ It is common in the sovereign bond literature to separate the bonds into on-the-run and off-the-run issues, or to only consider the former, reckoning that the former are more liquid and more sought after by investors. The Italian sovereign issuer, the Tesoro, often re-issues existing bonds, thus enhancing their liquidity, and hence, the on-the-run/off-the-run dichotomy loses its relevance. In any event, we checked whether there were differences in the quoted or effective bid-ask spread for "new" issues compared to the prior issues and did not find any significant differences. For this reason, we average across all bonds without sorting them by remaining maturity or age since issue.

${ }^{19}$ The Effective Spread is calculated per transaction, then volume-weighted and averaged for the whole market. The Quoted Spread, the Quoted Quantity and the Lambda are calculated at a 5-minute frequency, then averaged per bond,
} 
The three columns on the right show the cross-sectional averages, the maximum and the minimum value, across 152 different bonds, of the respective time-series averages. While this study focuses on the analysis of the time-series data presented in the columns on the left, the columns on the right are referred to in this section in order to highlight the heterogeneity in the cross-section of bonds.

The mean (median) number of bonds quoted each day on the MTS is 90 (90), and the daily volume of trading in the market is slightly above 2 billion $€(1.9$ billion $€)$, which translates into a daily traded volume of each quoted bond of about 30.5 million $€$. Based on these numbers, the daily trading volume in the Italian sovereign bond market (as represented by the MTS) is much smaller than in the US Treasury market, by a couple of orders of magnitude, with the average traded quantity in the latter being around $\$ 500$ billion per day. ${ }^{20}$ The average daily trading volume in the MTS Italian bond market is even smaller than the US municipal market (around $\$ 15$ billion), the US corporate bond market (around $\$ 15$ billion), and the spot US securitized fixed income market (around $\$ 2.7$ billion in asset-backed securities, around $\$ 9.1$ billion in collateralized mortgage obligations, and around $\$ 13.4$ billion in mortgage-backed securities). ${ }^{21}$

Our volume statistics are in line with the stylized facts documented in the previous literature, taken together with the consistent shrinkage of market volume since the Euro-zone crisis began. Darbha and Dufour (2012) report that the Italian segment of the MTS market volume as a whole, over their 1,641-day sample, was 4,474 billion $€ .^{22}$ This translates into an average daily volume of about 3.8 billion $€ .^{23}$ Darbha and Dufour report that the daily volume per bond shrank from 12 million $€$ in 2004 to 7 million $€$ in 2007 . Their sample only includes coupon-bearing bonds; thus, their figures for overall market volume are not directly comparable to ours.

The daily number of trades on the MTS Italian sovereign bond market is 265 in total (or about 3 per bond), which is similar to the 3.47 trades a day per corporate bond on TRACE, as reported in Friewald, Jankowitsch and Subrahmanyam (2012a). Dufour and Nguyen (2011) report an average of 10 trades per day per Italian bond in an earlier period, between 2003 and 2007. As with the trading volume, the number of trades declined during the crisis period compared to earlier years. Our sample period covers the most stressed months of the Euro-zone crisis, when the creditworthiness of several European countries was seriously questioned by market participants. As we will show later, the liquidity in the MTS market was intimately related to the evolution of spreads in the sovereign CDS market, and varied just as drastically, as the time series plots of the CDS spread and the Quoted Spread in Figure 4 shows: Up to the end of 2011, at the peak of the crisis, the two series share a common trend, which is not repeated in the second half of our sample.

Panel (a) of Figure 2 shows the evolution of the Quoted Spread and the Effective Spread, while Panel (b) presents the movements of Quoted Quantity and Lambda. The close correspondence between the liquidity variables can be seen, for example, by considering the highest spike for the Quoted Spread (448bp), which happened on November 8, 2011. On that date, the Italian Prime Minister, Silvio Berlusconi, lost his majority in the parliament, which led to his resignation. The spike in the Quoted Spread corresponds to a similar spike in the Effective Spread, Lambda, and (the inverse of) the Total Quoted Quantity. The event clearly had medium-term effects, as the Quoted Spread persisted at

and finally across all bonds quoted on the MTS on a given day.

${ }^{20}$ See, for example, Bessembinder and Maxwell (2008).

${ }^{21}$ Details for the corporate bond, municipal bond and securitized fixed income markets are provided in Friewald, Jankowitsch and Subrahmanyam (2012a), Vickery and Wright (2010), and Friewald, Jankowitsch and Subrahmanyam (2012b) respectively.

${ }^{22}$ Their sample spans the period from January 2004 through July 2010.

${ }^{23}$ This calculation assumes 250 business days per year. Cf. Table 1, page 34 of their paper. 
around 100bp for about two months, before returning to the time-series median value of $42 \mathrm{bp}$ in January 2012, after the LTRO program had been launched in December 2011. Similar patterns can be observed for the other liquidity variables.

On average, the market-wide average Quoted Spread is $0.506 €$ per $100 €$ of face value: however, this arises with considerable heterogeneity across bonds, and ranges from one bond averaging $0.0009 €$ to another averaging $1.405 €$. The market-wide average Quoted Spread peaked on November 8, 2011 at an average of $4.477 €$ per $100 €$ of face value, while it was at its minimum of $0.131 €$ at the beginning of the sample, and then again towards the second half of 2012. Similarly, the Quoted Quantity was the highest around June 2011 (182 million $€$ per bond) and then declined towards its time-series average of 123 million $€$. Bonds are also heterogeneous in terms of their offered quantity, since they range from 70 million $€$ to 524 million $€$ offered on average per day.

The Lambda measure is plotted in Panel (b) of Figure 2. This depth measure ranges from 0.0038 to 0.255 , which means that, on the worst day, trading 15 million $€$ would move the price by $0.255 €$ per bond, on average, toward the side of the market hit by the order. This measure is also heterogeneous across bonds, ranging from 0 to $0.05 €$. It is relevant to notice that the time-series development of this measure mirrors that of the Quoted Spread, even though it is a more comprehensive measure of liquidity. Incidentally, its behavior is also similar to that of the Quoted Quantity, which is derived from the same quote data.

The second panel of Figure 3 shows the dynamics of the two liquidity measures defined in the above section: the Amihud Measure, which mirrors fairly faithfully the behavior of the bid-ask spread, and the Roll Measure, which does not. The variation in the Amihud Measure over time, from a minimum of $0.25 \mathrm{bp} /$ million to a maximum of $28.60 \mathrm{bp} /$ million, is less dramatic than the changes in the Quoted Spread. This can be attributed to the fact that the Amihud Measure is derived from actual trading data, and thus corresponds more directly to the Effective Spread. The Roll measure, on the other hand, should be closely related to the bid-ask spread, assuming a "bid-ask bounce" however, since $78 \%$ of buy (sell) trades follow a buy (sell) trade in the Italian sovereign bond market, the Roll measure performs poorly by infringing its key assumption. ${ }^{24}$

Due to the endogeneity of the trading decisions of dealers, given the Quoted Spread, the Effective Spread in Figure 2 Panel (a) is typically much lower than the Quoted Spread, and varies from $0.03 €$ to $0.71 €$ per 100 of face value. This is in line with the figure of $0.70 €$ for the 99 th percentile of the quoted spread, at the time of trade execution, that appears in Darbha and Dufour (2012). ${ }^{25}$

\section{Results}

In this section, we address the research questions highlighted in Section III, focusing on the dynamic relationships between credit risk and market liquidity and the effect of the ECB's deus ex machina. Although we conduct our analysis with a range of liquidity proxies, as defined and discussed in Section IV.I, to conserve space, especially in the context of the multiple specifications that we estimate, we

\footnotetext{
${ }^{24}$ Roll (1984) states: "Given no new information about the security, it is reasonable to assume further that successive transactions are equally likely, equally likely to be a purchase or a sale by the market maker as traders arrive randomly on both sides of the market for exogenous reason of their own" (emphasis ours). In our sample, a buy (sell) is twice as likely to follow a buy (sell) than a sell (buy) transaction.

${ }^{25}$ Although we do not focus on the cross-sectional differences between the bonds in this study, we report a multivariate analysis of the cross-sectional relationship between bond characteristics and liquidity measures in Appendix B, which summarizes the results from the companion paper Pelizzon, Subrahmanyam, Tomio and Uno (2013).
} 
only report detailed results in the text for the Quoted Spread, the bid-ask spread that is quoted on any given day. ${ }^{26}$

\section{VI.I The Dynamics of Credit Risk and Liquidity}

The first hypothesis stated earlier relates to the link between changes in the credit risk, measured by the changes in the CDS spread, and changes in liquidity, proxied by the Quoted Spread.

H1: The dynamics of credit risk is an important factor in the determination of the dynamics of liquidity in the Italian sovereign bond market: Changes in credit risk have an important bearing on changes in liquidity.

To investigate this issue, we regress the changes in the liquidity measure on the changes in the CDS spread, and their respective lags. Equation 1 presents our regression specification:

$$
\Delta L M_{t}=\alpha_{0}+\sum_{i=1}^{M} \alpha_{i} \Delta L M_{t-i}+\sum_{j=0}^{N} \beta_{j} \Delta C D S_{t-j}+\epsilon_{t}
$$

where $\Delta L M_{t}$ is the change in the liquidity measure from time $t-1$ to time $t$, and $\Delta C D S_{t}$ is the change in the CDS. ${ }^{27}$ We estimate several variations of the regression in Equation 1 for the liquidity measure, the Quoted Spread, and the results are reported in Table 3, Panel A. ${ }^{28}$

Table 3, Panel A shows that the regression model has significant explanatory power for several independent variables, with an adjusted $R^{2}$ for Specification 6 equal to 0.21. Consistent with Hypothesis 1, we find that the contemporaneous change in the Quoted Spread is strongly related to the change in the CDS spread, with the coefficient being positive and statistically significant. The magnitude of the coefficient suggests that a 100bp (1\%) increase in credit risk is associated with an increase in the quoted spread of 115bp (see Specification 2).

\section{INSERT TABLE 3 HERE}

The change in the CDS spread has both a contemporaneous and a lagged effect on market liquidity, i.e., the reaction of market liquidity to changes in the CDS spread occurs both the same day and the next. The Quoted Spread also shows evidence of an autoregressive component, which indicates that it is also strongly related to the change in the Quoted Spread the day before, with a negative sign: this suggests a dynamic adjustment in the Quoted Spread through a mean reversion effect. This effect can be ascribed to the actions of the market-makers, who adjust their quotes as a reaction, not only to the changes in the traded price, but also to the changes in the quotes of the other primary dealers. If this process of adjustment applies repeatedly after a shock to credit risk, then the market will take time to reach the new steady state of quotations as a response to the shock. This will be revealed in

\footnotetext{
${ }^{26}$ A similar analysis was performed for the other important liquidity proxies and the results are reported in Section VI.V.

${ }^{27}$ We consider log-changes of the variables, to ease the interpretation of the results. Here and henceforth we refer to "log-changes" simply as "changes".

${ }^{28}$ Throughout the paper, statistical significance is always determined on the basis of $t$-tests that are always calculated using heteroskedasticity-robust standard errors.
} 
the data as the impact of the previous day's credit shock, as well as the same-day impact. Moreover, since the calculation of the dealer's VaR generally takes place at the end of the day, the exposure to the credit risk will be taken into account only in the liquidity that the dealer is offering to the market on the day following a credit shock, thus implying the significance of the lagged change in credit risk.

In Specifications 1 to 6, we consider several lags for both the autoregressive terms of the liquidity measure (Quoted Spread) and the change in the CDS spread, and find that, for the CDS changes, the lags beyond the first (i.e., two or more days prior to the dependent variable observation) exhibit a low level of statistical significance. We estimate Equation 1 for different values of $\mathrm{M}$ and $\mathrm{N}$ (i.e., different lag lengths for the changes in the Quoted Spread and the CDS spread, respectively). Various information criteria - Akaike, Modified Akaike, and Bayesian - are all minimized by a model with $\mathrm{M}=3$ and $N=1$ (Specification 6). The Durbin-Watson test rejects the null hypothesis of autocorrelation of errors for all specifications containing at least one lag of the Quoted Spread, and the contemporaneous change in the CDS spread, and so Specification 4 would be sufficient to capture the dynamics of the system, and still ensure well-behaved residuals. However, in an attempt to provide the model that explains the data, we will focus on Specification 6, which is indicated as the best fit by the aforementioned information criteria.

Equation 1 1 above implicitly assumes that the estimated relationship holds independent of the level of credit risk, in particular when the CDS spread is above a particular threshold level. For the reasons discussed in Section III, it is possible that there is a much higher sensitivity of the change in the liquidity measure to changes in credit risk when the CDS spread breaches a particular threshold.

H2: The relationship between credit risk and liquidity risk is altered when credit risk is high, in particular when the CDS spread on the obligor crosses a certain threshold.

We investigate this hypothesis by allowing the data to uncover the presence of a threshold in the level of the CDS spread, above which a different relationship between changes in CDS and changes in market liquidity is observed. We use the test proposed by Hansen (2000), described in detail in Appendix C, to examine this hypothesis, estimating Equation 2 for different $\gamma$.

$$
\begin{aligned}
\Delta L M_{t} & =\alpha_{0}+\alpha_{1} \Delta L M_{t-1}+\alpha_{2} \Delta L M_{t-2}+\alpha_{3} \Delta L M_{t-3}+\beta_{0} \Delta C D S_{t}+\beta_{1} \Delta C D S_{t-1} \\
& +I\left[C D S \leq \gamma_{0}\right]\left(\tilde{\alpha}_{0}+\tilde{\alpha}_{1} \Delta L M_{t-1}+\tilde{\alpha_{2}} \Delta L M_{t-2}+\tilde{\alpha_{3}} \Delta L M_{t-3}+\tilde{\beta}_{0} \Delta C D S_{t}+\tilde{\beta}_{1} \Delta C D S_{t-1}\right) \\
& +\epsilon_{t}
\end{aligned}
$$

Figure 6 shows the test statistic for the estimated $\hat{\gamma}_{0}=496.5 \mathrm{bp}$ to be equal to $\gamma_{1}$ on the $x$-axis, and can be interpreted to obtain the confidence interval. It is striking that this threshold has a point-estimate of 496.5, with a $5 \%$ confidence interval between 487 and 504, and is almost identical for various alternative specifications of the relationship (including whether or not lagged variables are included) and for the range of liquidity measures we employ. ${ }^{29}$

\section{INSERT FIGURE [ 6 HERE}

\footnotetext{
${ }^{29}$ This threshold of $500 \mathrm{bp}$ corresponds closely to the one indicated by many market participants, and corroborated in our conversations in with market makers, as the critical threshold. It has also been identified by reports in the main Italian news agency as a psychologically important barrier, suggesting that Italian sovereign debt would spiral out of control if the spread persisted above this level. See ANSA-Agenzia Nazionale Stampa Associata, December 23, 2011. http: //www.ilsole24ore.com/art/notizie/2011-12-23/spread-torna-sfiorare-quota-063646.shtml?uuid=AaXuwtWE
} 
This confirmation of the presence of a structural shift in the data when the CDS spread crosses a certain threshold is, therefore, quite robust and indicates how important the level of the CDS spread is for market liquidity. As mentioned in the hypothesis section, this break point could be identified as the dividing line between the credit spreads for investment grade bonds and those for high-yield bonds. Once this line is crossed, it may change the clientele of investors who hold Italian sovereign bonds, and also involve different levels of margins, accounting treatment and regulatory capital requirements, fundamentally altering the relationship between changes in credit risk and market liquidity. ${ }^{30}$ Having identified the presence of a threshold, it is interesting to also analyze how the relationship between changes in the CDS spread and changes in market liquidity is modified when the threshold is breached. Panels $\mathrm{B}$ and $\mathrm{C}$ of Table 3 report the results of the threshold regressions for alternative specifications of Equation 1, estimated when the CDS spread has values below and above $500 \mathrm{bp}$.

As the panels show, the relationships below and above $500 \mathrm{bp}$ are rather different from each other. When we investigate only the contemporaneous CDS variables, we find that changes in the CDS spread have a significantly larger economic impact on market liquidity above the threshold of 500 bp than below: As the regression in column 1 shows, the coefficient of the contemporaneous change below the threshold is 0.72 , while above it is 3.64 , with the differences being statistically significant. This means that an increase in the CDS spread by 10bp, below the threshold of $500 \mathrm{bp}$, induces a contemporaneous increase in the bid-ask spread, the Quoted Spread, of 7bp, while above the threshold it induces an increase of 36bp! Adding the lagged variables we find, as reported in Column 6, that below $500 \mathrm{bp}$, market liquidity reacts slowly to changes in the CDS spread, with a significant impact of the autoregressive component and the lagged component of the change in the CDS and the contemporaneous change in the CDS spread the same day is not significant anymore. Above $500 \mathrm{bp}$, the relationship is rather different: market liquidity reacts immediately to changes in the CDS spread, with the impact being largely contemporaneous, since the change in the CDS spread has no impact on the change in the market liquidity the following day. Our conclusion, therefore, is that, in a stressed environment, credit shocks have an immediate impact on market liquidity. ${ }^{31}$

Although the sample period we consider is relatively short (June 15, 2011 to December 31, 2012), we have clear evidence that the several various interventions that occurred during the period may have generated a structural break in the relationship between credit risk and market liquidity. Therefore, the third research question of this paper is whether such a structural break can be detected. Again, we let the data alert us to the presence of a structural break over time.

\section{VI.II Macro-economic Factors and Policy Intervention}

\section{H3: Monetary policy interventions made by the central bank affect the relationship between credit risk} and market liquidity.

\footnotetext{
${ }^{30}$ For instance, on November 17, 2010, the clearing house LCH.Clearnet reported that the margins on Irish sovereign bonds repo transactions would be raised from 16-18\% to 31-33\%, arguing that this decision had been taken "in response to the sustained period during which the yield differential of 10 year Irish government debt against a AAA benchmark has traded consistently over 500 bp". Source: http://www.lchclearnet.com/risk_management/ltd/margin_ rate_circulars/repoclear/2010-11-17.asp

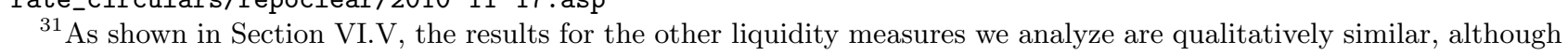
the precise magnitudes vary. In all cases, the threshold of $500 \mathrm{bp}$ is confirmed in a statistically significant manner. The magnified impact of changes in the CDS spread on market liquidity is also confirmed, although the quantitative impact varies across measures.
} 
We investigate this hypothesis using the standard Chow (1960) test for "structural change breaks". As shown in Figure 7, we find that, from a statistical perspective, the test indicates a break at December 8, 2011 for the relationships between the Quoted Spread, and both the CDS and its lag. Again, the result is robust for each of the alternative liquidity measures. Although December 8 was identified purely based on the statistical evidence, as the date where the significance of the Chow test ultimately crosses the $10 \%$ level for relevant relationships between the quoted spread and the CDS spread, it coincides exactly with the date of the announcement of the LTRO program by the ECB! $!^{32}$ Our evidence suggests that this announcement had a clear impact on the restoration of market liquidity.

In order to account for this structural break in our estimations, we split the sample into two periods, and again perform the threshold test in both sub-samples. The threshold test confirms the presence of a different relationship below and above the threshold level of $500 \mathrm{bp}$ for the CDS spread in the first sub-sample (June 1, 2011 to December 8, 2011), but fails to reject the null hypothesis of the absence of a threshold for the second sub-sample. This result indicates that, thanks to the assurance of massive liquidity from the ECB, even if the Italian CDS spread had breached the level of $500 \mathrm{bp}$, post-LTRO, the relationship between changes in the CDS spread and market liquidity would not have been altered, unlike in the period before the intervention. Panels A and B of Table 4 present the results of the estimation for the first sub-sample, split by the level of the CDS spread (Panel A: $C D S \leq 500$ and $T=2011$, Panel B: $C D S>500$ and $T=2011$ ), and confirms the results we presented above. The main difference is that, for the split sample, the relationship between the change in the CDS spread and market liquidity, when the CDS spread is above $500 \mathrm{bp}$, is even stronger in the pre-LTRO regime, with a 10bp increase in CDS translating into a 59bp increase in the quoted spread.

\section{INSERT TABLE \HERE}

Table 4, Panel C, presents the results of the estimation for the second sub-sample (from January 2012 onwards) and shows that the presence of the autoregressive component in market liquidity is still apparent. ${ }^{33}$ However, the contemporaneous relationship between changes in the CDS spread and changes in market liquidity is no longer significant in any specification, while there is a lagged adjustment of market liquidity related to changes in the CDS spread on the previous day, with an economic intensity that is about half that in the full sample reported in Table 3, Panel A (0.600 vs. 1.123).

H4: Market liquidity is driven by both global systemic factors and macro-economic factors specific to Italy.

In the analysis we reported above, we focused exclusively on the contemporaneous and lagged effects in the relationship between market liquidity and the Italian CDS spread. We now consider several other mechanisms that are not strictly related to Italian sovereign risk alone, but may affect

\footnotetext{
${ }^{32}$ The policy implementation announcement of December 8, 2011 can be found online at http://www.ecb.europa.eu/ press/pr/date/2011/html/pr111208_1.en.html

${ }^{35}$ We split the sample at the beginning of January 2012 in order to effectively separate the consequences of the announcement, which happened on December 8, 2011, and the subsequent adjustment period, which encompassed the introduction date, December 22, 2011, from the period following the implementation. The low frequency of our data (daily) does not allow us to clearly distinguish between the effects of the announcement and the implementation, since there are only 9 observations in between the two dates.
} 
market liquidity indirectly. In particular, we analyze the possibility that systemic risk factors could contemporaneously affect both the Italian CDS spread and bond market liquidity. More specifically, we analyze the effects of stock market systematic risk, measured by the returns of the Euro Stoxx50 index, global uncertainty and appetite for risk taking, measured by the volatility index, USVIX, the general increase in the cost of funding by banks in the Euro-zone, because of the banking crisis, measured by the Euribor-Eonia spread, funding liquidity risk, measured by the Eonia-German T-Bill spread, and the macro-funding constraints in the Euro versus the US Dollar markets, measured by the the CCBSS.

To investigate the role of global systemic factors and funding liquidity variables, we perform several analyses, being mindful of the limited number of observations in one of the three sub-samples we are investigating: the sub-sample from 2011 with CDS spreads above 500. We add each of the five aforementioned macro-variables, with their corresponding lagged terms, to the relationship already established. The results are reported in Table 5 .

\section{INSERT TABLES 5 AND 6 HERE}

Panel A, Column 4, of Table 5 shows that, during the second half of 2011, when the CDS spread is below $500 \mathrm{bp}$, changes in the USVIX are significant at the $5 \%$ level in explaining changes in liquidity. It also shows the continuing statistical relevance of the lagged change in the CDS spread. A similar result is obtained for the the Euribor-Eonia spread and the CCBSS (see Column 2 and 5, respectively). However, in both these cases, their respective lagged terms are not significant. Moreover, neither the Eonia-German T-Bill spread nor the stock market systematic risk appear to affect market liquidity when the CDS spread is below 500 bp (see Columns 1 and 3). When we perform the regression including USVIX as well as the CCBSS and the Euribor-Eonia spread, they are not significantl, and the lagged effect of changes in CDS and the autoregressive term of the market liquidity variable are also still significant, as shown in Table 6 Column 1.

Panel B of Table 5 shows that, for 2011, when the CDS spread is above $500 \mathrm{bp}$, the variables that are statistically significant in explaining the change in the CDS spread are the changes in the USVIX, which is contemporaneously significant, and the Euribor-Eonia spread and its lag. This indicates that, under conditions of extreme market stress, the primary dealers adjust their quotes rapidly to changing market risk perceptions, and prudential risk management and internal capital constraints induce them to reduce market liquidity as soon as the quoted asset becomes a high-yield bond. ${ }^{34}$

Panel C of Table 5 shows that, for 2012, the only variable that is individually significant is the contemporaneous change in CCBSS, a macro-liquidity variable that is likely to influence liquidity in all Euro-zone markets. From the analysis of the inclusion of several macro-variables and their lags, we can conclude that, on the one hand, credit risk variables do not have an impact on market liquidity once the massive operations of the ECB through the LTRO take effect; the only relevant variable that continues to influence market liquidity is the Eurozone-wide macro-liquidity factor, the CCBSS (see Table 6. ${ }^{35}$

\footnotetext{
${ }^{34}$ This is not dissimilar to the observations in Friewald, Jankowitsch and Subrahmanyam (2012a), where similar reactions of market liquidity in the US corporate bond market in times of crisis are documented.

${ }^{35}$ One issue that we cannot disentangle is whether this effect is strictly related to the ECB intervention or to the short-selling ban on the CDS market under the European Market Infrastructure Regulation (EMIR) imposed by the
} 


\section{INSERT TABLES 7 AND 8 HERE}

It should be pointed out that, in the above analysis, the effect of global factors on the Italian CDS spread itself has not been taken into account. To account for this effect, we next try to separate the impact of the Italian CDS spread on market liquidity into the component that is driven by global systemic factors and the effects that are more specific to the Italian economy. To investigate this issue, we orthogonalize the change in the CDS spread (both contemporaneous and with one lag) with respect to the global systemic factors, and study the relationship between market liquidity and the residual effect on the Italian sovereign-specific risk. The orthogonalization is conducted by taking the residuals of the regression presented in Table 7. Both the orthogonalization considering only contemporaneous macro-variables and that including lagged macro-variables are conducted, as shown in Columns 1 and 2 of the table respectively. ${ }^{36}$

The effect of the global risk factors and the Italian specific credit risk are shown in Table 8 , Although we estimated several alternative specifications, we report here only the variables that were significant at least in one of the regressions reported in Table 6. As the table shows, we find that the results of this estimation are similar to those obtained earlier, implying that both global systemic factors and Italian sovereign-specific risk affect market liquidity.

\section{VI.III Funding Liquidity}

H5: The level of financial distress of the primary dealers ( market-makers) adversely affects market liquidity.

We next consider how the riskiness of the primary dealers (i.e., the market-makers) affects market liquidity through the borrowing constraint that primary dealers themselves face when their credit risk is heightened. Unfortunately, when there are adverse global macro-shocks, both Italian sovereign risk as well as the credit risk of the primary dealers (both Italian and foreign) are likely to be adversely affected simultaneously; therefore, it is not sufficient to simply investigate the relationship between the CDS spread of the primary dealers and market liquidity to determine whether there is a strict relationship between the two, because of the presence of confounding variables: global risk factors that affect both Italian sovereign risk and the CDS spread of primary dealers. To our knowledge, there is no clear evidence as to how much the banking sector affects sovereign risk in the Euro-zone and vice versa and, in any event, this issue is not the primary focus of this paper. ${ }^{37}$

To try to disentangle the effect on market liquidity arising from the credit risk of the primary dealers from the effect of sovereign risk itself, we consider the CDS spreads of different groups of primary dealers: Italian, European, US and other non-European. In principle, US and other nonEuropean primary dealers should be less exposed to the Eurozone-specific risk factors that affect

European Securities Market Authority (ESMA), which may have reduced the relevance of this market or at least its informativeness. However, a deeper investigation of the volume of Italian CDS trading based on data provided by the DTCC indicates that volume in the CDS market, perhaps outside of the Euro-zone, is still substantial, with changes in net positions per week of the order of about one billion Euros.

${ }^{36}$ The variables that significantly affect the changes in CDS spreads are in line with those highlighted by Longstaff, Pan, Pedersen and Singleton (2012).

${ }^{37} \mathrm{~A}$ recent theoretical analysis of this linkage between bank balance sheets and sovereign risk is provided by Acharya, Drechsler and Schnabl (2012) . 
Italian sovereign risk. Therefore, after controlling for global risk factors such as USVIX, the EuriborEonia spread, the Eonia-German T-Bill spread and the CCBSS, as well as specific Italian sovereign risk-related factors, we investigate whether the specific risk of the primary dealers affects market liquidity. We perform this analysis by orthogonalizing several combinations of groups of primary dealers, we report the estimates from the regressions to this goal in Table 9. Our analysis, reported in Table 10 indicates that, overall, there is no clear relationship between the specific credit risk of the primary dealers and market liquidity. One exception to this statement is that the credit risk of Euro-zone based market-makers affect the liquidity of the Italian government bonds in periods of distress, which is when the Italian sovereign risk, as measured by the CDS spread, is above $500 \mathrm{bp}$. Moreover, accounting for the market-makers' own funding liquidity does not affect the economic and statistical significance of the changes in the Italian CDS spread.

\section{VI.IV Lead-Lag Relationships between Credit Risk and Liquidity}

H6: Over time, the change in credit risk leads changes in market liquidity and vice versa.

In the previous regression analysis, we showed that there is a relationship between changes in the liquidity measures and changes in the CDS spread. However, the analysis did not indicate whether it is the increase in credit risk that drove the reduction of liquidity in the bond market or vice versa. We now address the question of which of the two economic variables drives the other using a simple Granger causality test, a statistical notion of causality based on the relative forecasting power of two time-series for each other: Time-series $j$ is said to "Granger-cause" time-series $i$ if past values of $j$ contain information that helps predict $i$, above and beyond the information contained in past values of $i$ alone. The mathematical formulation of this test is based on linear regressions of $\Delta L M_{t}$ and $\triangle C D S_{t}$ on their $p$ lags.

Specifically, let $\Delta L M_{t}$ and $\Delta C D S_{t}$ be two stationary time-series. We can represent their linear inter-relationships with the following model:

$$
\begin{aligned}
\left(\begin{array}{c}
\Delta L M_{t} \\
\Delta C D S_{t}
\end{array}\right)= & \left(\begin{array}{c}
K_{L M} \\
K_{C D S}
\end{array}\right)+\left(\begin{array}{ll}
a_{11_{1}} & a_{12_{1}} \\
a_{21_{1}} & a_{22_{1}}
\end{array}\right)\left(\begin{array}{c}
\Delta L M_{t-1} \\
\Delta C D S_{t-1}
\end{array}\right)+\left(\begin{array}{cc}
a_{11_{2}} & a_{12_{2}} \\
a_{21_{2}} & a_{22_{2}}
\end{array}\right)\left(\begin{array}{c}
\Delta L M_{t-2} \\
\Delta C D S_{t-2}
\end{array}\right) \\
& +\left(\begin{array}{cc}
a_{11_{3}} & a_{12_{3}} \\
a_{21_{3}} & a_{22_{3}}
\end{array}\right)\left(\begin{array}{c}
\Delta L M_{t-3} \\
\Delta C D S_{t-3}
\end{array}\right)+\cdots+\left(\begin{array}{ll}
a_{11_{P}} & a_{12_{P}} \\
a_{21_{P}} & a_{22_{P}}
\end{array}\right)\left(\begin{array}{c}
\Delta L M_{t-P} \\
\Delta C D S_{t-P}
\end{array}\right) \\
& +\left(\begin{array}{cc}
b_{11} & b_{12} \\
b_{21} & b_{22} \\
\vdots & \vdots \\
b_{q 1} & b_{q 2}
\end{array}\right)\left(\begin{array}{c}
\Delta X 1_{t} \\
\Delta X 2_{t} \\
\vdots \\
\Delta X q_{t}
\end{array}\right)+\left(\begin{array}{c}
\epsilon_{L M t} \\
\epsilon_{C D S t}
\end{array}\right)
\end{aligned}
$$

where $\epsilon_{\mathbf{t}} \sim N(\mathbf{0}, \boldsymbol{\Omega})$, and $a_{i j_{p}} \mathrm{~s}$ are the $p$-lag coefficients of the model. This formulation allows for the presence of $q$ contemporaneous exogenous variables $X$ to control for factors which might affect the dynamics of the endogenous variables. Then, $\triangle C D S$ Granger-causes $\Delta L M$ when the $a_{12_{p}}$ s are contemporaneously different from zero. Similarly, $\Delta L M$ Granger-causes $\triangle C D S$ when the $a_{21} p$ s are 
contemporaneously different from zero. When both of these statements are true, there is a feedback relationship between the time-series.

The results of the Granger causality test are reported in Table 11, for the relationship between the changes in the CDS spread and the Quoted Spread, and Tables 12 and 13 for the orthogonalized CDS spread allowing for the presence of exogenous variables. As the table shows, CDS spreads Grangercause liquidity in the bond market. Indeed, for almost all the liquidity variables considered, $a_{12_{p}}$ 's are statistically different than zero at the $1 \%$ level. The results are very similar to those we show above where we include the CDS as a contemporaneous explanatory variable. Note that changes in the CDS spreads are not affected by the lagged liquidity variable in any of the sub-samples we consider.

\section{INSERT TABLE 11 THROUGH 13 HERE}

This result has important policy implications: By improving liquidity in the bond market, the ECB could attenuate the direct linkage between credit risk and market liquidity, especially under conditions of stress.

\section{VI.V Results for Other Liquidity Measures}

To check the robustness of the results in the previous sections, we repeated the analysis estimating Equation 1 using the other liquidity variables described in Section IV.I. namely the Quoted Quantity, the Effective Spread, and Lambda. The number of lags for each variable and the CDS spread are determined with the same methodology as for the Quoted Spread. The results are reported in Table 14. while Figure 9 shows the plots of the threshold identification in the relationship between changes in liquidity and changes in the Italian CDS spread level for the 2011 sub-sample, and the significance of the Chow test for the presence of structural break, as performed in Section VI.II, for the Quoted Spread.

\section{INSERT TABLE 14] AND FIGURE 9 HERE}

Figure 9 shows that the structural break around the LTRO announcement is also a feature of the alternative liquidity measures, and so is the $500 \mathrm{bp}$ threshold in the regression of the changes in the liquidity measure on its lags and the changes in Italian CDS and its lag, for the 2011 sub-sample. A 10bp change in the Italian CDS spread is associated with a $0.25 \%$ decrease in Quoted Quantity, a $0.34 \%$ increase in the Effective Spread, and a $0.89 \%$ increase in Lambda when the CDS spread for Italian bonds is above $500 \mathrm{bp}$, compared to a $0.07 \%$ decrease, a $0.12 \%$ increase, and a $0.25 \%$ increase when the Italian CDS spread is below the same threshold. After the ECB intervention, a change in the Italian CDS spread has no effect on Quoted Quantity and Lambda and only a marginal effect on Effective Spread. The sensitivity of the Effective Spread is lower than that of the Quoted Spread because of the endogeneity of the trading decision: Traders will choose to trade when the Quoted Spread is comparatively low, thus dampening the sensitivity of the effective spread to changes in the market conditions. The dynamics of the relationship between credit risk and liquidity are confirmed by the analysis of the alternative liquidity measures, so that the lagged change in credit risk is significant when the market is quiet, while, in a stressed market, when the Italian CDS is above $500 \mathrm{bp}$, the liquidity changes contemporaneously with the credit risk. ${ }^{38}$

\footnotetext{
${ }^{38}$ This is in line with the discussion in Section III] where the frequency of intervention by risk managers on an intraday basis during crisis periods was highlighted.
} 


\section{Conclusion}

The sovereign debt crisis in the Euro-zone has been the most important development in the global economy of the past three years. This crisis stemmed from both liquidity and credit risk concerns in the market and led to a sharp spike in CDS and sovereign bond yield spreads in late 2011, particularly in the Euro-zone periphery. It was only after the launch of the LTRO program, and to a greater extent after Mario Draghi's "whatever it takes" comment in July 2012, and the OMT program that was subsequently launched, that the market's alarm diminished. Consequently, CDS spreads as well as sovereign bond yields had dropped to sustainable levels in most countries by late 2012 . Hence, there is no doubt, prima facie, that the ECB programs were a crucial factor in, at least partially, abating the crisis, although it is still an open issue whether the fundamental problems of the Euro-zone have been addressed.

These events provide us with an unusual laboratory in which to study how the interaction between credit risk and illiquidity played out, in a more comprehensive framework than previous studies of corporate or other sovereign bond markets have used, for the reasons we have already highlighted in the introduction. We employ a wide range of liquidity measures and investigate several hypotheses about the main drivers of the dynamic relationship between credit risk, global systemic factors, global funding liquidity, and market liquidity. Our main findings are that, prior to ECB intervention, the relationship between credit risk and market liquidity was strong, and depended, not simply on the dynamics of credit risk, but also on the level of credit risk. Using a new econometric methodology that allows us to identify the threshold above which the dynamic relationship is altered, we estimate that this level corresponds to a CDS spread of $500 \mathrm{bp}$. This break point of $500 \mathrm{bp}$ is often identified as the dividing line between the credit spread for investment grade bonds and that for speculative grade bonds. Once this threshold is crossed by the Italian sovereign, the clientele of investors who hold its bonds may be fundamentally altered. Furthermore, the margin requirements, the accounting treatment, and regulatory capital regulations will be quite different, thus fundamentally altering the relationship between changes in credit risk and market liquidity. On top of the specific Italian sovereign risk, other global factors such as VIX, Euribor-Eonia and CCBSS, are relevant to the relationship between credit risk and market liquidity.

We also examine the improvement in market liquidity following the intervention by the ECB. Our analysis of the data indicates that there is a clear structural break in the data following the announcement of the implementation of the LTRO on December 8, 2012. Remarkably, the data show that, following ECB intervention, the improvement in liquidity (or the reduction in illiquidity) in the government bond market strongly attenuated the dynamic relationship between credit risk and market liquidity to such an extent that, although the CDS spread breached the $500 \mathrm{bp}$ mark once again, market liquidity and the relationship between credit risk and market liquidity did not change significantly between the regimes below and above this level. Actually, the only variable that still has an impact on market liquidity after the ECB intervention is the global funding liquidity variable, CCBSS. Thus, ECB intervention not only vastly improved the liquidity of the market, but also substantially loosened the link between credit risk and market liquidity. This conclusion is confirmed by the Granger causality analysis, aimed at investigating whether liquidity risk drives credit risk or vice versa. Our analysis shows that, prior to the introduction in December 2011 of the LTRO by the ECB, credit risk was exacerbating the illiquidity of the Italian sovereign bond market. Subsequently, however, the Granger causality is no longer observable in the data.

Our results will be of interest to the Euro-zone national treasuries, helping them to understand the 
dynamic nature of the relationship between credit risk, global risk factors and market liquidity, which has strong consequences for the pricing of their issues in the auctions as well as in secondary markets. The ECB may also derive some insights from our analysis that could help them to better understand the impact of the unconventional instruments of new monetary policy. Apart from targeting both funding and market liquidity, the central bank ought to also focus on the market's perceptions of sovereign credit risk. The introduction of the LTRO program, having the objective of providing short-term liquidity to banks, shows that the channel from bank bailout to sovereign risk (described by Acharya, Drechsler and Schnabl (2012) could also be reversed: offering liquidity to banks may improve the market liquidity of sovereign bonds and also indirectly reduce sovereign risk! Our analysis could be similarly employed by market regulators (the national central banks or European market regulators such as ESMA), since it identifies the main factors that affect sovereign bonds' market liquidity in the Euro area.

Given the strong linkage between bank and sovereign risk, our findings will be of interest to bank regulators, helping them to improve their tools for monitoring both bank capital adequacy and liquidity risk. In particular, our analysis highlights an important aspect of the sterilization of the effect of credit risk on market liquidity through ECB intervention: market liquidity is largely affected by investor behavior, their risk attitudes and perceptions, and regulatory restrictions. This indicates that changes in bank regulation (with regard to sovereign credit risk, market risk or liquidity risk) have a strong impact on market liquidity. Therefore, close coordination between different regulators (market regulators and bank regulators) is fundamental to the avoidance of strong negative externalities, for example that the liquidity of a market freezes because bank capital requirements for holding sovereign bonds increases or the liquidity coverage ratio changes adversely, with even more perverse effects on the probability of default of the country and the consequent costs to tax payers.

The relevance of our findings to other countries bears mention. The results of our paper are of interest also for economists, central bankers, and finance ministry officials: we demonstrate the structural linkages between monetary policy, credit risk and market liquidity in the sovereign bond market, and a rationale for including this issue in monetary policy making. The insights we provide have implications for monitoring the capital adequacy of banks, margining and collateral management by clearing corporations and traders, and the functioning of the repo market. 


\section{Appendix A: The MTS Datasets and Market Structure}

There are four types of databases currently offered by MTS. At the highest level, "daily summaries" including aggregate price and volume information regarding the trading of European bonds, are published. At the second level, the "trade-by-trade" data, including all transactions, stamped at the millisecond level, are available. However, neither of the two aggregate databases has any information on the price quotations of the instruments, at the dealer, or even the market-wide, level. The publicly available data set at the third level includes the best three bid and ask prices and the aggregate quantities offered at those levels. Prior studies that use this data set are unable to describe the market in its entirety, as the two dimensions indicating willingness to trade, quotes and orders, for primary dealers and dealers respectively, were not available previously. Only actual trading events are observable, and trading intent as a pre-trade measure cannot be measured. Thus, it is not possible to study liquidity provision, as measured by the dealers' willingness to trade, as evidenced by their bid and offer quotations, based on this data set. In contrast, the data set we analyze in the present study is at the fourth level, and is, by far, the most complete representation of the market available, and has been released only recently. It covers all trades, quotes, and orders that took place on the MTS market between June 1, 2011 and December 31, 2012. Every event is stamped at the millisecond level, and the order IDs permit us to link each order to the trade that was eventually consummated from it. Every quote in this market, henceforth called "proposals" can be followed in the database in terms of their "revisions" over time, thanks to a "single proposal" identifier.

Market participants can decide whether they want to trade a government bond on the European market or on that country's domestic market. While every Euro-zone bond is quoted on the domestic markets, only bonds that are issued for an amount higher than a certain threshold can be traded on the EuroMTS. Even though the two markets are not formally linked, most dealers participate in both venues. The previous literature (Cheung, de Jong and Rindi (2005), Caporale and Girardi (2011)) has shown that the two markets essentially constitute a single venue. ${ }^{39}$ Thus, in our analysis, we consider trading in both markets. The liquidity measures used in this paper do not depend on where the order placement and trading activity takes place.

There are two kinds of traders in the sovereign bond markets, primary dealers and other dealers. Primary dealers are authorized market-making members of the market. That is, they issue standing quotes, which can either be single-sided or double-sided, on the bonds they have been assigned. They indicate the quantity they are willing to trade and the non-negative fraction of that quantity they are willing to "show" to the market. Primary dealers can be on the passive side, when their proposals are "hit" or "lifted," and/or on the active side of the market, when they submit orders aimed at "hitting" or "lifting" another primary dealer's standing quote. Primary dealers have market-making obligations that, in spite of some relaxations after 2007, still require each primary dealer not to diverge from the average quoted times and spreads, calculated among all market makers. In this market, the event of crossed quotes is guaranteed not to occur, except by chance, since, when the opposite sides of two proposals cross, a trade takes place for the smaller of the two quoted quantities. ${ }^{40}$ Other dealers with no market-making responsibilities can originate a trade only by "hitting" or "lifting" the primary dealers' standing quotes with market orders. However, it should be noted that primary dealers are

\footnotetext{
${ }^{39}$ By this we mean that a sell or buy order could "trade-through" a better price if the trader sent the order to the market with the worse of the bid or ask price, respectively. However, MTS assures market participants that their trading platforms always show quotations from both the domestic and the European market, when available.

${ }^{40}$ While this is one way for the primary dealers to trade, it seldom happens. Hence, we do not include trades originating in this manner in our sample.
} 
also on the active side of $96 \%$ of the trades present in our database. 


\section{Appendix B: The Bond Characteristics}

To confirm that the finding of previous literature regarding the relationship between liquidity measures and bond characteristics apply to this market as well, we estimate cross-sectional regressions to study the drivers of liquidity, in the Italian sovereign bond market. Specifically, we explore whether each of our defined liquidity measures can be explained by product characteristics and trading activity variables.

We estimate cross-sectional regressions where we use time-series averages of all variables. We analyze coupon-bearing bonds and non-coupon-bearing bonds separately, according to the following regressions:

$$
\begin{aligned}
& \text { Coupon: } L M_{i}=\beta_{1}+\beta_{2} \text { AmountIssued }_{i}+\beta_{3}{\text { Daily } \text { Trades }_{i}+}^{+} \\
& +\beta_{4} \text { CouponRate }_{i}+\beta_{5-8} \text { Maturity Dummies }_{i} \\
& +\beta_{9} \frac{\text { Time to Maturity }}{\text { Maturity }}_{i}+\beta_{10}\left(\frac{\text { Time to Maturity }}{\text { Maturity }}\right)^{2}+\epsilon_{i} \\
& \text { Non-Coupon: } L M_{i}=\beta_{1}+\beta_{2} \text { AmountIssued }_{i}+\beta_{3}{\text { Daily } \text { Trades }_{i}} \\
& +\beta_{4-7} \text { MaturityDummies }_{i}+ \\
& +\left(\beta_{8} \text { AmountIssued }_{i}+\beta_{9} \text { NTrades }_{i}\right) \cdot \text { FDummy }_{i} \\
& +\beta_{10} \frac{\text { Time to Maturity }}{\text { Maturity }}+\beta_{i 1}\left(\frac{\text { Time to Maturity }}{\text { Maturity }}\right)_{i}^{2}+\epsilon_{i}
\end{aligned}
$$

where Amount Issued $_{i}$ is the bond $i$ amount issued, taking into consideration eventual re-issuance, Daily Trades Tis $_{i}$ the bond $i$ average number of daily trades, Coupon Rate R $_{i}$ is the coupon rate in percentage points, Maturities Dummies $i$ are dummies which equal 1 if bond $i$ belongs to a maturity group and 0 otherwise, Time to Maturity and Maturity are calculated considering the issuance date

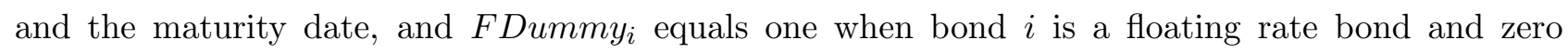
otherwise. $L M_{i}$ is the $i$ th liquidity measure. Our proxies for liquidity, as defined in Section IV.I are as follows: Quoted Spread, Effective Spread, Quoted Quantity, Roll Measure, and Amihud Measure. The results for the coupon-bearing bonds from Equation 4 are presented in Table 15, Panel A, while the results for non-coupon-bearing bonds, as per Equation 5, are presented in Table 15, Panel B.

\section{INSERT TABLE 15 HERE}

As far as coupon bonds are concerned, the two spread measures (Quoted Spread and Effective Spread) show similar results. The relationships between them and the Time-to-maturity (or, conversely, Age) of the bond are highly non-linear. As shown in Figure 10, which plots the averages, for the sample of 60 coupon-bearing bonds, of the bid-ask spread and the time-to-maturity, it is clear that, within the same maturity group, bonds that are on-the-run and bonds that are close to maturity have the lowest bid-ask spreads, while those in their "mid-life" have higher spreads, reflecting an inverted U-shaped pattern.

\section{INSERT FIGURE 10 HERE}

In our estimations, we include the ratio of Time-to-maturity to Maturity and its square as independent variables. The coefficients are both significant, and the signs clearly confirm the initial 
conjecture from the graphs. The parameters imply that the spread increases from the issue date and reaches its maximum at around one-fourth of the total maturity, and then declines as the maturity date approaches. Since the base case is the 3-year maturity group, the maturity dummies (Maturity5 to Maturity30) show the positive relationship between spread and maturity. The number of trades has a negative sign, meaning that the larger the trading activity, the smaller is the spread. Darbha and Dufour (2012) find, for the period from January 2004 to July 2010, that the more recently issued bonds with larger issue sizes have smaller Quoted Spread, which we also confirm for our sample period, June 2011 to December 2012. On the other hand, bonds of a longer maturity (as measured by the dummies) have larger spreads. This is consistent with what Dufour and Nguyen (2011), and Darbha and Dufour (2012) find for the MTS market, and with what Goyenko, Subrahmanyam and Ukhov (2011) report for US Treasury bonds. Darbha and Dufour (2012) suggest that, during the period from August 2007 to July 2010, prior to the Euro-zone crisis, investors shifted funds into short-term bonds. This explains why the Amihud Measure (market impact) is higher for longer-maturity bonds. The cross-sectional regressions for floating rate and zero coupon bonds yield similar results to those for coupon bonds. Although the Roll Measure should produce similar results to those for the effective spread, Daily Trades is the only variable that is consistent with this conjecture. These results for the Roll measure are somewhat puzzling; however, it should be noted that the pattern of trades in our sample violates the crucial assumption needed for the Roll measure to act as a good proxy for the bid-ask spread. The Amihud Measure has a negative relation with age and the number of trades, and a positive relation with maturity. These results are consistent with those for the Quoted Spread and Effective Spread. 


\section{Appendix C: Methodological Appendix}

\section{Threshold Analysis}

In empirical settings, a regression such as the ordinary least squares (OLS) specification $y_{i}=\beta^{\prime} x_{i}+e_{i}$, where $y_{i}$ is the dependent variable which is regressed on the independent variable $x_{i}$, is often repeated for sub-samples, either as a robustness check or to verify whether the same relationship applies to appropriately grouped observations. The sample split is often conducted in a exogenous fashion, thus dividing the data according to the distribution of a key variable (such as size and book-to-market quantiles portfolio in a Fama-French (1993) setting). Hansen $(1996,2000)$ develops the asymptotic approximation of the distribution of the estimated threshold value $\hat{\gamma}$, when the sample split, based on the values of an independent variable $q_{i}$, can be rewritten as

$$
Y=X \theta+X_{\gamma} \delta+e \quad \text { where } X_{\gamma}=X I(q \leq \gamma)
$$

or $y_{i}=\theta^{\prime} x_{i}+\delta I\left(q_{i} \leq \gamma\right) x_{i}+e_{i}$, where $I\left(q_{i} \leq \gamma\right)$ equals 1 if $q_{i} \leq \gamma$, and 0 otherwise. He shows that, under a set of regularity conditions, which exclude time-trending and integrated variables, the model can be estimated by least squares, minimizing $S S R_{n}(\theta, \delta, \gamma)=\left(Y-X \theta-X_{\gamma} \delta\right)^{\prime}\left(Y-X \theta-X_{\gamma} \delta\right) .{ }^{41}$ Concentrating out all parameters but $\gamma$ yields $S_{n}(\gamma)=S S R_{n}(\hat{\theta}(\gamma), \hat{\delta}(\gamma), \gamma)=Y^{\prime} Y-Y^{\prime} X_{\gamma}^{*}\left({ }^{\prime} X_{\gamma}^{*}{ }^{\prime} X_{\gamma}^{*}\right)^{-1} X_{\gamma}^{*}{ }^{\prime} Y$ with $X_{\gamma}^{*}=\left[\begin{array}{ll}X & X_{\gamma}\end{array}\right]$. The parameters $\theta$ and $\delta$ are formulated as functions of $\gamma$ and the sum of squared residuals depends exclusively on the observed variables and on $\gamma$. Thus, the value of $\gamma$ that minimizes $S_{n}(\gamma)$ is its least squares estimator $\hat{\gamma}$ and the estimators of the remaining parameters $\hat{\theta}(\hat{\gamma})$ and $\hat{\delta}(\hat{\gamma})$ can be calculated.

When there are $N$ observations, there are at most $N$ values of the threshold variable $q_{i}$, or, equivalently, $N$ values that the $S S R(\gamma)$ (step-)function can take. After re-ordering the values $q_{i}$ in $\left(q_{(1)}, q_{(2)}, \ldots q_{(N)}\right)$, such that $q_{(j)} \leq q_{(j+1)}$, the method is implemented by:

1. [1.]

2. Estimating by OLS, $y_{i}=\theta_{2}^{\prime} x_{i}+\delta I\left(q \leq q_{(j)}\right) x_{i}+e_{i}$ (or, equivalently, when all parameters are allowed to depend on the threshold, estimating separately $y_{i}=\theta_{1}^{\prime} x_{i}+e_{1 i}$ where $q_{i} \leq q_{(j)}$ and $y_{i}=\theta_{2}^{\prime} x_{i}+e_{2 i}$ where $\left.q_{i}>q_{(j)}\right)$,

3. Calculating the sum of squared residuals, $\operatorname{SSR}\left(q_{(j)}\right)=\sum e_{i}\left(\right.$ or $\left.=\sum e_{1 i}+\sum e_{2 i}\right)$,

4. Repeating 1 and 2 with $q_{(j+1)}$,

5. Finding the least square estimate of $\gamma$ as $\hat{\gamma}=\arg \min _{q_{(j)}} S\left(q_{(j)}\right)$, and

6. Repeating the estimation of the equations on the sub-samples defined by the $\hat{\gamma}$ threshold, calculating heteroskedasticity-consistent standard errors for the parameters.

As suggested by Hansen (1999), we allow each equation to contain at least $20 \%$ of the observations, and, to minimize computing time, we search only through 0.5\%-quantiles. Although Hansen (1999) presents an extension of the procedure to several thresholds, we focus in this paper on a single sample split.

\footnotetext{
${ }^{41} \mathrm{~A}$ theory for the latter case was developed in Caner and Hansen (2001).
} 
To test the presence of the threshold, thus testing whether $\theta_{1}=\theta_{2}$, the usual tests cannot be used, since $\gamma$ is not identified under the null hypothesis (the "Davies' Problem", as analyzed by Davies $(1977,1987))$. Hansen (1996) provides a test whose asymptotic properties can be approximated by boostrap techniques.

To provide confidence intervals for the threshold estimate $\hat{\gamma}$, Hansen (2000) argues that no-rejection regions should be used. To test $\gamma=\gamma_{0}$, the likelihood ratio test can be used such that $L R(\gamma)=$ $(S S R(\gamma)-S S R(\hat{\gamma})) / \hat{\sigma}^{2}$, where $\hat{\sigma}^{2}=S S R(\hat{\gamma}) / N$ is the estimated error variance, will be rejected if $\hat{\gamma}$ is sufficiently far from $\gamma$, i.e. the test statistic is large enough. In its homoskedastic version, the test has a non-standard pivotal distribution, such that the test is rejected at a $\alpha$-confidence level if $L R(\gamma)>-2 \ln (1-\sqrt{\alpha})$. In this paper, we choose $\alpha=0.95$, consistent with Hansen (2000); thus, the null hypothesis is considered rejected if $L R(\gamma)>=-2 \ln (1-\sqrt{0.95})=7.35$. This level is plotted as a horizontal line in the plots of the test. The confidence interval for the threshold will be $\left[\gamma_{L}, \gamma_{U}\right]$, such that $L R\left(\gamma \mid \gamma<\gamma_{U}\right)>7.35$, and $L R\left(\gamma \mid \gamma>\gamma_{U}\right)>7.35$, or, graphically, the portion of the x-axis where the plot of the test is below the 7.35 horizontal line.

In Section VI.II we claim that we can clearly identify a threshold for the CDS spread around 500 bp for the regression of the change in the quoted spread on the changes in the CDS spread and their lags, only for the period up to December 31, 2011, and not for the sub-sample after this date. The plots of the test are presented in Figure 8. The test values for the whole sample, for the 2011, and 2012 sub-samples are reported in Panels (a), (b), and (c) of the figure, respectively. Clearly, the result for the overall sample is driven by the first sub-sample, since in Panel C, no clear conclusion can be reached. Hence, the conservative no-rejection regions imply that the threshold in our case is above a CDS spread of 350bp; thus, the point-estimate provides little information in 2012.

\section{The Chow Test}

The Chow test is a standard breakpoint analysis used widely in the economics literature. Based on two nested regressions, it follows an $f_{k, T-2 k}$-distribution and its statistic is

$$
f=\frac{\left(S S R_{0}-S S R_{1}\right) / k}{S S R_{1} /(T-2 k)}
$$

where $S S R_{0}$ and $S S R_{1}$ are the SSR of the restricted regression, $y_{t}=x_{t}^{\prime} \beta+\epsilon_{t}$ (with $t=1, \ldots, T$ ), and the unrestricted regression, $y_{t}=x_{t}^{\prime} \beta+g_{t} x_{t}^{\prime} \gamma+\epsilon_{t}$, respectively.

In the unrestricted regressions, the observations following the break point $t^{*}$, selected by the dummy variable $g_{t}$ (such that $g_{t}=1$ if $t<t^{*} \leq T$ and 0 otherwise), are allowed to depend on $x_{t}$ through the composite parameters $\beta+\gamma$, compared to the previous observations, which depend on $x_{t}$ through $\beta$ only. The restriction $\gamma=0$, thus, imposes the condition that all $y_{t}$ to depend on $x_{t}$ in a homogeneous fashion. In our study, we calculate the Chow test statistics using each day as potential break point, and allow all the regression parameters to change from one sub-sample to another. ${ }^{42}$

\footnotetext{
${ }^{42}$ We exclude the first and last $10 \%$ of the observations, in order to estimate meaningful regressions. Thus, $0.1 T<$ $t^{*}<0.9 T$.
} 


\section{Tables}

Table 1: Maturity and Coupon Rate by Maturity Group and Bond Type. This table presents the distribution of the bonds in terms of Maturity and Coupon Rate, by maturity group (Panel A) and bond type (Panel B). Maturity groups were determined by the time distance between bond maturities and the closest whole year. Our data set, obtained from the Mercato dei Titoli di Stato (MTS), consists of transactions, quotes, and orders for all 152 fixed-rate and floating Italian government bonds (Buoni Ordinari del Tesoro (BOT) or Treasury Bills or Certificato del Tesoro Zero-coupon (CTZ) or Zero coupon bonds, Certificati di Credito del Tesoro (CCT) or Floating notes, and Buoni del Tesoro Poliennali (BTP) or Fixed-income Treasury Bonds) from June 1, 2011 to December 31, 2012.

\begin{tabular}{cccccc}
\hline \multicolumn{5}{c}{ Panel A } \\
\hline Maturity Group & \# Bonds & Coupon Rate & Maturity & MinMaturity & MaxMaturity \\
\hline 0.25 & 8 & $a$ & 0.26 & 0.21 & 0.27 \\
0.50 & 27 & $a$ & 0.51 & 0.36 & 0.53 \\
1.00 & 33 & $a$ & 1.01 & 0.83 & 1.03 \\
2.00 & 11 & $b$ & 2.02 & 2.01 & 2.09 \\
3.00 & 11 & 3.16 & 2.98 & 2.93 & 3.02 \\
5.00 & 13 & 3.87 & 5.03 & 4.92 & 5.25 \\
6.00 & 13 & $c$ & 6.67 & 5.29 & 7.09 \\
10.00 & 19 & 4.45 & 10.41 & 10.10 & 10.52 \\
15.00 & 7 & 4.57 & 15.71 & 15.44 & 16.00 \\
30.00 & 10 & 5.88 & 30.88 & 29.30 & 31.79 \\
\hline \multicolumn{7}{c}{ Panel B } & & \\
\hline Bond Type & $\mathrm{N}$ & Coupon Rate & Maturity & MinMaturity & MaxMaturity \\
\hline BOT & 68 & ZCB & 0.72 & 0.21 & 1.03 \\
BTP & 60 & 4.34 & 11.91 & 2.93 & 31.79 \\
CCT & 13 & Floating & 6.70 & 5.29 & 7.09 \\
CTZ & 11 & ZCB & 2.02 & 2.01 & 2.09 \\
\hline
\end{tabular}

\footnotetext{
${ }^{a}$ All bonds in this group are BOT, Buoni Ordinari del Tesoro (Treasury bills)

${ }^{b}$ All bonds in this group are CTZ, Certificati del Tesozo Zero-coupon (zero coupon bonds, ZCB)

${ }^{c}$ All bonds in this group are CCT, Certificati di Credito del Tesoro (floating bonds)
} 
Table 2: Time-series Descriptive Statistics of Trade- and Quote-based Liquidity Measures. This table shows the time-series distribution of various liquidity measures defined in Section IV.T. The sample consists of the quotes and trades from 406 days in our sample. Each day's data are summarized by the cross-sectional (across bonds) average. However, Quoted Bonds is the number of bonds actually traded on each day, Trades is the total number of trades on the day, and Fill Ratio is the fraction of ordered quantity that is in fact filled. Quoted Spread is the difference between the best bid and the best ask, Effective Spread is the effective bid-ask spread paid by the traders, Quoted Quantity is the face-value quantity offered on average per bond on the bid and ask side in millions of euros, Lambda is a measure of depth, and the Amihud and Roll measures are illiquidity measures. Our data set, obtained from the Mercato dei Titoli di Stato (MTS), consists of transactions, quotes, and orders for all 152 fixed-rate and floating Italian government bonds (Buoni Ordinari del Tesoro (BOT) or Treasury Bills or Certificato del Tesoro Zero-coupon (CTZ) or Zero coupon bonds, Certificati di Credito del Tesoro (CCT) or Floating notes, and Buoni del Tesoro Poliennali (BTP) or Fixed-income Treasury Bonds) from June 1, 2011 to December 31, 2012.

\begin{tabular}{|c|c|c|c|c|c|c|c|c|c|c|c|c|c|c|}
\hline \multicolumn{11}{|c|}{ Time Series } & \multicolumn{4}{|c|}{ Cross Section } \\
\hline \multicolumn{15}{|c|}{ Panel A: Activity Measures } \\
\hline Variable & $\mathrm{N}$ & Mean & STD & Min & 5th Pct & 25th Pct & Median & 75th Pct & 95th Pct & Max & $\mathrm{N}$ & Mean & Min & Max \\
\hline Quoted Bonds & 406 & 89.781 & 2.108 & 86.000 & 87.000 & 88.000 & 90.000 & 92.000 & 93.000 & 94.000 & & & & \\
\hline Trades & 406 & 265.256 & 108.064 & 43.0000 & 116.000 & 194.000 & 249.000 & 321.000 & 449.000 & 837.000 & 152 & 3.520 & 0.2512 & 19.000 \\
\hline Fill Ratio & 406 & 0.685 & 0.091 & 0.0777 & 0.556 & 0.654 & 0.698 & 0.740 & 0.789 & 0.872 & 152 & 0.689 & 0.1154 & 0.901 \\
\hline \multicolumn{15}{|c|}{ Panel B: Liquidity Measures } \\
\hline Volume & 406 & 2.027 & 0.953 & 0.3235 & 0.772 & 1.442 & 1.888 & 2.431 & 3.781 & 7.188 & 152 & 30.482 & 1.4606 & 190.000 \\
\hline Quoted Spread & 406 & 0.506 & 0.376 & 0.1314 & 0.176 & 0.299 & 0.419 & 0.551 & 1.236 & 4.477 & 152 & 0.346 & 0.0009 & 1.405 \\
\hline Effective Spread & 406 & 0.148 & 0.094 & 0.0314 & 0.057 & 0.088 & 0.120 & 0.177 & 0.327 & 0.706 & 152 & 0.125 & 0.0010 & 0.619 \\
\hline Quoted Quantity & 406 & 122.519 & 17.787 & 42.9455 & 96.238 & 112.485 & 122.537 & 132.299 & 153.195 & 181.985 & 152 & 128.472 & 70.2121 & 524.494 \\
\hline Lambda & 406 & 0.019 & 0.020 & 0.0038 & 0.006 & 0.009 & 0.014 & 0.023 & 0.052 & 0.255 & 152 & 0.013 & 0.0000 & 0.045 \\
\hline Amihud & 406 & 3.394 & 3.649 & 0.2510 & 0.566 & 1.288 & 2.188 & 4.343 & 9.596 & 29.243 & 152 & 2.515 & 0.0010 & 18.406 \\
\hline Roll & 406 & 0.038 & 0.014 & 0.0115 & 0.019 & 0.028 & 0.036 & 0.045 & 0.066 & 0.085 & 152 & 0.031 & 0.0000 & 0.168 \\
\hline
\end{tabular}


Table 2: Time-series Descriptive Statistics of Global Credit- and Liquidity-Risk Measures. The global systemic variables are the return of the Euro 50 Index Euro50, the spread between 3-month Euribor and 3-month Eonia EuriborEonia, the spread between 3-month Eonia and the yield of a 3-month German T-Bill Eonia-DeTBill, the USVIX, and the Cross-Currency Basis Swap Spread CCBSS. Global variables are described in detail in Section IV. All data are obtained from Bloomberg.

\begin{tabular}{c|cccccccccc}
\hline \multicolumn{10}{c}{ Panel C: Liquidity- and Credit-Risk Variables } \\
\hline Variable & $\mathrm{N}$ & Mean & STD & Min & 5th Pct & 25th Pct & Median & 75th Pct & 95th Pct & Max \\
\hline Italian CDS & 406 & 401.523 & 108.244 & 145.098 & 194.015 & 318.554 & 421.296 & 491.711 & 552.843 & 591.536 \\
Euro 50 & 406 & -0.0002 & 0.0169 & -0.0632 & -0.0287 & -0.0086 & -0.0000 & 0.0095 & 0.0266 & 0.059 \\
Euribor-Eonia & 406 & 0.4761 & 0.2820 & 0.1040 & 0.1175 & 0.2200 & 0.3990 & 0.7495 & 0.9510 & 1.006 \\
Eonia-DeTBill & 404 & 0.3418 & 0.1630 & 0.0660 & 0.1210 & 0.2030 & 0.3078 & 0.4735 & 0.6220 & 0.788 \\
USVIX & 394 & 21.8880 & 7.3773 & 13.4500 & 14.8000 & 16.6400 & 18.8600 & 24.7900 & 37.3200 & 48.000 \\
CCBSS & 406 & 50.2142 & 20.2852 & 20.8000 & 24.5000 & 29.5000 & 50.9375 & 64.6500 & 87.8600 & 106.500 \\
\hline
\end{tabular}


Table 3: Results for the Regression of the Quoted Spread for the Whole Sample and Sub-Samples This table presents the results for the regression of the change in the Quoted Spread, (the change in the quoted bid-ask spread) on day t, $\Delta \mathrm{BA}_{t}$, in Equation 1 , on its lagged terms, and the change in the CDS spread on day t, $\Delta \mathrm{CDS}_{t}$, and its lagged terms, using daily data for the Quoted Spread and the CDS spread. The statistical significance refers to heteroskedasticity-robust $t$-tests. Our data set consists of 406 days of trading for Italian government bonds, from June 15, 2011 to December 31, 2012, and are obtained from the Mercato dei Titoli di Stato (MTS) Global Market bond trading system. The CDS spread refers to a USD-denominated, 5-year CDS spread and is obtained from Bloomberg. Sub-samples are taken with regards to the the CDS level.

\begin{tabular}{|c|c|c|c|c|c|c|}
\hline \multicolumn{7}{|c|}{ Panel A: Whole Sample } \\
\hline Variable & 1 & 2 & 3 & 4 & 5 & 6 \\
\hline Intercept & -0.001 & -0.001 & 0. & -0.002 & -0.001 & -0.001 \\
\hline$\Delta \mathrm{BA}_{t-1}$ & & $-0.291 * * *$ & $-0.352 * * *$ & $-0.339 * * *$ & $-0.329 * * *$ & $-0.394 * * *$ \\
\hline$\Delta \mathrm{CDS}_{t}$ & $1.172 * * *$ & $1.149 * * *$ & . & $0.909 * *$ & $0.87 * *$ & $0.89 * *$ \\
\hline$\Delta \mathrm{CDS}_{t-1}$ & . & . & $1.261 * * *$ & $1.042 * * *$ & $1.133 * * *$ & $1.123 * * *$ \\
\hline$\Delta \mathrm{CDS}_{t-2}$ & . & . & . & . & -0.411 & \\
\hline$\Delta \mathrm{BA}_{t-2}$ & . & . & . & . & . & $-0.172^{* *}$ \\
\hline$\Delta \mathrm{BA}_{t-3}$ & . & . & . & . & . & $-0.176 * * *$ \\
\hline $\operatorname{Adj} R^{2}$ & 0.051 & 0.134 & 0.141 & 0.17 & 0.174 & 0.206 \\
\hline \multicolumn{7}{|c|}{ Panel B: Below 500} \\
\hline Intercept & -0.001 & -0.002 & 0 & 0. & 0. & 0 \\
\hline$\Delta \mathrm{BA}_{t-1}$ & & $-0.264 * * *$ & $-0.318 * * *$ & $-0.311 * * *$ & $-0.297 * * *$ & $-0.358^{* * *}$ \\
\hline$\Delta \mathrm{CDS}_{t}$ & $0.72 * *$ & $0.671 * *$ & . & 0.427 & 0.404 & 0.422 \\
\hline$\Delta \mathrm{CDS}_{t-1}$ & 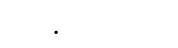 & . & $1.334 * * *$ & $1.248 * * *$ & $1.313 * * *$ & $1.322^{* * *}$ \\
\hline$\Delta \mathrm{CDS}_{t-2}$ & . & . & . & . & -0.315 & . \\
\hline$\Delta \mathrm{BA}_{t-2}$ & . & . & . & . & . & $-0.150^{*}$ \\
\hline$\Delta \mathrm{BA}_{t-3}$ & . & . & . & . & . & $-0.176^{* *}$ \\
\hline $\operatorname{Adj} R^{2}$ & 0.023 & 0.092 & 0.157 & 0.163 & 0.165 & 0.196 \\
\hline \multicolumn{7}{|c|}{ Panel C: Above 500} \\
\hline Intercept & -0.024 & -0.02 & 0.003 & -0.014 & -0.007 & -0.012 \\
\hline$\Delta \mathrm{BA}_{t-1}$ & . & $-0.371^{* * *}$ & $-0.404 * * *$ & $-0.326 * * *$ & $-0.353 * * *$ & $-0.374 * * *$ \\
\hline$\Delta \mathrm{CDS}_{t}$ & $3.64 * * *$ & $3.78 * * *$ & . & $4.03 * * *$ & $3.822 * * *$ & $3.916^{* * *}$ \\
\hline$\Delta \mathrm{CDS}_{t-1}$ & & & 0.932 & -0.743 & -0.447 & -0.648 \\
\hline$\Delta \mathrm{CDS}_{t-2}$ & . & . & . & . & -0.861 & . \\
\hline$\Delta \mathrm{BA}_{t-2}$ & . & . & . & . & . & -0.140 \\
\hline$\Delta \mathrm{BA}_{t-3}$ & . & . & . & . & . & $-0.181^{* *}$ \\
\hline $\operatorname{Adj} R^{2}$ & 0.216 & 0.339 & 0.104 & 0.338 & 0.341 & 0.357 \\
\hline
\end{tabular}

${ }^{*}$ Significant at a $10 \%$ level. ${ }^{* * *}$ Significant at a $5 \%$ level. ${ }^{* * *}$ Significant at a $1 \%$ level. 
Table 4: Results for the Sub-Samples Based on Time and CDS Level This table presents the results for the regression of the change in the Quoted Spread, or the change in the bid-ask spread on day t, $\Delta \mathrm{BA}_{t}$, in Equation 1 on its lagged terms, and the change in the CDS spread on day t, $\Delta \mathrm{CDS}_{t}$, and its lagged terms, using daily data for the Quoted Spread and CDS spread. The significance refers to heteroskedasticity-robust $t$-tests. The sub-samples are based on our data set, which consists of 406 days of trading in Italian government bonds, from June 15, 2011 to December 31, 2012, and are obtained from the MTS (Mercato dei Titoli di Stato) Global Market bond trading system. The CDS spread refers to a USD-denominated, 5-year CDS spread and is obtained from Bloomberg. Sub-samples are taken with regards to the time frame and the CDS level.

\begin{tabular}{|c|c|c|c|c|c|c|}
\hline \multicolumn{7}{|c|}{ Whole Sample } \\
\hline Variable & 1 & 2 & 3 & 4 & 5 & 6 \\
\hline \multicolumn{7}{|c|}{ Panel A: $\mathrm{CDS}_{t} \leq 500, \mathrm{~T}=2011$} \\
\hline Intercept & 0.004 & 0.006 & 0.007 & 0.003 & 0.005 & 0.006 \\
\hline$\Delta \mathrm{BA}_{t-1}$ & & -0.228 & $-0.331 * *$ & $-0.318 * *$ & $-0.291 * *$ & $-0.334^{* *}$ \\
\hline$\Delta \mathrm{CDS}_{t}$ & $1.086 * *$ & $1.035 *$ & . & 0.702 & 0.646 & 0.680 \\
\hline$\Delta \mathrm{CDS}_{t-1}$ & . & . & $1.893 * * *$ & $1.754 * * *$ & $1.849 * * *$ & $1.846^{* * *}$ \\
\hline$\Delta \mathrm{CDS}_{t-2}$ & . & . & . & . & -0.438 & \\
\hline$\Delta \mathrm{BA}_{t-2}$ & . & . & . & . & . & -0.090 \\
\hline$\Delta \mathrm{BA}_{t-3}$ & . & . & . & . & . & -0.154 \\
\hline Adj R-Sq & 0.043 & 0.088 & 0.193 & 0.207 & 0.207 & 0.218 \\
\hline \multicolumn{7}{|c|}{ Panel B: $\mathrm{CDS}_{t}>500, \mathrm{~T}=2011$} \\
\hline Intercept & -0.04 & -0.033 & 0.003 & 0. & 0.008 & 0.003 \\
\hline$\Delta \mathrm{BA}_{t-1}$ & . & $-0.284 * *$ & $-0.387 *$ & -0.088 & -0.141 & -0.092 \\
\hline$\Delta \mathrm{CDS}_{t}$ & $4.667 * * *$ & $4.67 * * *$ & . & $5.844 * * *$ & $5.489 * * *$ & $5.940 * * *$ \\
\hline$\Delta \mathrm{CDS}_{t-1}$ & . & . & 1.399 & $-2.658^{* *}$ & -2.135 & $-2.740 * *$ \\
\hline$\Delta \mathrm{CDS}_{t-2}$ & . & . & . & . & -0.984 & \\
\hline$\Delta \mathrm{BA}_{t-2}$ & . & . & . & . & . & -0.095 \\
\hline$\Delta \mathrm{BA}_{t-3}$ & . & . & . & . & . & $-0.298^{* * *}$ \\
\hline Adj R-Sq & 0.349 & 0.413 & 0.044 & 0.452 & 0.447 & 0.506 \\
\hline \multicolumn{7}{|c|}{ Panel C: $\mathrm{T}=2012$} \\
\hline Intercept & -0.005 & -0.008 & -0.007 & -0.007 & -0.007 & -0.011 \\
\hline$\Delta \mathrm{BA}_{t-1}$ & . & $-0.367 * * *$ & $-0.38^{* * *}$ & $-0.378 * * *$ & $-0.375 * * *$ & $-0.492^{* * *}$ \\
\hline$\Delta \mathrm{CDS}_{t}$ & 0.432 & 0.42 & . & 0.313 & 0.305 & 0.270 \\
\hline$\Delta \mathrm{CDS}_{t-1}$ & . & . & $0.614^{* *}$ & $0.553 * *$ & $0.587 * *$ & $0.600^{* * *}$ \\
\hline$\Delta \mathrm{CDS}_{t-2}$ & . & . & . & . & -0.179 & \\
\hline$\Delta \mathrm{BA}_{t-2}$ & . & . & . & . & . & $-0.285^{* * *}$ \\
\hline$\Delta \mathrm{BA}_{t-3}$ & . & . & . & . & . & $-0.189 * * *$ \\
\hline $\operatorname{Adj} R^{2}$ & 0.005 & 0.137 & 0.146 & 0.147 & 0.145 & 0.206 \\
\hline
\end{tabular}

${ }^{*}$ Significant at a $10 \%$ level. ${ }^{* *}$ Significant at a $5 \%$ level. ${ }^{* * *}$ Significant at a $1 \%$ level. 
Table 5: Results for the Regressions with Global Systemic Variables on Sub-Samples Based on Time and the Level of the CDS Spread This table presents the results for the regression of the change in the Quoted Spread, or the change in the bid-ask spread on day t, $\Delta \mathrm{BA}_{t}$, in Equation 1, on its lagged terms, and the change in the CDS spread on day t, $\Delta \mathrm{CDS}_{t}$, and its lagged terms, and global variables and their lags. The global systemic variables are the return of the Euro 50 Index $\Delta$ Eur $50_{t}$, the change in spread between 3-month Euribor and 3-month Eonia $\Delta$ Euribor-Eonia $t$, the change in spread between 3-month Eonia and the yield of a 3-month German T-Bill $\Delta$ Eonia-DeTBill ${ }_{t}$, the change in the USVIX $\Delta$ USVIX $_{t}$, and the change in the Cross-Currency Basis Swap Spread $\Delta \mathrm{CCBSS}_{t}$. Global systemic variables are described in detail in Section IV. The data have a daily frequency. The statistical significance refers to heteroskedasticity-robust $t$-tests. The sub-samples are based on our data set, which consists of 406 days of trading in Italian government bonds, from June 15, 2011 to December 31, 2012, and is obtained from the MTS (Mercato dei Titoli di Stato) Global Market bond trading system. The CDS spread refers to a USD-denominated, 5-year CDS spread. The CDS spread and all global variables are obtained from Bloomberg. Sub-samples are based on the time frame and the level of the CDS spread.

\begin{tabular}{|c|c|c|c|c|c|c|c|}
\hline \multicolumn{8}{|c|}{ Panel A: $\mathrm{CDS}_{t} \leq 500, \mathrm{~T}=2011$} \\
\hline Variable & 1 & 2 & 3 & 4 & 5 & 6 & 7 \\
\hline Intercept & 0.004 & 0.001 & 0.006 & 0.009 & 0.007 & 0.006 & -0.004 \\
\hline$\Delta \mathrm{CDS}_{t}$ & 0.392 & 0.405 & 0.683 & 0.377 & 0.33 & 0.274 & 0.442 \\
\hline$\Delta \mathrm{CDS}_{t-1}$ & $2.289 * * *$ & $1.718^{* *}$ & $1.872 * * *$ & $1.726 * * *$ & $1.985 * * *$ & $1.749 * * *$ & 2.276 *** \\
\hline$\Delta \mathrm{BA}_{t-1}$ & $-0.341 * *$ & $-0.324 * *$ & $-0.35 * *$ & $-0.353 * *$ & $-0.34 * *$ & $-0.34 * *$ & $-0.336 * *$ \\
\hline$\Delta \mathrm{BA}_{t-2}$ & -0.085 & -0.112 & -0.093 & -0.119 & -0.092 & -0.124 & -0.098 \\
\hline$\Delta \mathrm{BA}_{t-3}$ & -0.137 & -0.154 & -0.154 & -0.144 & -0.128 & -0.123 & -0.124 \\
\hline$\Delta$ Eur50 & -1.257 & . & . & . & . & 0.967 & 1.85 \\
\hline$\Delta$ Eur $50_{t-1}$ & 1.763 & . & . & . & . & . & $2.98 *$ \\
\hline$\Delta$ Euribor-Eonia $t$ & . & $0.558 *$ & . & . & . & 0.179 & 0.382 \\
\hline$\Delta$ Euribor-Eonia $_{t-1}$ & . & 0.173 & & . & . & . & 0.364 \\
\hline$\Delta$ Eonia-DeTBill $_{t}$ & . & . & -0.083 & . & . & -0.024 & -0.048 \\
\hline$\Delta$ Eonia-DeTBill $_{t-1}$ & . & . & -0.067 & . & . & . & -0.081 \\
\hline $\mathrm{UUSVIX}_{t}$ & . & . & . & $0.539 * *$ & . & $0.484 *$ & $0.59 *$ \\
\hline$\Delta$ USVIX $_{t-1}$ & . & . & . & 0.081 & . & . & 0.367 \\
\hline$\Delta \mathrm{CCBSS}_{t}$ & . & . & . & . & $0.695 *$ & 0.585 & 0.477 \\
\hline$\Delta \mathrm{CCBSS}_{t-1}$ & . & . & . & . & -0.292 & $\cdot$ & -0.269 \\
\hline $\operatorname{Adj} R^{2}$ & 0.223 & 0.222 & 0.209 & 0.238 & 0.241 & 0.24 & 0.238 \\
\hline \multicolumn{8}{|c|}{ Panel B: $\mathrm{CDS}_{t}>500, \mathrm{~T}=2011$} \\
\hline Intercept & -0.003 & -0.003 & 0.003 & 0.017 & 0.01 & 0.02 & 0.01 \\
\hline$\Delta \mathrm{CDS}_{t}$ & $6.554 * * *$ & $6.007 * * *$ & $6.168 * * *$ & $3.642 * * *$ & $6.284 * * *$ & $5.074 * * *$ & $5.359 * * *$ \\
\hline$\Delta \mathrm{CDS}_{t-1}$ & $-3.644 * *$ & $-2.812 * * *$ & $-3.45 * *$ & $-2.314 *$ & -2.454 & $-2.692 * *$ & $-4.739 * *$ \\
\hline$\Delta \mathrm{BA}_{t-1}$ & -0.091 & 0.055 & -0.032 & 0.105 & -0.085 & 0.092 & $0.32 * *$ \\
\hline$\Delta \mathrm{BA}_{t-2}$ & -0.057 & -0.127 & -0.096 & -0.048 & -0.09 & -0.057 & -0.075 \\
\hline$\Delta \mathrm{BA}_{t-3}$ & $-0.272 * * *$ & $-0.3^{* * *}$ & $-0.307 * * *$ & $-0.247 * * *$ & $-0.314 * * *$ & $-0.272 * * *$ & $-0.222 * * *$ \\
\hline$\Delta$ Eur50 & 1.027 & . & . & . & . & $3.96 * *$ & $3.698 * *$ \\
\hline$\Delta$ Eur $50_{t-1}$ & -2.415 & . & . & . & . & . & $-4.296 *$ \\
\hline$\Delta$ Euribor-Eonia $_{t}$ & . & $2.866 *$ & . & . & . & 1.336 & $1.841 * *$ \\
\hline$\Delta$ Euribor-Eonia $_{t-1}$ & . & $-1.762 * *$ & . & . & . & . & $-1.997 * *$ \\
\hline$\Delta$ Eonia-DeTBill $_{t}$ & . & . & -0.136 & . & . & -0.143 & -0.005 \\
\hline$\Delta$ Eonia-DeTBill $_{t-1}$ & . & . & 0.18 & . & . & . & $0.201 *$ \\
\hline$\Delta$ USVIX $_{t}$ & . & . & . & $2.358 * *$ & . & $2.501 * * *$ & $2.693 * * *$ \\
\hline$\Delta$ USVIX $_{t-1}$ & . & . & . & -0.395 & . & . & -0.751 \\
\hline$\Delta \mathrm{CCBSS}_{t}$ & . & . & . & . & -0.723 & -0.42 & -0.03 \\
\hline$\Delta \mathrm{CCBSS}_{t-1}$ & . & . & . & . & 0.167 & $\cdot$ & 0.244 \\
\hline $\operatorname{Adj} R^{2}$ & 0.486 & 0.564 & 0.5 & 0.65 & 0.485 & 0.682 & 0.726 \\
\hline \multicolumn{8}{|c|}{ Panel C: $T=2012$} \\
\hline Intercept & -0.01 & -0.006 & -0.01 & -0.011 & -0.007 & -0.005 & 0 \\
\hline$\Delta \mathrm{BA}_{t-1}$ & $-0.483 * * *$ & $-0.485 * * *$ & $-0.488 * * *$ & $-0.491 * * *$ & $-0.5 * * *$ & $-0.477 * * *$ & $-0.482 * * *$ \\
\hline$\Delta \mathrm{BA}_{t-2}$ & $-0.264 * * *$ & $-0.278 * * *$ & $-0.281 * * *$ & $-0.284 * * *$ & $-0.311^{* * *}$ & $-0.294 * * *$ & $-0.263 * * *$ \\
\hline$\Delta \mathrm{BA}_{t-3}$ & $-0.174 * *$ & $-0.185 * *$ & $-0.179 * *$ & $-0.192 * * *$ & $-0.192 * * *$ & $-0.168 * *$ & $-0.152 * *$ \\
\hline$\Delta \mathrm{CDS}_{t}$ & -0.076 & 0.223 & 0.268 & 0.257 & -0.055 & -0.212 & -0.336 \\
\hline$\Delta \mathrm{CDS}_{t-1}$ & 0.351 & $0.609 * * *$ & $0.611 * * *$ & $0.562 * *$ & $0.536 * *$ & 0.576 *** & 0.356 \\
\hline$\Delta \operatorname{Eur} 50_{t}$ & -1.373 & . & . & . & . & -1.145 & -1.498 \\
\hline$\Delta \operatorname{Eur} 50_{t-1}$ & -1.515 & . & . & . & . & . & $-1.576 *$ \\
\hline$\Delta$ Euribor-Eonia $_{t}$ & . & 0.34 & . & . & . & 0.271 & 0.328 \\
\hline$\Delta$ Euribor-Eonia $_{t-1}$ & . & 0.238 & . & . & . & . & 0.38 \\
\hline$\Delta$ Eonia-DeTBill $_{t}$ & . & . & -0.028 & . & . & -0.065 & -0.039 \\
\hline$\Delta$ Eonia-DeTBill $_{t-1}$ & . & . & 0.122 & . & . & . & 0.097 \\
\hline$\Delta$ USVIX $_{t-1}$ & . & . & . & 0.077 & . & . & -0.131 \\
\hline$\Delta$ USVIX $_{t}$ & . & . & . & -0.007 & . & -0.188 & -0.196 \\
\hline$\Delta \mathrm{CCBSS}_{t}$ & . & . & 36 & . & $0.835 * * *$ & $0.815 * * *$ & $0.795 * * *$ \\
\hline$\Delta \mathrm{CCBSS}_{t-1}$ & . & . & . & . & 0.079 & . & -0.016 \\
\hline $\operatorname{Adj} R^{2}$ & 0.213 & 0.205 & 0.207 & 0.2 & 0.231 & 0.231 & 0.231 \\
\hline
\end{tabular}

${ }^{*}$ Significant at a $10 \%$ level. ${ }^{* *}$ Significant at a $5 \%$ level. ${ }^{* * *}$ Significant at a $1 \%$ level. 
Table 6: Results for the Regressions with Global Systemic Variables on Sub-samples Based on Time and CDS Level This table presents the results for the regression of the change in the Quoted Spread, or the change in the bid-ask spread on day t, $\Delta \mathrm{BA}_{t}$, in Equation 1, on its lagged terms, and the change in the CDS spread on day t, $\Delta \mathrm{CDS}_{t}$, and its lagged terms, and global systemic variables and their lags. The global systemic variables are the return of the Euro 50 Index $\Delta$ Eur $50_{t}$, the change in spread between 3-month Euribor and 3-month Eonia $\Delta$ Euribor-Eonia ${ }_{t}$, the change in spread between 3-month Eonia and the yield of a 3-month German T-Bill $\Delta$ Eonia-DeTBill $t$, the change in the USVIX $\Delta$ USVIX $_{t}$, and the change in the Cross-Currency Basis Swap Spread $\Delta$ CCBSS $_{t}$. Global systemic variables are described in detail in Section IV] The data have a daily frequency. The statistical significance refers to heteroskedasticity-robust $t$-tests. The sub-samples are based on our data set, which consists of 406 days of trading in Italian government bonds, from June 15, 2011 to December 31, 2012, and is obtained from the MTS (Mercato dei Titoli di Stato) Global Market bond trading system. The CDS spread refers to a USD-denominated, 5-year CDS spread. The CDS spread and all global variables are obtained from Bloomberg. Sub-samples are based on the time frame and the level of the CDS spread.

\begin{tabular}{l|ccc}
\hline Variable & Below 500 2011 & Above 500 2011 & 2012 \\
\hline Intercept & 0.007 & 0.017 & -0.007 \\
$\Delta$ CDS $_{t}$ & 0.079 & $4.037^{* * *}$ & -0.053 \\
$\Delta$ CDS $_{t-1}$ & $1.759^{* * *}$ & $-2.656^{* *}$ & $0.565^{* *}$ \\
$\Delta$ BA $_{t-1}$ & $-0.346^{* * *}$ & 0.164 & $-0.497^{* * *}$ \\
$\Delta$ BA $_{t-2}$ & $-0.127^{* *}$ & -0.074 & $-0.308^{* * *}$ \\
$\Delta$ BA $_{t-3}$ & -0.125 & $-0.248^{* * *}$ & $-0.189^{* * *}$ \\
$\Delta$ Euribor-Eonia $_{t}$ & 0.182 & $1.664^{* *}$ & $\cdot$ \\
$\Delta$ Euribor-Eonia $_{t-1}$ &. & $-1.929^{* *}$ & $\cdot$ \\
$\Delta$ USVIX $_{t}$ & 0.39 & $2.146^{* *}$ &. \\
$\Delta$ CCBSS $_{t}$ & 0.563 & $\cdot$ & $0.838^{* * *}$ \\
\hline Adj R-Sq & 0.252 & 0.694 & 0.234 \\
\hline
\end{tabular}

${ }^{*}$ Significant at a $10 \%$ level. ${ }^{* *}$ Significant at a $5 \%$ level. ${ }^{* * *}$ Significant at a $1 \%$ level. 
Table 7: Results for the Orthogonalization of Italian CDS Spread This table presents the results for the regression of the changes of the CDS spread on day t, $\triangle C D S_{t}$, on its lag and various global variables, using daily data. The global systemic variables are the return of the Euro 50 Index $\Delta$ Eur $50_{t}$, the change in spread between $3-$ month Euribor and 3-month Eonia $\Delta$ Euribor-Eonia $t$, the change in spread between 3-month Eonia and the yield of a 3-month German T-Bill $\Delta$ Eonia-DeTBill $t$, the change in the USVIX $\Delta$ USVIX $_{t}$, and the change in the Cross-Currency Basis Swap Spread $\Delta$ CCBSS $_{t}$. Global systemic variables are described in detail in Section IV] The data have a daily frequency. The statistical significance refers to heteroskedasticity-robust $t$-tests. The sample coincides with that of our data set, which consists of 406 days of trading in Italian government bonds, from June 15, 2011 to December 31, 2012, and are obtained from the MTS (Mercato dei Titoli di Stato) Global Market bond trading system. The CDS spread refers to a USD-denominated, 5-year CDS spread. The CDS spread and all global variables are obtained from Bloomberg.

\begin{tabular}{l|cc}
\hline Variable & 1 & 2 \\
\hline Intercept & 0.001 & 0.001 \\
$\Delta$ CDS $_{t-1}$ & $0.116^{*}$ & \\
$\Delta$ Eur50 $_{t}$ & $-1.395^{* * *}$ & $-1.366^{* * *}$ \\
$\Delta$ Euribor-Eonia $_{t}$ & $0.07^{*}$ & $0.073^{*}$ \\
$\Delta$ Eonia-DeTBill $_{t}$ & 0.01 & 0.007 \\
$\Delta$ USVIX $_{t}$ & -0.018 & -0.014 \\
$\Delta$ CCBSS $_{t}$ & $0.137^{* * *}$ & $0.161^{* * *}$ \\
$\Delta$ Eur50 $_{t-1}$ & -0.174 & \\
$\Delta$ Euribor-Eonia $_{t-1}$ & 0.056 & \\
$\Delta$ Eonia-DeTBill $_{t-1}$ & 0.013 & \\
$\Delta$ USVix $_{t-1}$ & -0.038 & \\
$\Delta$ CCBSS $_{t-1}$ & 0. & \\
\hline Adj $R^{2}$ & 0.432 & 0.408 \\
\hline
\end{tabular}

${ }^{*}$ Significant at a $10 \%$ level. $\quad{ }^{* *}$ Significant at a $5 \%$ level. ${ }^{* * *}$ Significant at a $1 \%$ level. 
Table 8: Results for the Regression of the Quoted Spread the Orthogonalized Italian CDS Spread This table presents the results for the regression of the change in the Quoted Spread, or the change in the bid-ask spread on day t, $\Delta \mathrm{BA}_{t}$, on its lagged term, and the orthogonalized change in the CDS spread on day $\mathrm{t}, \Delta \mathrm{CDS}_{t}^{\perp 1}$ or $\Delta \mathrm{CDS}_{t}^{\perp 2}$, and its lagged term, and global variables and their lags. The global systemic variables are the return of the Euro 50 Index $\Delta$ Eur50t, the change in spread between 3-month Euribor and 3-month Eonia $\Delta$ Euribor-Eonia $t$, the change in spread between 3 -month Eonia and the yield of a 3-month German T-Bill $\Delta$ Eonia-DeTBill $t_{t}$, the change in the USVIX $\Delta$ USVIX $_{t}$, and the change in the Cross-Currency Basis Swap Spread $\Delta \mathrm{CCBSS}_{t}$. Global systemic variables are described in detail in Section IV] The data have a daily frequency. The statistical significance refers to heteroskedasticity-robust $t$-tests. The sub-samples are based on our data set, which consists of 406 days of trading in Italian government bonds, from June 15, 2011 to December 31, 2012, and is obtained from the MTS (Mercato dei Titoli di Stato) Global Market bond trading system. The CDS spread refers to a USD-denominated, 5-year CDS spread. The CDS spread and all global variables are obtained from Bloomberg. Sub-samples are based on the time frame and the level of the CDS spread.

\begin{tabular}{|c|c|c|c|c|c|c|}
\hline Variable & Below 5002011 & Above 5002011 & 2012 & Below 5002011 & Above 5002011 & 2012 \\
\hline Intercept & 0.005 & -0.011 & -0.006 & 0.004 & -0.01 & -0.006 \\
\hline$\Delta \operatorname{CDS}_{t}^{\perp 1}$ & 0.321 & $5.437^{* * *}$ & -0.172 & . & . & . \\
\hline$\Delta \operatorname{CDS}_{t-1}^{\perp 1}$ & $2.318^{* * *}$ & $-3.374 *$ & 0.274 & . & . & . \\
\hline$\Delta \mathrm{CDS}_{t}^{\perp 2}$ & . & . & . & 0.449 & $5.199 * * *$ & -0.091 \\
\hline$\Delta \operatorname{CDS}_{t-1}^{\perp 2}$ & . & . & . & $2.176 * * *$ & $-3.206 *$ & 0.315 \\
\hline$\Delta \mathrm{BA}_{t-1}$ & $-0.258 *$ & 0.015 & $-0.465 * * *$ & $-0.258 *$ & 0.024 & $-0.467 * * *$ \\
\hline$\Delta \mathrm{BA}_{t-2}$ & -0.086 & -0.01 & $-0.293 * * *$ & -0.092 & -0.002 & $-0.295^{* * *}$ \\
\hline$\Delta \mathrm{BA}_{t-3}$ & -0.076 & $-0.238 * * *$ & $-0.165 * *$ & -0.071 & $-0.231 * * *$ & $-0.165^{* *}$ \\
\hline$\Delta \operatorname{Eur} 50_{t}$ & 0.149 & -2.851 & -0.869 & 0.083 & -2.571 & -0.854 \\
\hline$\Delta$ Euribor-Eonia $_{t}$ & 0.393 & 1.762 & 0.221 & 0.386 & 1.353 & 0.224 \\
\hline$\Delta$ Eonia-DeTBill $_{t}$ & -0.042 & -0.114 & -0.078 & -0.027 & -0.186 & -0.074 \\
\hline$\Delta$ USVIX $_{t}$ & 0.329 & $2.425^{* *}$ & -0.206 & 0.337 & $2.601 * * *$ & -0.207 \\
\hline$\Delta \mathrm{CCBSS}_{t}$ & 0.609 & 0.457 & $0.844^{* * *}$ & 0.587 & 0.397 & $0.836^{* * *}$ \\
\hline $\operatorname{Adj} R^{2}$ & 0.228 & 0.677 & 0.219 & 0.222 & 0.681 & 0.219 \\
\hline
\end{tabular}

\footnotetext{
${ }^{*}$ Significant at a $10 \%$ level. ${ }^{* *}$ Significant at a $5 \%$ level. ${ }^{* * *}$ Significant at a $1 \%$ level.
} 
Table 9: Results for the Orthogonalization of the CDS Spread of Market-Makers This table presents the results for the regression of the changes of the average of CDS spreads for the market-makers on day t, $\triangle M M C D S_{t}$, on its lag and various global variables, using daily data. The regression is estimated for the change in the averages subsets of the market-makers' CDSs, the subsets of the market-makers for the four columns are as follow: All, Only Italian, European but not Italian, non-European market-makers. The global systemic variables are the return of the Euro 50 Index $\Delta$ Eur $50_{t}$, the change in spread between 3-month Euribor and 3-month Eonia $\Delta$ Euribor-Eonia $t$, the change in spread between 3-month Eonia and the yield of a 3-month German T-Bill $\Delta$ Eonia-DeTBill $t$, the change in the USVIX $\Delta$ USVIX $_{t}$, and the change in the Cross-Currency Basis Swap Spread $\Delta$ CCBSS $_{t}$. Global systemic variables are described in detail in Section IV] The data have a daily frequency. The statistical significance refers to heteroskedasticity-robust $t$-tests. The sample coincides with our data set, which consists of 406 days of trading in Italian government bonds, from June 15, 2011 to December 31 , 2012, and is obtained from the MTS (Mercato dei Titoli di Stato) Global Market bond trading system. The CDS spreads and all global variables are obtained from Bloomberg.

\begin{tabular}{l|cccc}
\hline Variable & All MM CDSs & Italian MM CDSs & European (Non IT) MM CDSs & Non European MM CDSs \\
\hline Intercept & 0. & 0.001 & 0. & -0.001 \\
$\Delta$ CDS $_{t}$ & $0.329^{* * *}$ & $0.509^{* * *}$ & $0.364^{* * *}$ & $0.196^{* * *}$ \\
$\Delta$ CCBSS $_{t}$ & $0.089^{* * *}$ & $0.091^{* * *}$ & $0.12^{* * *}$ & $0.07 * * *$ \\
$\Delta$ Eonia-DeTBill $_{t}$ & 0.001 & 0.004 & 0.011 & -0.007 \\
$\Delta$ Euribor-Eonia $_{t}$ & -0.023 & -0.016 & -0.03 & -0.019 \\
$\Delta$ Eur50 $_{t}$ & $-0.871^{* * *}$ & $-0.682^{* * *}$ & $-0.99^{* * *}$ & $-0.902^{* * *}$ \\
$\Delta$ USVix $_{t}$ & 0.011 & -0.009 & -0.026 & $0.047^{*}$ \\
\hline Adj $R^{2}$ & 0.7 & 0.676 & 0.664 & 0.573 \\
\hline
\end{tabular}

${ }^{*}$ Significant at a $10 \%$ level. ${ }^{* *}$ Significant at a $5 \%$ level. ${ }^{* * *}$ Significant at a $1 \%$ level. 
Table 10: Results for the Regression of the Quoted Spread the Orthogonalized CDS Spread of the Market-Makers This table presents the results for the regression of the change in the Quoted Spread, or the change in the bid-ask spread on day t, $\triangle \mathrm{BA}_{t}$, on its lagged term, and the orthogonalized change in the CDS spread of a subset of the market-

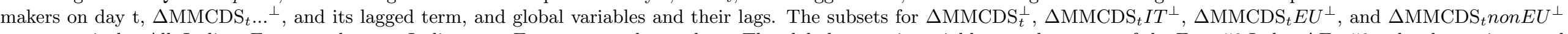
are respectively: All, Italian, European but not Italian, non-European market-makers. The global systemic variables are the return of the Euro 50 Index $\Delta$ Eur $50_{t}$, the change in spread between 3-month Euribor and 3-month Eonia $\Delta$ Euribor-Eoniat, the change in spread between 3-month Eonia and the yield of a 3-month German T-Bill $\Delta$ Eonia-DeTBillt, the change in the USVIX $\Delta$ USVIX $_{t}$, and the change in the Cross-Currency Basis Swap Spread $\Delta$ CCBSS $_{t}$. Global systemic variables are described in detail in Section IV. The orthogonalization follows from the Regressions in Table 9. The data have a daily frequency. The statistical significance refers to heteroskedasticity-robust $t$-tests. The sub-samples are based on our data set, which consists of 406 days of trading in Italian government bonds, from June 15, 2011 to December 31, 2012, and is obtained from the MTS (Mercato dei Titoli di Stato) Global Market bond trading system. The CDS spreads refers to USD- or EUR-denominated, 5-year CDS contracts. The CDS spreads and all global variables are obtained from Bloomberg. Sub-samples are based on the time frame and the level of the CDS spread: Sub-sample 1 is 2011 days where the Italian CDS spread is below 500, Sub-sample 2 is 2011 days where the Italian CDS spread is above 500, Sub-sample 3 contains days of the year 2012.

\begin{tabular}{|c|c|c|c|c|c|c|c|c|c|c|c|c|}
\hline \multirow[b]{2}{*}{ Variable } & \multicolumn{3}{|c|}{ All MM CDSs } & \multicolumn{3}{|c|}{ Italian MM CDSs } & \multicolumn{3}{|c|}{ European (Non IT) MM CDSs } & \multicolumn{3}{|c|}{ Non European MM CDSs } \\
\hline & 1 & 2 & 3 & 1 & 2 & 3 & 1 & 2 & 3 & 1 & 2 & 3 \\
\hline Intercept & 0.003 & 0.029 & -0.005 & 0.007 & 0.023 & -0.005 & 0.001 & 0.029 & -0.005 & 0.008 & 0.028 & -0.005 \\
\hline$\Delta \mathrm{BA}_{t-1}$ & $-0.35 * * *$ & 0.119 & $-0.477 * * *$ & $-0.343 * *$ & 0.135 & $-0.481 * * *$ & $-0.36 * * *$ & 0.088 & $-0.477 * * *$ & $-0.357 * * *$ & 0.111 & $-0.476 * * *$ \\
\hline$\Delta \mathrm{BA}_{t-2}$ & -0.119 & -0.041 & $-0.296 * * *$ & -0.131 & 0.01 & $-0.299 * * *$ & -0.105 & -0.069 & $-0.291 * * *$ & -0.134 & -0.059 & $-0.296 * * *$ \\
\hline$\Delta \mathrm{BA}_{t-3}$ & -0.122 & $-0.198 * *$ & $-0.169 * *$ & -0.126 & $-0.233 * * *$ & $-0.169 * *$ & -0.116 & $-0.23 * *$ & $-0.167 * *$ & -0.135 & $-0.191 * *$ & $-0.171 * *$ \\
\hline$\Delta \mathrm{CDS}_{t}$ & 0.101 & $5.481 * * *$ & -0.214 & 0.273 & $5.056 * * *$ & -0.209 & 0.128 & $5.153^{* * *}$ & -0.205 & 0.071 & $5.762 * * *$ & -0.192 \\
\hline$\Delta \mathrm{CDS}_{t-1}$ & $1.842 * * *$ & $-3.693 * * *$ & $0.566 * *$ & $1.729 * *$ & $-3.269 * * *$ & $0.555 * *$ & $1.906 * * *$ & $-3.173 * *$ & $0.575^{* * *}$ & $1.769 * * *$ & $-3.821 * *$ & $0.547 * *$ \\
\hline$\Delta \mathrm{CCBSS}_{t}$ & 0.564 & -0.149 & $0.814 * * *$ & 0.595 & -0.238 & $0.806 * * *$ & 0.584 & -0.289 & $0.813 * * *$ & 0.593 & -0.139 & $0.823 * * *$ \\
\hline$\Delta$ Eonia-DeTBill $_{t}$ & -0.039 & -0.233 & -0.066 & -0.02 & -0.226 & -0.066 & -0.045 & -0.206 & -0.064 & -0.036 & -0.211 & -0.064 \\
\hline$\Delta$ Euribor-Eonia $t$ & 0.217 & 0.472 & 0.268 & 0.18 & 0.411 & 0.275 & 0.2 & 0.722 & 0.274 & 0.202 & 0.78 & 0.258 \\
\hline$\Delta$ Eur $50_{t}$ & 0.601 & $4.877^{* *}$ & -1.137 & 0.995 & $4.631 * * *$ & -1.125 & 0.694 & $4.675 * *$ & -1.153 & 0.63 & $4.68^{* *}$ & -1.101 \\
\hline$\Delta$ USVix $_{t}$ & 0.382 & $2.704^{* * *}$ & -0.187 & $0.497 *$ & $2.697^{* * *}$ & -0.188 & 0.395 & $2.758 * * *$ & -0.189 & 0.389 & $2.549 * * *$ & -0.186 \\
\hline$\Delta \operatorname{MMCDS}_{t}^{\perp}$ & -1.168 & $3.806 * *$ & 0.012 & $\cdot$ & . & . & . & . & . & 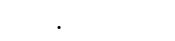 & . & . \\
\hline$\Delta \operatorname{MMCDS}_{t-1}^{\perp}$ & $-1.392 *$ & $-3.463 * *$ & 0.153 & & & & . & . & & & . & . \\
\hline$\Delta \mathrm{MMCDS}_{t} I T^{\perp}$ & . & . & . & 0.206 & $3.134 * * *$ & 0.19 & . & . & . & & . & . \\
\hline$\Delta \mathrm{MMCDS}_{t-1} I T^{\perp}$ & . & . & . & 0.304 & $-2.473 * *$ & 0.255 & . & . & . & & . & . \\
\hline$\Delta \mathrm{MMCDS}_{t-1} E U^{\perp}$ & . & . & . & . & . & . & -0.986 & $2.636 * *$ & 0.008 & & . & . \\
\hline$\Delta \mathrm{MMCDS}_{t-1} E U^{\perp}$ & . & . & & . & . & & $-1.728 * *$ & $-2.272 * *$ & -0.166 & & . & . \\
\hline$\Delta \mathrm{MMCDS}_{t}$ non $E U^{\perp}$ & . & . & . & . & . & . & . & . & . & -0.838 & 3.122 & -0.142 \\
\hline$\Delta \mathrm{MMCDS}_{t-1}$ non $E U^{\perp}$ & . & . & . & . & . & . & . & . & . & $-1.1 * *$ & $-3.169 *$ & 0.242 \\
\hline $\operatorname{Adj} R^{2}$ & 0.254 & 0.728 & 0.225 & 0.226 & 0.748 & 0.226 & 0.271 & 0.709 & 0.225 & 0.256 & 0.689 & 0.225 \\
\hline
\end{tabular}

Significant at a $10 \%$ level. ${ }^{* *}$ Significant at a $5 \%$ level. ${ }^{* * *}$ Significant at a $1 \%$ level. 
Table 11: Results for the Granger Causality Analysis of Italian CDS Spread and Quoted Spread This table presents the results for the regressions of the day-t changes in Quoted Spread, $\triangle \mathrm{BA}_{t}$, and Italian CDS spread $\triangle C D S_{t}$, on the lagged terms of both variables. The data have a daily frequency. The significance refers to heteroskedasticity-robust $t$-tests. The two bottom rows report heteroskedasticity-robust F-test statistics and their significance for the null of $\Delta B A_{t}=\Delta B A_{t-1}=0(B A \stackrel{G C}{\longrightarrow} C D S)$, and $\Delta C D S_{t}=\Delta C D S_{t-1}=0(C D S \stackrel{G C}{\longrightarrow} B A)$ respectively. The sub-samples are based on our data set, which consists of 406 days of trading in Italian government bonds, from June 15,2011 to December 31, 2012, and is obtained from the MTS (Mercato dei Titoli di Stato) Global Market bond trading system. The CDS spread refers to a USD-denominated, 5-year CDS spread. The CDS spread is obtained from Bloomberg. Sub-samples are taken with regards to the time frame and the CDS level.

\begin{tabular}{|c|c|c|c|c|c|c|}
\hline \multirow[b]{2}{*}{ Variable } & \multicolumn{2}{|c|}{$C D S_{t} \leq 500 T=2011$} & \multicolumn{2}{|c|}{$C D S_{t}>500 T=2011$} & \multicolumn{2}{|c|}{$\mathrm{T}=2012$} \\
\hline & CDS & BA Spread & CDS & BA Spread & CDS & BA Spread \\
\hline Intercept & 0.007 & 0.01 & 0.003 & 0.026 & -0.002 & -0.009 \\
\hline$\Delta \mathrm{CDS}_{t-1}$ & $0.227 * *$ & $1.991 * * *$ & $0.783 * * *$ & $2.169 * *$ & $0.203 * *$ & $0.648^{* *}$ \\
\hline$\Delta \mathrm{CDS}_{t-2}$ & $-0.189 *$ & -0.511 & $-0.296 *$ & $-2.913 * * *$ & -0.045 & -0.071 \\
\hline$\Delta \mathrm{BA}_{t-1}$ & -0.001 & $-0.301 * *$ & $-0.064 * * *$ & $-0.471^{* * *}$ & -0.004 & $-0.453^{* * *}$ \\
\hline$\Delta \mathrm{BA}_{t-2}$ & 0.029 & -0.008 & -0.006 & 0.05 & 0.002 & $-0.199 * * *$ \\
\hline $\operatorname{Adj} R^{2}$ & 0.038 & 0.189 & 0.308 & 0.096 & 0.024 & 0.175 \\
\hline$B A \stackrel{G C}{\longrightarrow} C D S$ & 2.289 & . & $13.672 * * *$ & . & 0.152 & . \\
\hline$C D S \stackrel{G C}{\longrightarrow} B A$ & . & $10.034 * * *$ & . & $9.136 * *$ & . & $6.241 * *$ \\
\hline
\end{tabular}

${ }^{*}$ Significant at a $10 \%$ level. ${ }^{* *}$ Significant at a $5 \%$ level. ${ }^{* * *}$ Significant at a $1 \%$ level. 
Table 12: Results for the Granger Causality Analysis of Orthogonalized Italian CDS Spread and Quoted Spread This table presents the results for the regressions of the day-t changes in Quoted Spread, $\Delta \mathrm{BA}_{t}$, and orthogonalized Italian CDS spread $\triangle C D S_{t}$, on the lagged terms of both variables and contemporaneous changes of global systemic variables. The global systemic variables are the return of the Euro 50 Index $\Delta$ Eur $50_{t}$, the change in spread between 3-month Euribor and 3-month Eonia $\Delta$ Euribor-Eonia $_{t}$, the change in spread between 3 -month Eonia and the yield of a 3 -month German T-Bill $\Delta$ Eonia-DeTBill $t_{t}$, the change in the USVIX $\Delta$ USVIX $_{t}$, and the change in the Cross-Currency Basis Swap Spread $\Delta \mathrm{CCBSS}_{t}$. Global systemic variables are described in detail in Section IV The orthogonalization regressions are reported in Table 7. The data have a daily frequency. The statistical significance refers to heteroskedasticity-robust $t$-tests. The two bottom rows report heteroskedasticity-robust F-test statistics and their significance for the null of $\Delta B A_{t}=\Delta B A_{t-1}=0(B A \stackrel{G C}{\longrightarrow} C D S)$, and $\triangle C D S_{t}=\Delta C D S_{t-1}=0(C D S \stackrel{G C}{\longrightarrow} B A)$ respectively. The sub-samples are based on our data set, which consists of 406 days of trading in Italian government bonds, from June 15, 2011 to December 31, 2012, and are obtained from the MTS (Mercato dei Titoli di Stato) Global Market bond trading system. The CDS spread refers to a USD-denominated, 5 -year CDS spread. The CDS spread and all global variables are obtained from Bloomberg. Sub-samples are taken with regards to the time frame and the level of the CDS spread.

\begin{tabular}{|c|c|c|c|c|c|c|}
\hline \multirow[b]{2}{*}{ Variable } & \multicolumn{2}{|c|}{$C D S_{t} \leq 500 T=2011$} & \multicolumn{2}{|c|}{$C D S_{t}>500 T=2011$} & \multicolumn{2}{|c|}{$\mathrm{T}=2012$} \\
\hline & $\Delta \mathrm{CDS}^{\perp 1}$ & BA Spread & $\Delta \mathrm{CDS}^{\perp 1}$ & BA Spread & $\Delta \mathrm{CDS}^{\perp 1}$ & BA Spread \\
\hline Intercept & 0.003 & 0.004 & 0.004 & -0.002 & -0.001 & -0.004 \\
\hline$\Delta \operatorname{CDS}_{t-1}^{\perp 1}$ & 0.091 & $2.318 * * *$ & $0.703 * * *$ & -0.095 & 0.093 & 0.283 \\
\hline$\Delta \operatorname{CDS}_{t-2}^{\perp 1}$ & 0.06 & 0.461 & $-0.223 *$ & $-1.81 *$ & -0.017 & -0.342 \\
\hline$\Delta \mathrm{BA}_{t-1}$ & -0.019 & $-0.29 * *$ & $-0.014 *$ & -0.028 & 0.014 & $-0.425 * * *$ \\
\hline$\Delta \mathrm{BA}_{t-2}$ & -0.006 & -0.085 & -0.005 & 0.086 & -0.003 & $-0.217^{* * *}$ \\
\hline$\Delta$ Eur $50_{t}$ & -0.267 & 0.097 & 0.483 & -0.387 & -0.108 & -1.406 \\
\hline$\Delta$ Euribor-Eonia $_{t}$ & 0.025 & 0.363 & -0.162 & 0.377 & -0.025 & 0.267 \\
\hline$\Delta$ Eonia-DeTBill $_{t}$ & 0.007 & -0.038 & 0.022 & -0.035 & $-0.031 *$ & -0.076 \\
\hline$\Delta \mathrm{USVix}_{t}$ & -0.088 & 0.335 & 0.138 & $3.348^{* * *}$ & 0.029 & -0.276 \\
\hline$\Delta \mathrm{CCBSS}_{t}$ & -0.022 & $0.655 *$ & -0.116 & 0.068 & 0.034 & $0.802 * * *$ \\
\hline $\operatorname{Adj} R^{2}$ & -0.032 & 0.231 & 0.309 & 0.46 & 0.008 & 0.202 \\
\hline$B A \stackrel{G C}{\longrightarrow} C D S$ & 0.858 & . & 3.607 & . & 2.013 & . \\
\hline$C D S \stackrel{G C}{\longrightarrow} B A$ & . & $9.915 * * *$ & . & 3.507 & . & 1.916 \\
\hline
\end{tabular}

${ }^{*}$ Significant at a $10 \%$ level. ${ }^{* *}$ Significant at a $5 \%$ level. ${ }^{* * *}$ Significant at a $1 \%$ level. 
Table 13: Results for the Granger Causality Analysis of Orthogonalized Italian CDS Spread and Quoted Spread This table presents the results for the regressions of the day-t changes in Quoted Spread, $\Delta \mathrm{BA}_{t}$, and orthogonalized Italian CDS spread $\triangle C D S_{t}$, on the lagged terms of both variables and contemporaneous changes of global systemic variables. The global systemic variables are the return of the Euro 50 Index $\Delta$ Eur $50_{t}$, the change in spread between 3-month Euribor and 3-month Eonia $\Delta$ Euribor-Eonia $_{t}$, the change in spread between 3 -month Eonia and the yield of a 3 -month German T-Bill $\Delta$ Eonia-DeTBill $t_{t}$, the change in the USVIX $\Delta$ USVIX $_{t}$, and the change in the Cross-Currency Basis Swap Spread $\Delta \mathrm{CCBSS}_{t}$. Global systemic variables are described in detail in Section IV The orthogonalization regressions are reported in Table 7. The data have a daily frequency. The statistical significance refers to heteroskedasticity-robust $t$-tests. The two bottom rows report heteroskedasticity-robust F-test statistics and their significance for the null of $\Delta B A_{t}=\Delta B A_{t-1}=0(B A \stackrel{G C}{\longrightarrow} C D S)$, and $\triangle C D S_{t}=\Delta C D S_{t-1}=0(C D S \stackrel{G C}{\longrightarrow} B A)$ respectively. The sub-samples are based on our data set, which consists of 406 days of trading in Italian government bonds, from June 15, 2011 to December 31, 2012, and are obtained from the MTS (Mercato dei Titoli di Stato) Global Market bond trading system. The CDS spread refers to a USD-denominated, 5 -year CDS spread. The CDS spread and all global variables are obtained from Bloomberg. Sub-samples are taken with regards to the time frame and the level of the CDS spread.

\begin{tabular}{|c|c|c|c|c|c|c|}
\hline \multirow[b]{2}{*}{ Variable } & \multicolumn{2}{|c|}{$C D S_{t} \leq 500 T=2011$} & \multicolumn{2}{|c|}{$C D S_{t}>500 T=2011$} & \multicolumn{2}{|c|}{$\mathrm{T}=2012$} \\
\hline & $\Delta \mathrm{CDS}^{\perp 1}$ & BA Spread & $\Delta \mathrm{CDS}^{\perp 1}$ & BA Spread & $\Delta \mathrm{CDS}^{\perp 1}$ & BA Spread \\
\hline Intercept & 0.003 & 0.004 & 0.003 & -0.003 & -0.002 & -0.004 \\
\hline$\Delta \mathrm{CDS}_{t-1}^{\perp 2}$ & 0.059 & $2.114 * * *$ & $0.628^{* * *}$ & -0.535 & 0.082 & 0.344 \\
\hline$\Delta \mathrm{CDS}_{t-2}^{\perp 2}$ & 0.057 & 0.512 & -0.198 & $-1.62 *$ & -0.016 & -0.398 \\
\hline$\Delta \mathrm{BA}_{t-1}$ & -0.017 & $-0.297 * *$ & -0.014 & -0.014 & 0.015 & $-0.424 * * *$ \\
\hline$\Delta \mathrm{BA}_{t-2}$ & -0.009 & -0.094 & -0.007 & 0.086 & -0.006 & $-0.218 * * *$ \\
\hline$\Delta$ Eur $50_{t}$ & -0.285 & -0.064 & 0.475 & -0.262 & -0.105 & -1.392 \\
\hline$\Delta$ Euribor-Eonia $_{t}$ & 0.021 & 0.305 & -0.085 & 0.37 & -0.033 & 0.267 \\
\hline$\Delta$ Eonia-DeTBill $_{t}$ & 0.005 & -0.029 & $0.037 *$ & -0.039 & $-0.032 * *$ & -0.074 \\
\hline$\Delta$ USVix $_{t}$ & -0.082 & 0.351 & 0.117 & $3.397 * * *$ & 0.029 & -0.274 \\
\hline$\Delta \mathrm{CCBSS}_{t}$ & -0.046 & $0.633 *$ & -0.09 & 0.171 & 0.012 & $0.799 * * *$ \\
\hline Adj $R^{2}$ & -0.039 & 0.224 & 0.234 & 0.459 & 0.006 & 0.204 \\
\hline$B A \stackrel{G C}{\longrightarrow} C D S$ & 0.862 & & 2.563 & . & 2.877 & \\
\hline$C D S \stackrel{G C}{\longrightarrow} B A$ & . & $9.81 * * *$ & . & 3.237 & . & 2.645 \\
\hline
\end{tabular}

${ }^{*}$ Significant at a $10 \%$ level. ${ }^{* *}$ Significant at a $5 \%$ level. ${ }^{* * *}$ Significant at a $1 \%$ level. 
Table 14: Other Liquidity Variables: Results for Sub-samples Based on Time and CDS Level This table presents the results for the regression of the change in several liquidity measures in Equation 1 on their lagged terms, and the change in the CDS spread on day t, $\Delta \mathrm{CDS}_{t}$, and its lagged terms, using daily data for the liquidity measures and CDS spread. The results for changes in the liquidity measures Quoted Quantity $\Delta Q Q_{t}$, Effective Spread $\Delta E S_{t}$, and Lambda $\Delta \lambda_{t}$ are presented in Panel A, B, and C, respectively. The liquidity measures are described in Section IV.I. The significance refers to heteroskedasticity-robust $t$-tests. The sub-samples are based on our data set, which consists of 406 days of trading in Italian government bonds, from June 15, 2011 to December 31, 2012, and is obtained from the MTS (Mercato dei Titoli di Stato) Global Market bond trading system. "Below 500" and "Above 500" indicates a sample split based on the level of the CDS spread for Italian bonds, "2011" and "2012" refers to a sample split based on the timing of the observation. The CDS spread refers to a USD-denominated, 5-year CDS spread and is obtained from Bloomberg. Sub-samples are taken with regards to the time frame and the CDS level.

\begin{tabular}{|c|c|c|c|c|c|c|}
\hline Variable & All Sample & Below 500 & Above 500 & Below 5002011 & Above 5002011 & 2012 \\
\hline \multicolumn{7}{|c|}{ Dependent Variable: Quoted Quantity, $\Delta Q Q_{t}$} \\
\hline Intercept & -0.001 & -0.002 & -0.004 & -0.003 & -0.002 & 0.002 \\
\hline$\Delta Q_{t-1}$ & $-0.395^{* * *}$ & $-0.380^{* * *}$ & $-0.349^{* * *}$ & $-0.381^{* *}$ & $-0.341^{* *}$ & $-0.372^{* * *}$ \\
\hline$\Delta Q_{t-2}$ & $-0.325^{* * *}$ & $-0.335^{* * *}$ & $-0.234^{*}$ & -0.207 & -0.249 & $-0.415^{* * *}$ \\
\hline$\Delta Q_{t-3}$ & $-0.232^{* * *}$ & $-0.235^{* *}$ & $-0.226^{* *}$ & -0.150 & -0.253 & $-0.307^{* * *}$ \\
\hline$\Delta \mathrm{CDS}_{t}$ & $-0.310^{*}$ & -0.103 & $-1.731^{* * *}$ & -0.036 & $-2.486^{* *}$ & -0.197 \\
\hline$\Delta \mathrm{CDS}_{t-1}$ & -0.355 & $-0.446^{*}$ & -0.455 & $-0.742^{*}$ & 0.845 & -0.046 \\
\hline $\mathrm{R}^{2}$ & 0.195 & 0.189 & 0.275 & 0.173 & 0.290 & 0.232 \\
\hline \multicolumn{7}{|c|}{ Dependent Variable: Effective Spread, $\Delta E S_{t}$} \\
\hline Intercept & -0.002 & -0.001 & -0.029 & -0.000 & -0.039 & -0.008 \\
\hline$\Delta \mathrm{ES}_{t-1}$ & $-0.423^{* * *}$ & $-0.372^{* * *}$ & $-0.602^{* * *}$ & $-0.239 * * *$ & $-0.403^{* *}$ & $-0.573^{* * *}$ \\
\hline$\Delta \mathrm{ES}_{t-2}$ & $-0.315^{* * *}$ & $-0.300 * * *$ & $-0.384^{* * *}$ & $-0.237 * * *$ & -0.199 & $-0.438 * * *$ \\
\hline$\Delta \mathrm{ES}_{t-3}$ & $-0.227^{* * *}$ & $-0.209 * * *$ & $-0.279 * *$ & $-0.218^{* *}$ & -0.205 & $-0.291^{* * *}$ \\
\hline$\Delta \mathrm{CDS}_{t}$ & $1.278^{* * *}$ & $0.956^{* *}$ & $3.128^{* * *}$ & $1.153^{* *}$ & $3.386^{* * *}$ & $0.905^{*}$ \\
\hline$\Delta \mathrm{CDS}_{t-1}$ & 0.538 & 0.414 & 1.073 & $1.142^{* *}$ & 0.803 & -0.315 \\
\hline $\mathrm{R}^{2}$ & 0.212 & 0.181 & 0.313 & 0.153 & 0.229 & 0.288 \\
\hline \multicolumn{7}{|c|}{ Dependent Variable: Lambda, $\Delta \lambda_{t}$} \\
\hline Intercept & 0.000 & 0.000 & -0.027 & 0.007 & 0.022 & -0.020 \\
\hline$\Delta \lambda_{t-1}$ & $-0.561^{* * *}$ & $-0.555^{* * *}$ & $-0.576^{* * *}$ & $-0.523^{* * *}$ & $-0.332^{* *}$ & $-0.625^{* * *}$ \\
\hline$\Delta \lambda_{t-2}$ & $-0.315^{* * *}$ & $-0.334^{* * *}$ & $-0.233^{* *}$ & -0.176 & -0.157 & $-0.427 * * *$ \\
\hline$\Delta \lambda_{t-3}$ & $-0.302^{* * *}$ & $-0.256^{* * *}$ & $-0.382^{* * *}$ & -0.146 & $-0.378 * * *$ & $-0.416^{* * *}$ \\
\hline$\Delta \lambda_{t-4}$ & $-0.110^{* *}$ & -0.050 & $-0.266^{* * *}$ & 0.006 & $-0.430 * * *$ & $-0.195^{* * *}$ \\
\hline$\Delta \mathrm{CDS}_{t}$ & 0.559 & -0.157 & $5.157^{* * *}$ & 0.067 & $8.863^{* * *}$ & -0.318 \\
\hline$\Delta \mathrm{CDS}_{t-1}$ & $1.419^{* *}$ & $1.542^{* *}$ & -0.067 & $2.522^{* *}$ & $-3.291^{*}$ & 0.324 \\
\hline $\mathrm{R}^{2}$ & 0.263 & 0.247 & 0.427 & 0.245 & 0.541 & 0.293 \\
\hline
\end{tabular}

${ }^{*}$ Significant at a $10 \%$ level. ${ }^{* *}$ Significant at a $5 \%$ level. ${ }^{* * *}$ Significant at a $1 \%$ level. 
Table 15: Results for the Cross-sectional Regressions of Liquidity Measures on Bond Characteristics. This panel presents the results from the cross-sectional regression (eq. 4 ) of time-averaged liquidity measures on bond characteristics and number of trades, defined in Section IV.I The sub-sample consists of 60 Italian coupon-bearing bonds. Heteroskedasticity-robust t-statistics are reported in parentheses. $\mathrm{R}^{2}$ values are reported below the parameter estimates. Our data set consists of transactions, quotes, and orders for all 152 fixed-rate and floating Italian government bonds (Buoni Ordinari del Tesoro (BOT) or Treasury Bills or Certificato del Tesoro Zero-coupon (CTZ) or Zero coupon bonds, Certificati di Credito del Tesoro (CCT) or Floating notes, and Buoni del Tesoro Poliennali (BTP) or Fixed-income Treasury Bonds) from June 1, 2011 to December 31, 2012.

\begin{tabular}{l|ccccc}
\hline \multicolumn{7}{c}{ Panel A Sub-sample: Coupon-Bearing Bonds } \\
\hline Variable & Quoted Spread & Effective Spread & Total Quantity & Amihud & Roll \\
\hline Amount Issued & $-0.009^{* * *}$ & $-0.004^{* *}$ & 1.219 & 0.072 & -0.002 \\
Daily Trades & $-0.028^{* * *}$ & $-0.008^{* * *}$ & $-1.306^{* *}$ & $-0.311^{* * *}$ & $-0.003^{* * *}$ \\
Coupon Rate & 0.006 & 0.008 & 2.216 & -0.267 & -0.001 \\
Maturity 3 & $0.357^{* * *}$ & $0.103^{* *}$ & $152.389 * * *$ & -0.402 & 0.041 \\
Maturity 5 & $0.41^{* * *}$ & $0.131^{* *}$ & $150.261^{* * *}$ & 0.193 & 0.048 \\
Maturity 10 & $0.541^{* * *}$ & $0.182^{* * *}$ & $139.074 * * *$ & 1.238 & $0.074^{* *}$ \\
Maturity 15 & $0.737^{* * *}$ & $0.239^{* * *}$ & $125.012^{* * *}$ & $4.15^{* * *}$ & $0.0966^{* * *}$ \\
Maturity 30 & $1.145^{* * *}$ & $0.432^{* * *}$ & $99.698^{* * *}$ & $10.396^{* * *}$ & $0.111^{* *}$ \\
TTM/Maturity & $0.841^{* * *}$ & $0.309^{* * *}$ & $-172.211^{* *}$ & $7.588^{* * *}$ & $0.12^{* *}$ \\
(TTM/Maturity) $^{2}$ & $-0.595^{* * *}$ & $-0.236^{* * *}$ & $135.715^{* *}$ & -2.814 & $-0.094^{*}$ \\
\hline $\mathrm{R}^{2}$ & 0.985 & 0.985 & 0.986 & 0.978 & 0.887 \\
$\mathrm{~N}$ & 60 & 60 & 60 & 60 & 60 \\
\hline
\end{tabular}

${ }^{*}$ Significant at a $10 \%$ level. ${ }^{* *}$ Significant at a $5 \%$ level. ${ }^{* * *}$ Significant at a $1 \%$ level. 
Table 15: (continued) Panel B presents the results from the cross-sectional regression (eq. 5 of timeaveraged liquidity measures on bond characteristics and number of trades, defined in Section IV.I. The sub-sample consists of 92 Italian zero coupon and floating rate bonds. Heteroskedasticity-robust t-statistics are reported in parentheses. $\mathrm{R}^{2}$ values are reported below the parameter estimates.

\begin{tabular}{l|ccccc}
\hline \multicolumn{5}{c}{ Panel B Sub-sample: Non-Coupon-Bearing Bonds } \\
\hline Variable & Quoted Spread & Effective Spread & Total Quantity & Amihud & Roll \\
\hline Amount Issued & $-0.015^{* *}$ & $-0.009^{* *}$ & $5.048^{*}$ & -0.056 & $-0.002^{* * *}$ \\
Daily Trades & 0. & 0. & $-7.846^{* * *}$ & -0.036 & 0. \\
Maturity 0.25 & $-0.242^{* * *}$ & $-0.076^{* * *}$ & $238.539^{* * *}$ & $-1.596^{* *}$ & $-0.019 * * *$ \\
Maturity 0.5 & $-0.146^{* *}$ & -0.025 & $234.896^{* * *}$ & -1.27 & -0.009 \\
Maturity 1 & -0.064 & 0.002 & $222.01^{* * *}$ & -0.962 & -0.004 \\
Maturity 2 & $0.155^{*}$ & 0.085 & $223.089^{* * *}$ & 0.01 & $0.019^{*}$ \\
Maturity 6 & $0.585^{* * *}$ & $0.246^{* * *}$ & $179.395^{* * *}$ & $3.547^{* * *}$ & $0.05^{* * *}$ \\
TTM/Maturity & $1.241^{* * *}$ & $0.459^{* * *}$ & $-428.022^{* * *}$ & $6.726^{* * *}$ & $0.114^{* * *}$ \\
${\text { (TTM/Maturity })^{2}}^{* * * * * * *}$ & $-0.987^{* * *}$ & $-0.367^{* * *}$ & $341.19^{* * *}$ & $-4.675^{* * *}$ & $-0.1044^{* * *}$ \\
\hline $\mathrm{R}^{2}$ & 0.904 & 0.865 & 0.926 & 0.782 & 0.772 \\
$\mathrm{~N}$ & 92 & 92 & 92 & 92 & 92 \\
\hline
\end{tabular}

${ }^{a}$ Floating coupon bonds have a maturity of 6 years

${ }^{*}$ Significant at a $10 \%$ level. ${ }^{* *}$ Significant at a $5 \%$ level. ${ }^{* * *}$ Significant at a $1 \%$ level. 
Figures 


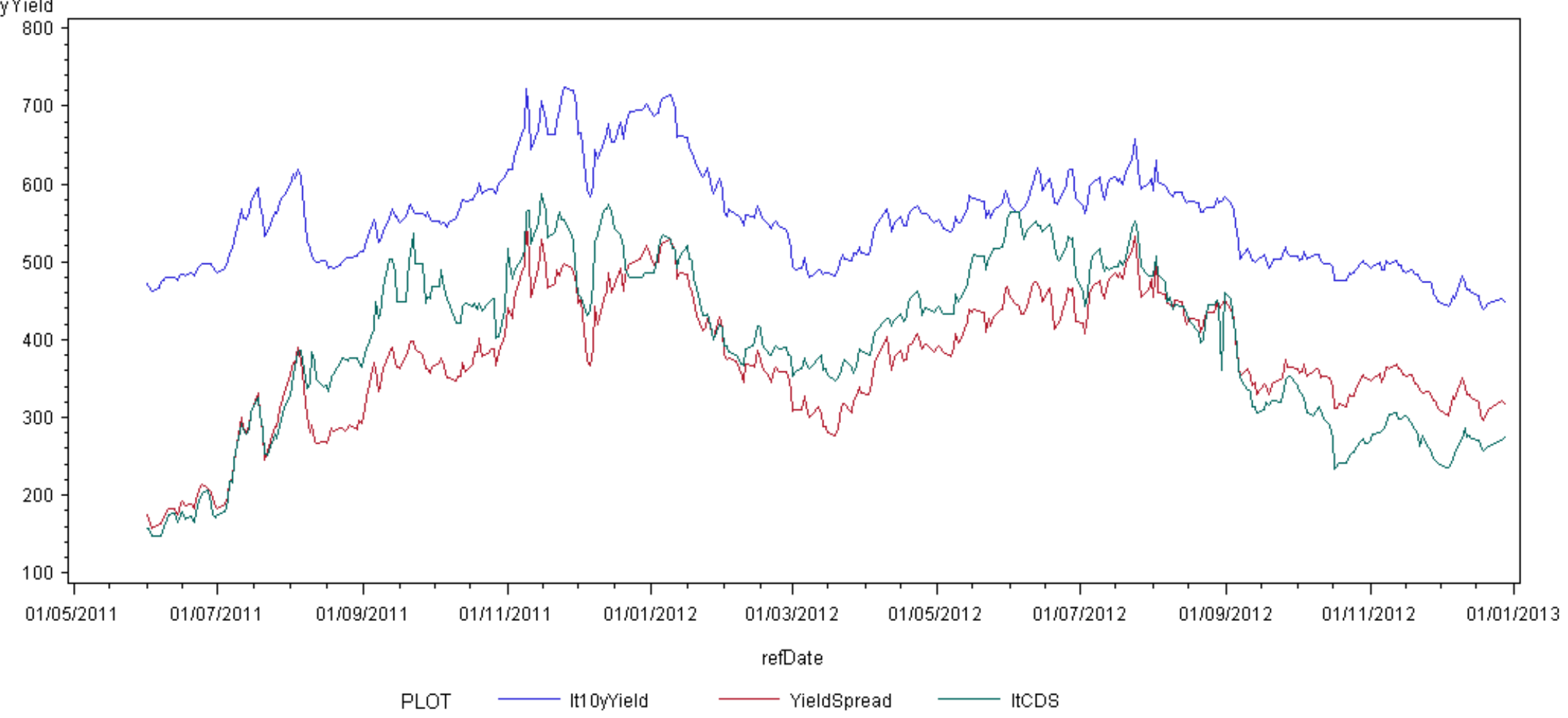

Figure 1: Time Series of Bond Yield, Bond Yield Spread and CDS Spread The bond yield spread is calculated between the Italian and German bonds with 10 years to maturity. The CDS Spread is the spread for a 5-year US-denominated CDS contract. All data are obtained from Bloomberg and span our data sample, June 1, 2011 to December 31, 2012. 


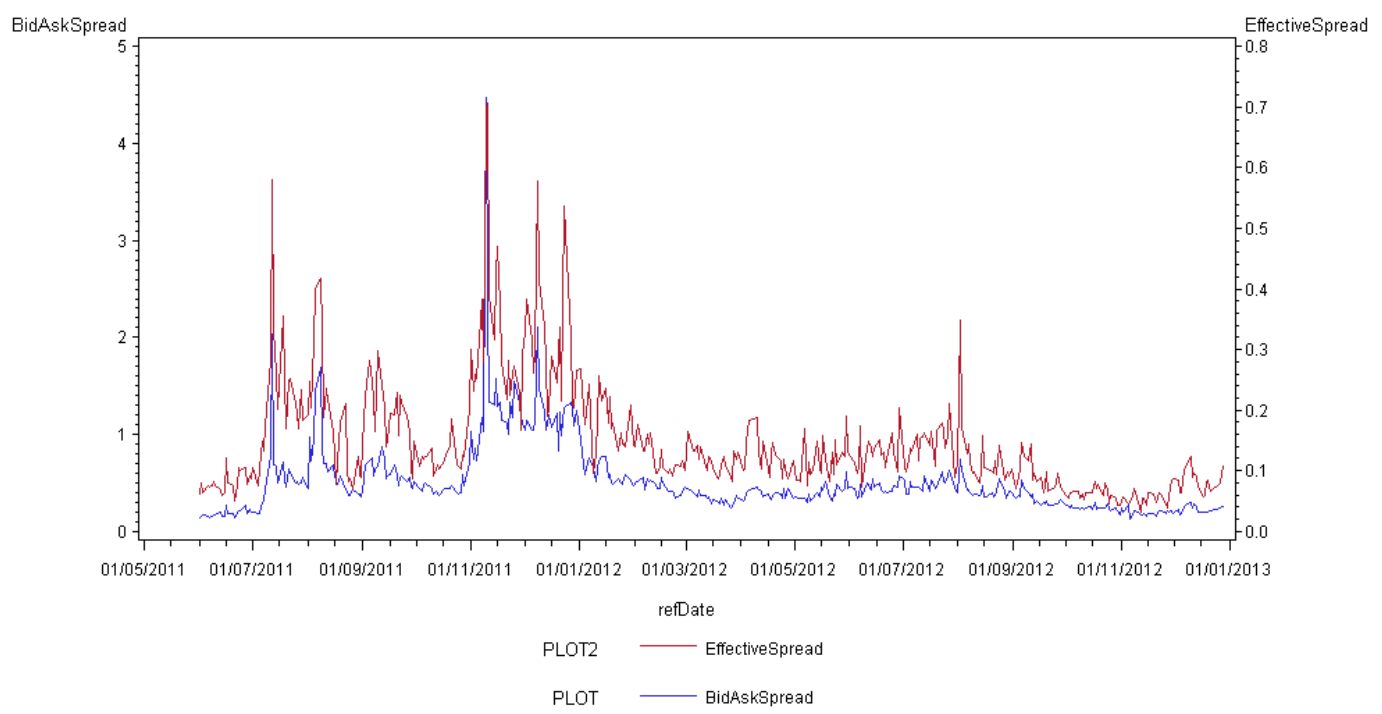

(a) Quoted and Effected Bid-Ask Spread

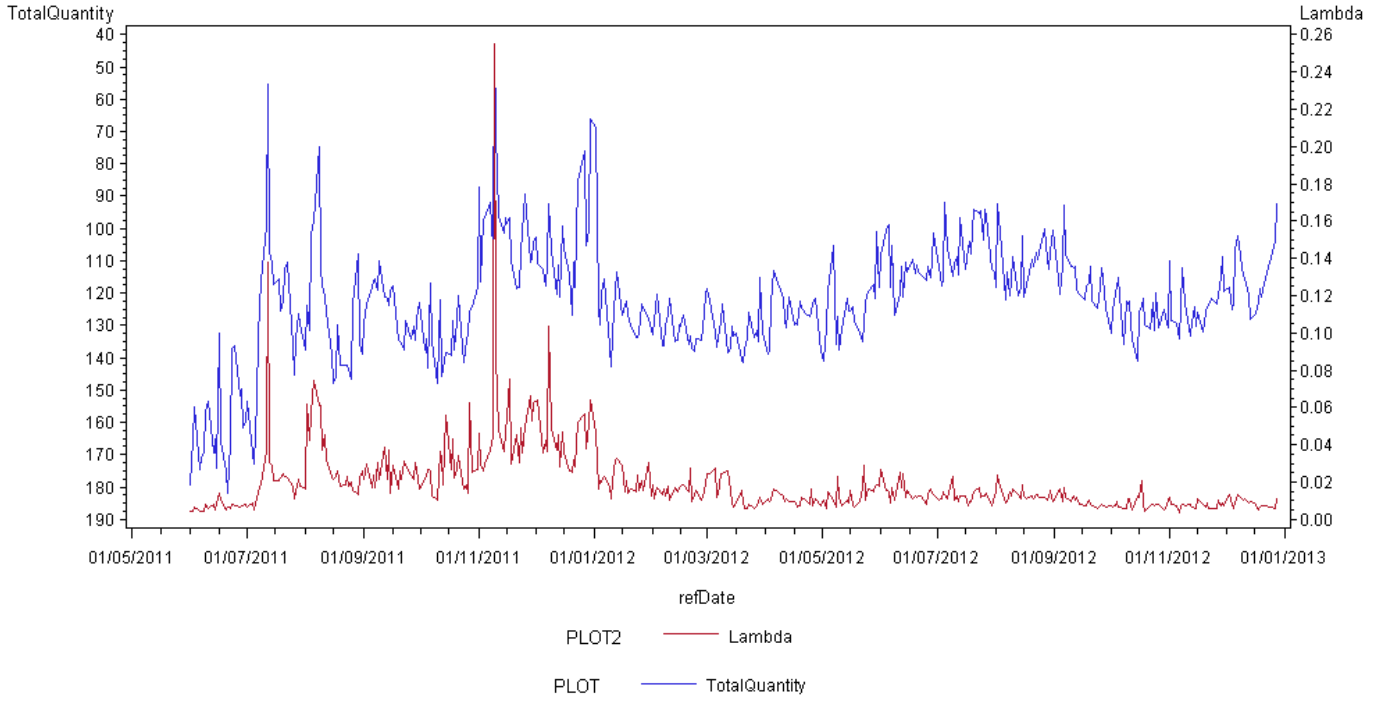

(b) Quoted Quantity and Lambda

Figure 2: Time Series of Liquidity Measures Panel A shows the time-series evolution of the Quoted and Effective Spread, while Panel B shows the depth measure Lambda and Quoted Quantity. Our data set consists of transactions, quotes, and orders for all 152 fixed-rate and floating Italian government bonds (Buoni Ordinari del Tesoro (BOT) or Treasury Bills or Certificato del Tesoro Zero-coupon (CTZ) or Zero coupon bonds, Certificati di Credito del Tesoro (CCT) or Floating notes, and Buoni del Tesoro Poliennali (BTP) or Fixed-income Treasury Bonds) from June 1, 2011 to December 31, 2012. 


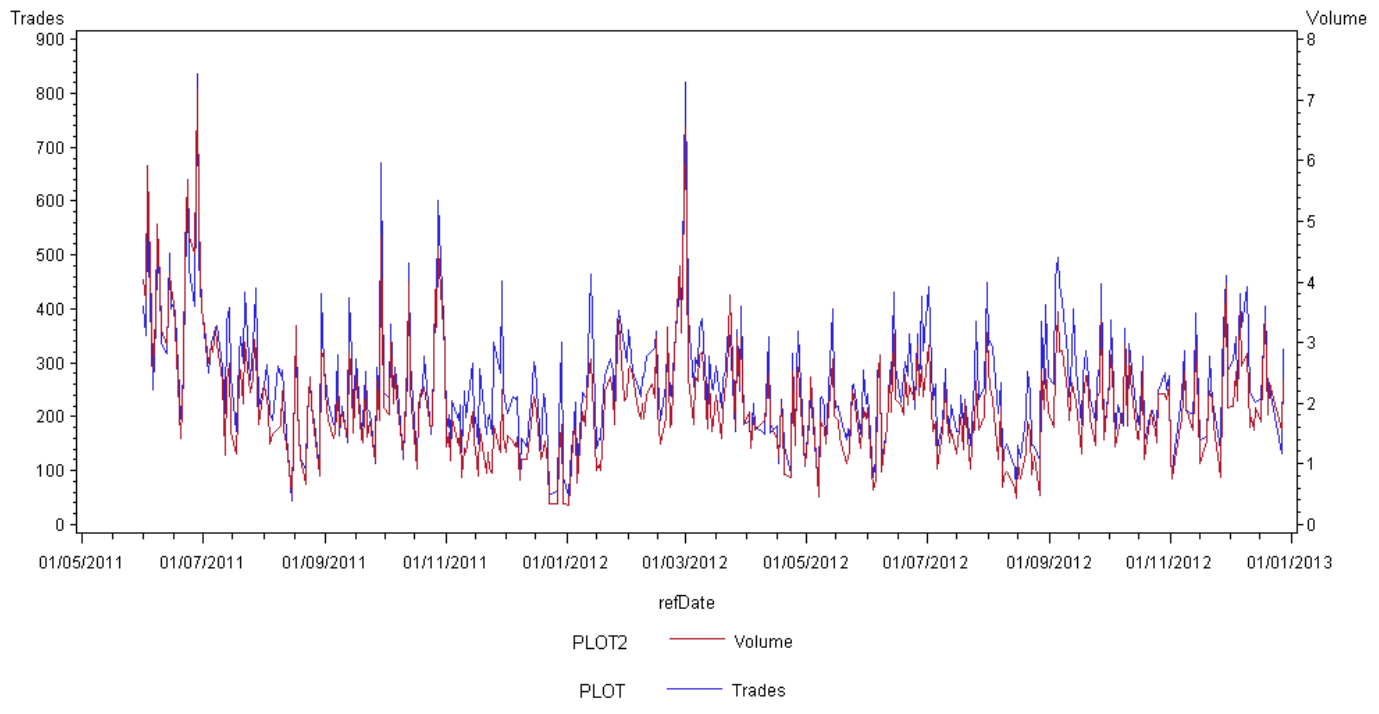

(a) Trades and Volume

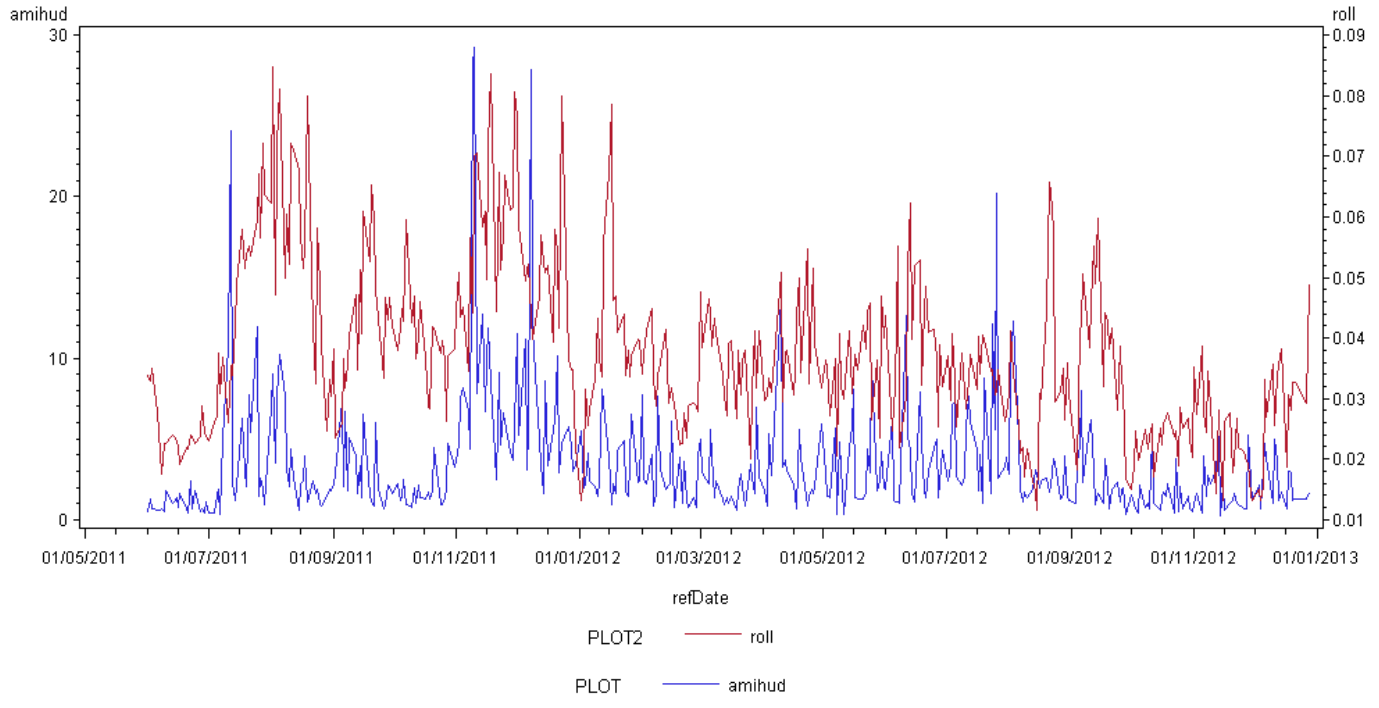

(b) Amihud and Roll Measures

Figure 3: Time Series of Liquidity Measures and Volume Panel A shows the time-series evolution of the overall market volume, right-hand side axis, in billions euro, and the overall number of trade, left-hand side axis. Panel B shows the time-series evolution of classical liquidity measures such as Roll and Amihud. Our data set consists of transactions, quotes, and orders for all 152 fixed-rate and floating Italian government bonds (Buoni Ordinari del Tesoro (BOT) or Treasury Bills or Certificato del Tesoro Zero-coupon (CTZ) or Zero coupon bonds, Certificati di Credito del Tesoro (CCT) or Floating notes, and Buoni del Tesoro Poliennali (BTP) or Fixed-income Treasury Bonds) from June 1, 2011 to December 31, 2012. 


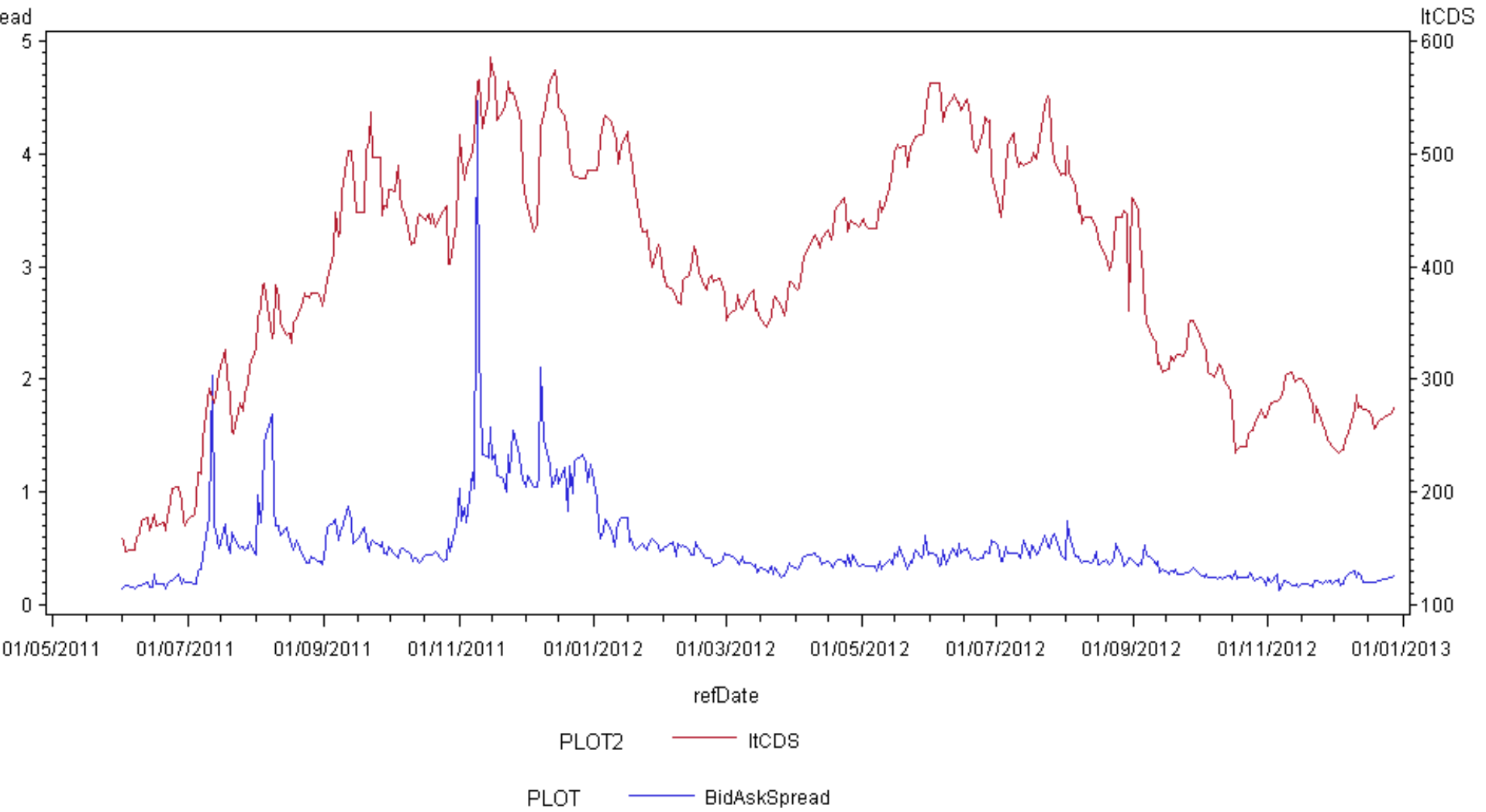

Figure 4: Time Series of Bid-Ask Spread and CDS Spread The figure shows the evolution of the MTS market quoted spread, left-hand side axis, in euro, and the Italian CDS spread, right-hand side axis, in bps. Our data set consists of transactions, quotes, and orders for all 152 fixed-rate and floating Italian government bonds (Buoni Ordinari del Tesoro (BOT) or Treasury Bills or Certificato del Tesoro Zero-coupon (CTZ) or Zero coupon bonds, Certificati di Credito del Tesoro (CCT) or Floating notes, and Buoni del Tesoro Poliennali (BTP) or Fixed-income Treasury Bonds) from June 1, 2011 to December 31, 2012. Data for the CDS Spread are obtain from Bloomberg for a 5-year US-denominated CDS contract. 


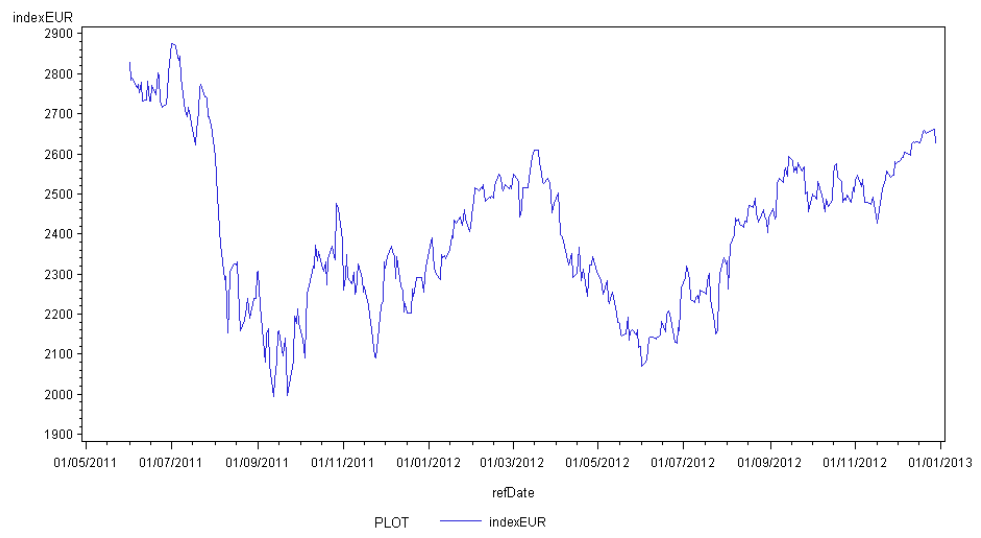

(a) Euro Stocks Index

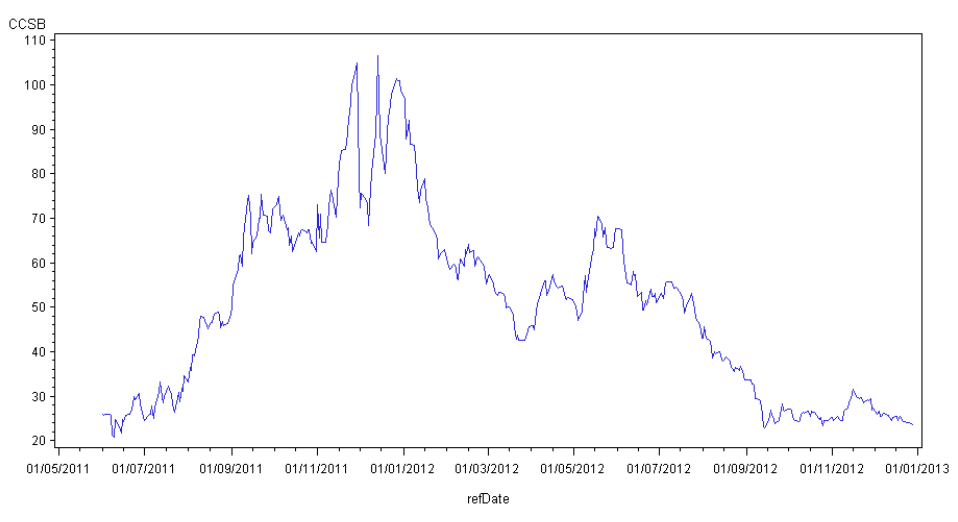

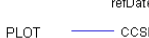

(c) Cross Currency Basis Swap Spread

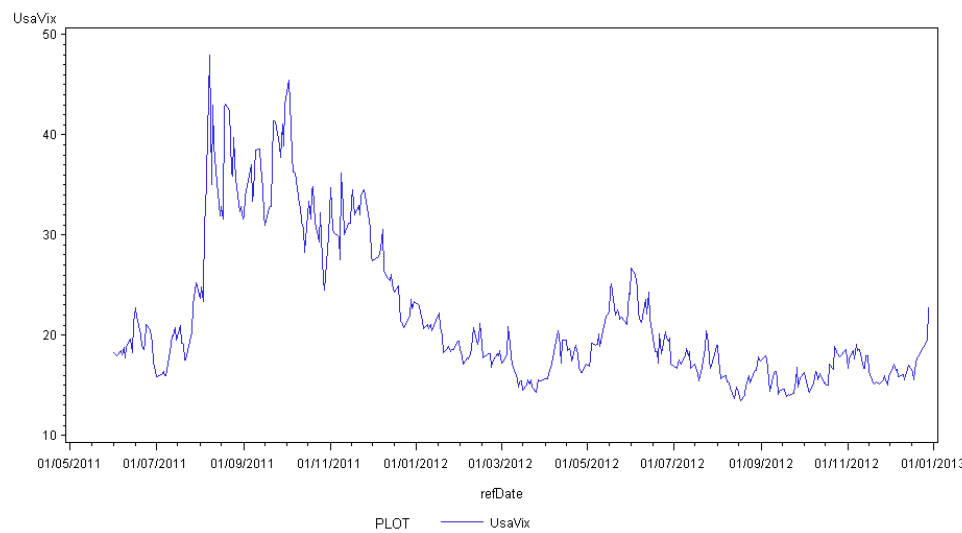

(b) USVIX Index

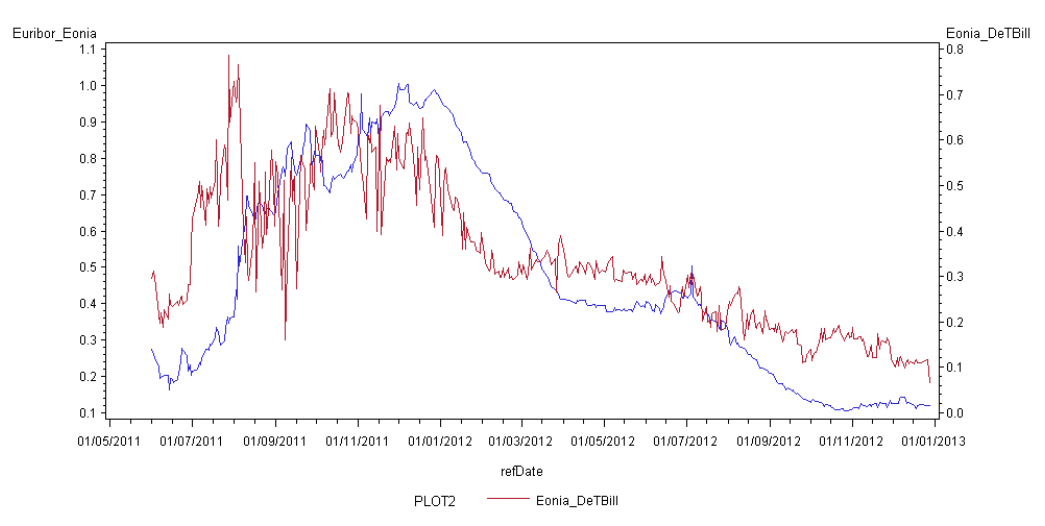

(d) 3-Month Euribor-Eonia and Eonia-German T-Bill Spreads

Figure 5: Time Series of Macro, Liquidity-, and Credit-Risk Variables The time-series evolution of the global variables Euro 50 Index, the USVIX, the Cross-Currency Basis Swap Spread, and the spreads between 3-month Euribor and 3-month Eonia and between 3-month Eonia and the yield of a 3-month German T-Bill are shown in Panels A, B, C, and D, respectively. Global variables are described in detail in Section IV Our data set was obtained from Bloomberg and covers the period from June 1, 2011 to December 31, 2012. 


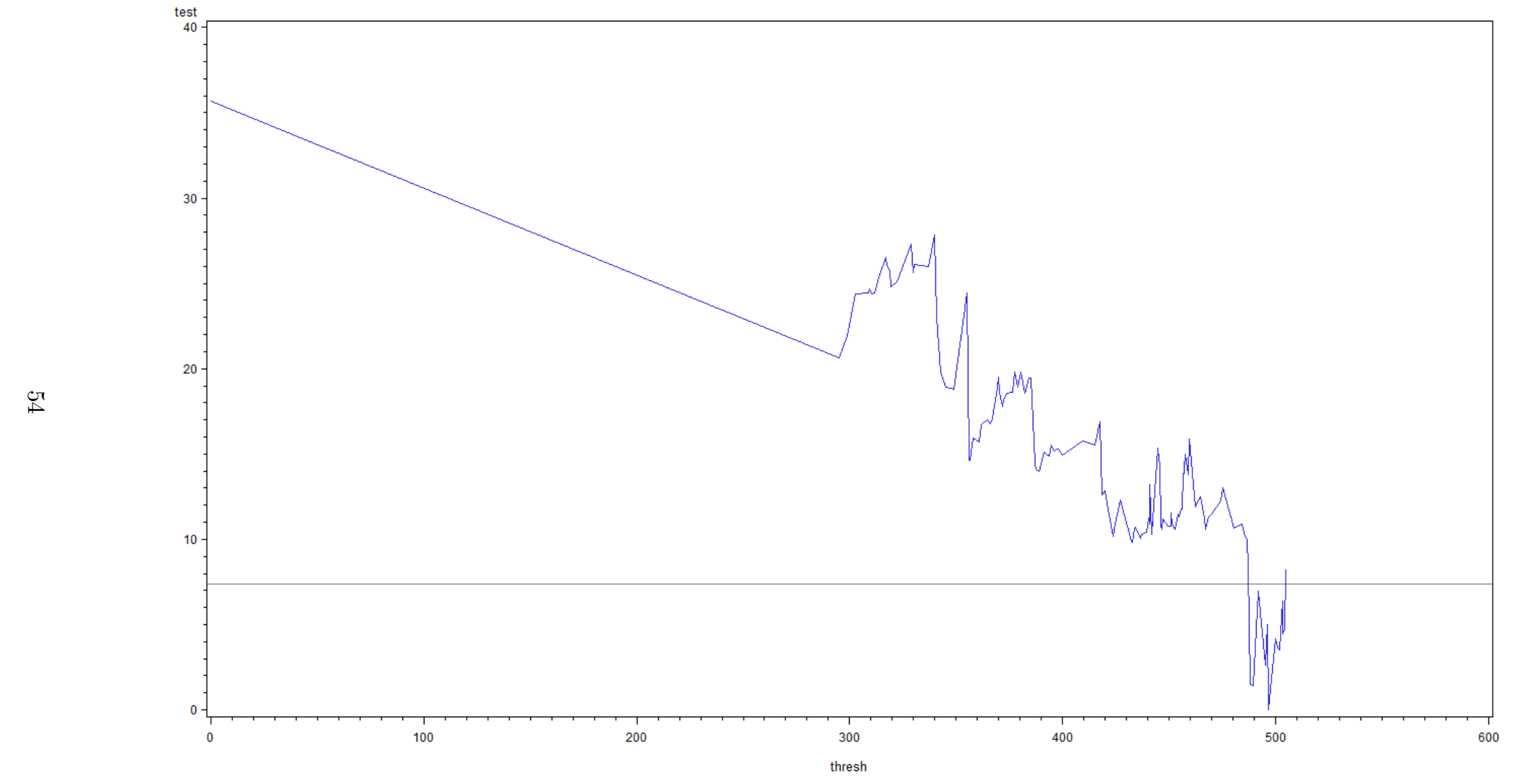

Figure 6: Test Statistic for CDS Threshold for Specification 6 The test statistic described in Appendix $\mathrm{C}$ is plotted here for the regression $\Delta L M_{t}=$ $\alpha_{0}+\alpha_{1} \Delta L M_{t-1}+\alpha_{2} \Delta L M_{t-2}+\alpha_{3} \Delta L M_{t-3}+\beta_{0} \Delta C D S_{t}+\beta_{1} \Delta C D S_{t-1}$, estimated on the whole sample. The test statistic is normalized at 0 at the threshold which minimizes the sum of squared residuals. The horizontal line at 7.35 individuates the $5 \%$ confidence values for the threshold. 


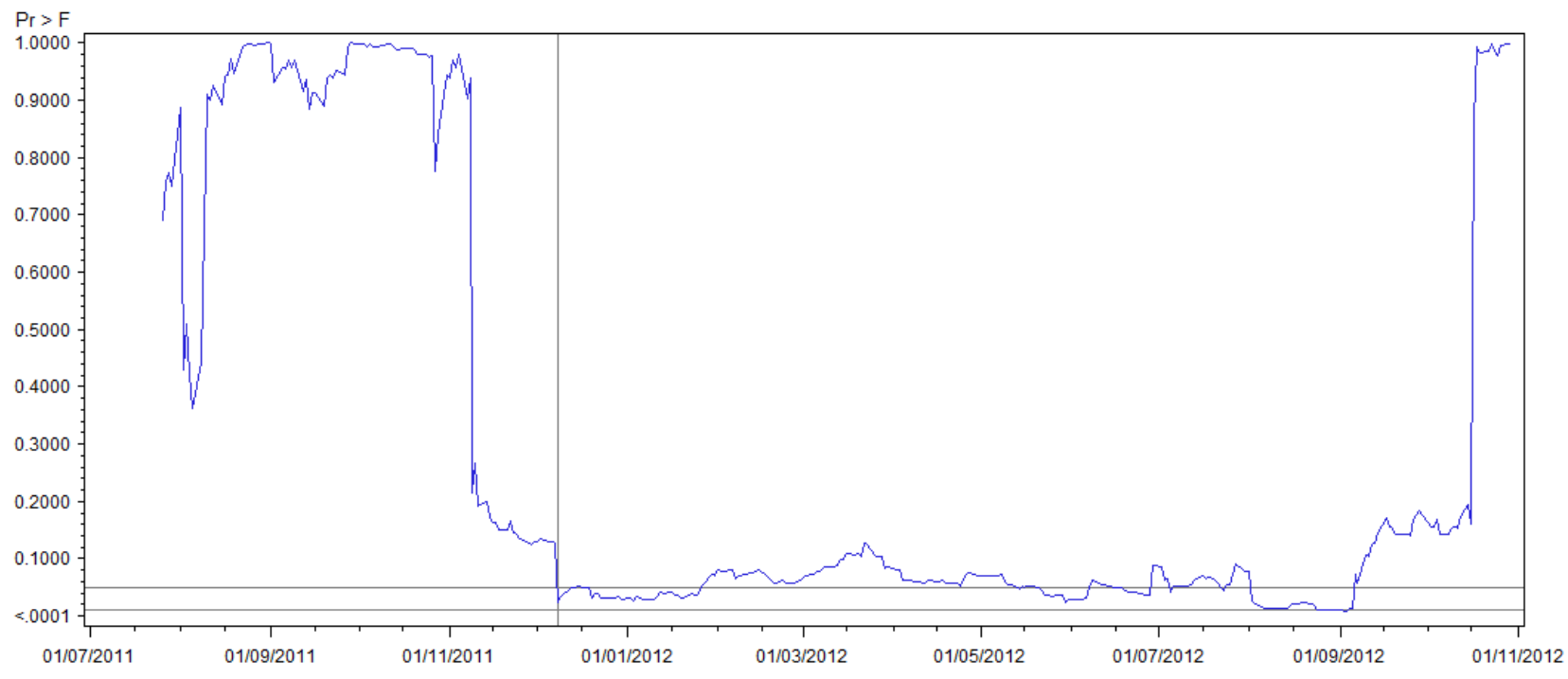

(a) Chow Test $\Delta B A_{t}=\alpha+\Delta C D S_{t}$

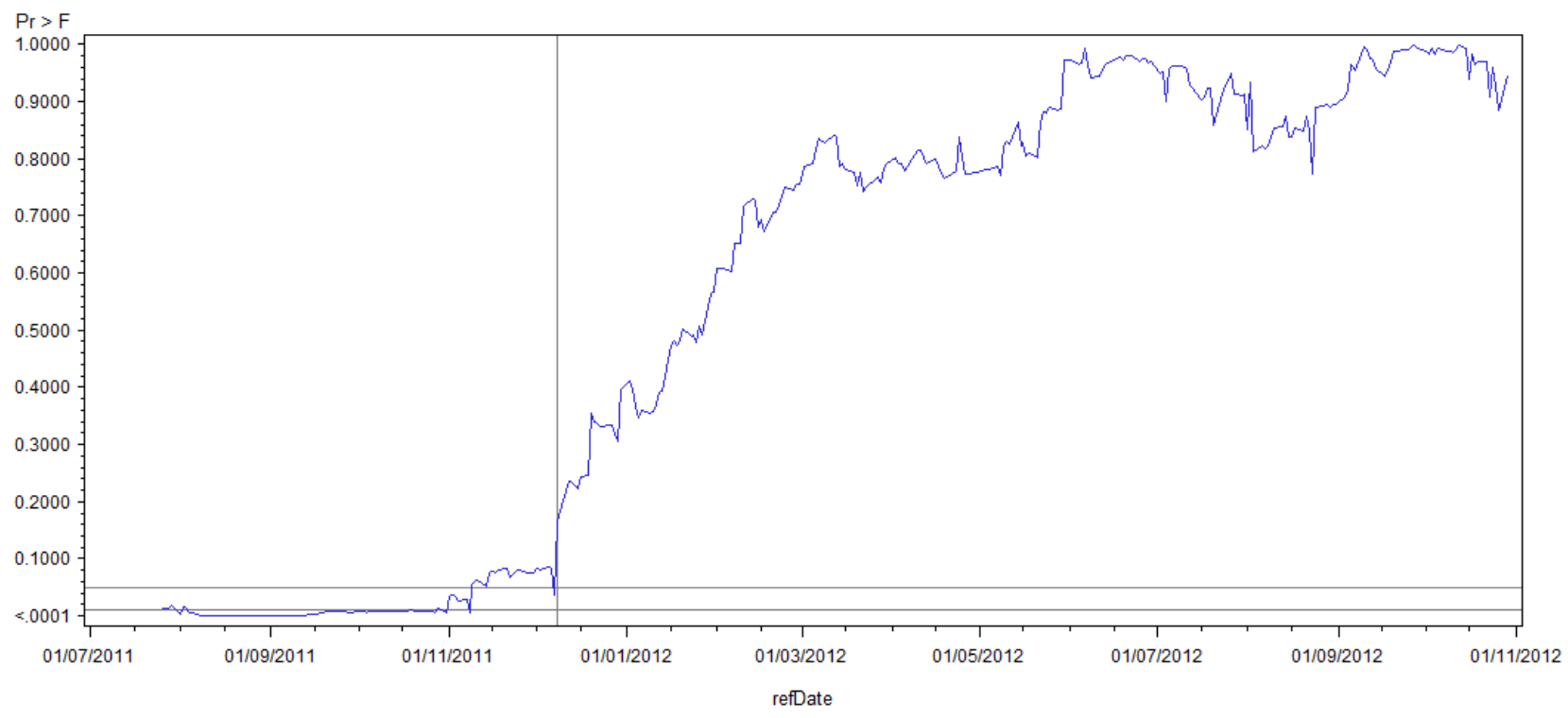

(b) Chow Test $\Delta B A_{t}=\alpha+\Delta C D S_{t-1}$

Figure 7: Chow Test Significance for Different Specifications Panel A and B show the significance of the Chow test calculated by testing each day in our sample as a structural-break point for the specifications $\Delta B A_{t}=\alpha+\Delta C D S_{t}$ and $\Delta B A_{t}=\alpha+\Delta C D S_{t-1}$, respectively, where $\Delta B A_{t}$ is the change in quoted spread on the MTS market and $\Delta C D S_{t}$ is the change in Italian CDS from day t- 1 to day t. The CDS data were obtained from Bloomberg and cover the period from June 1, 2011 to December 31, 2012. 


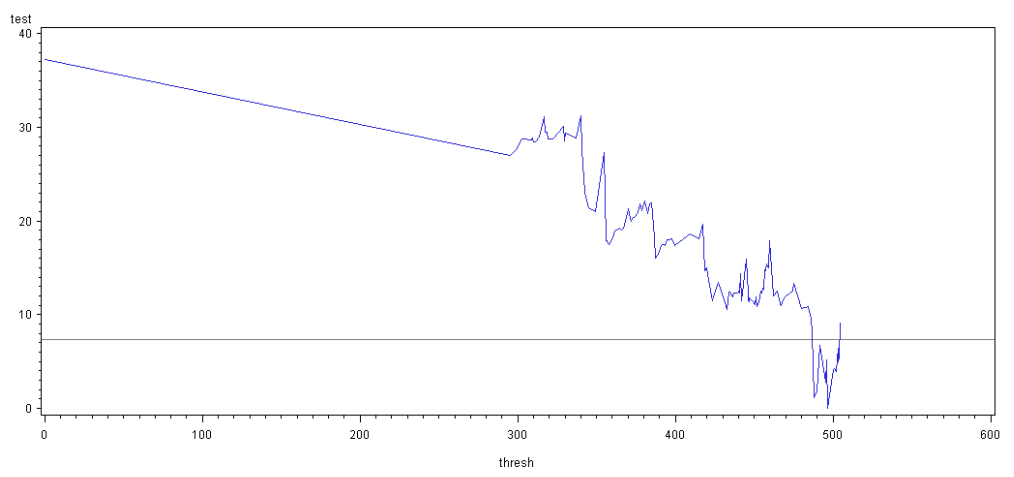

(a) Threshold Localization: Whole Sample

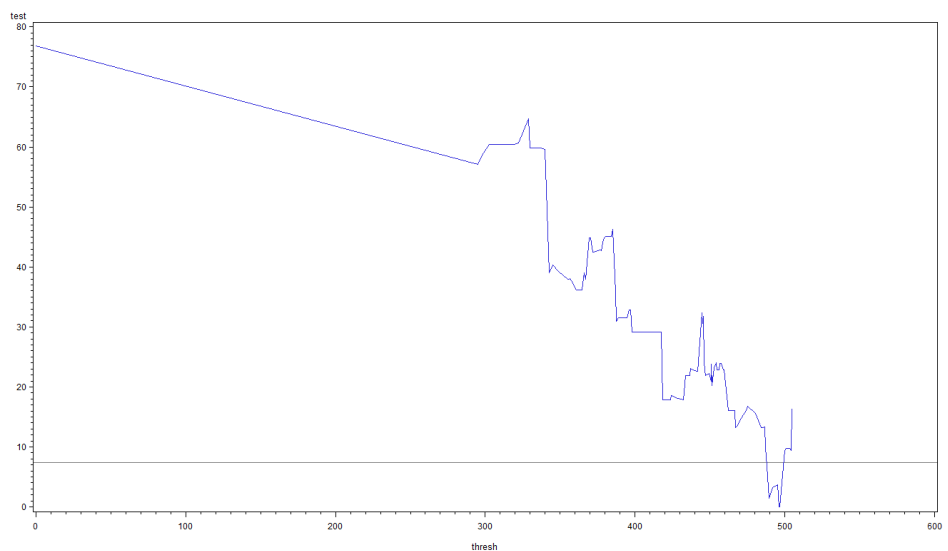

(b) Threshold Localization: 2011 Sample

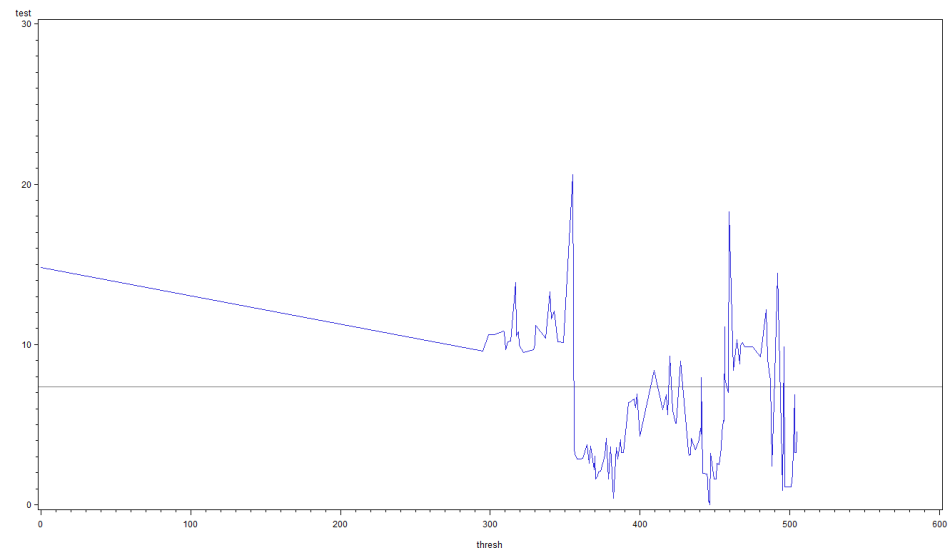

(c) Threshold Localization: 2012 Sample

Figure 8: Test Statistic for CDS Threshold for Specification 4 in Different Sub-samples The test statistic described in Appendix $\mathrm{C}$ is plotted here for the regression $\Delta L M_{t}=\alpha_{0}+\alpha_{1} \Delta L M_{t-1}+\alpha_{2} \Delta L M_{t-2}+\alpha_{3} \Delta L M_{t-3}+$ $\beta_{0} \Delta C D S_{t}+\beta_{1} \Delta C D S_{t-1}$, estimated on the different sub-samples. The test statistic is normalized at 0 at the threshold which minimizes the sum of squared residuals for each sub-sample. The horizontal line at 7.35 individuates the $5 \%$ confidence values for the threshold 


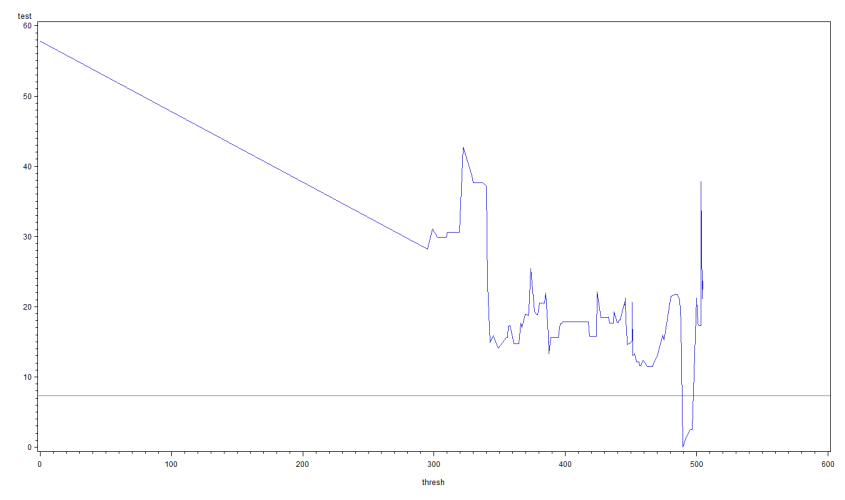

(a) Quoted Quantity: Threshold Localization

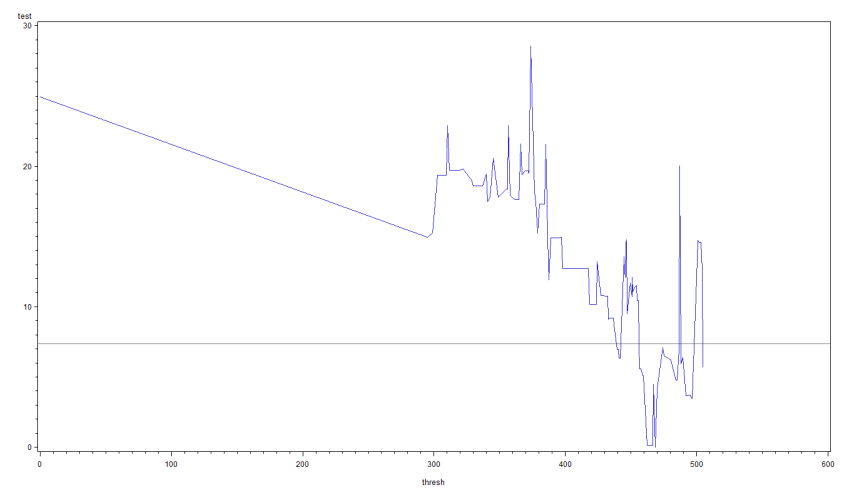

(c) Effective Spread: Threshold Localization

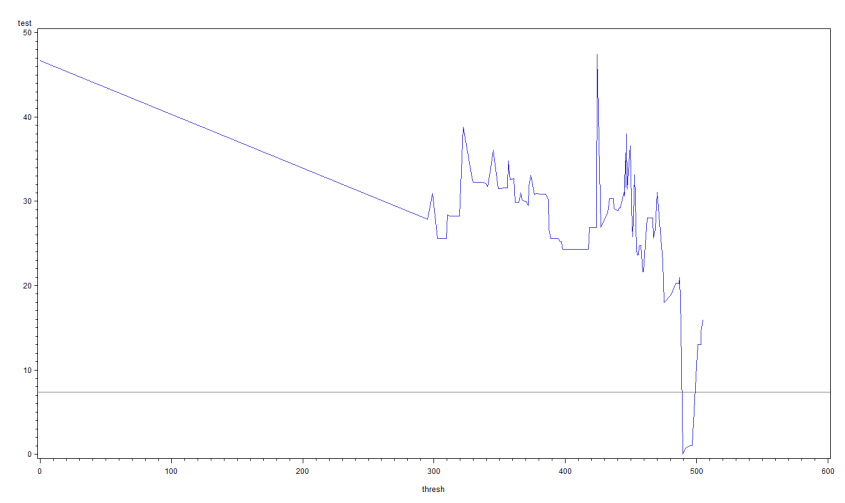

(e) Lambda: Threshold Localization

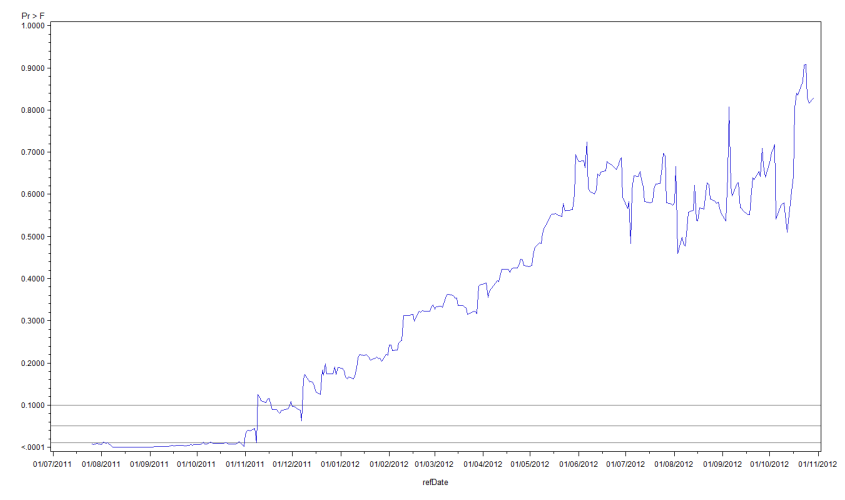

(b) Quoted Quantity: Structural Break

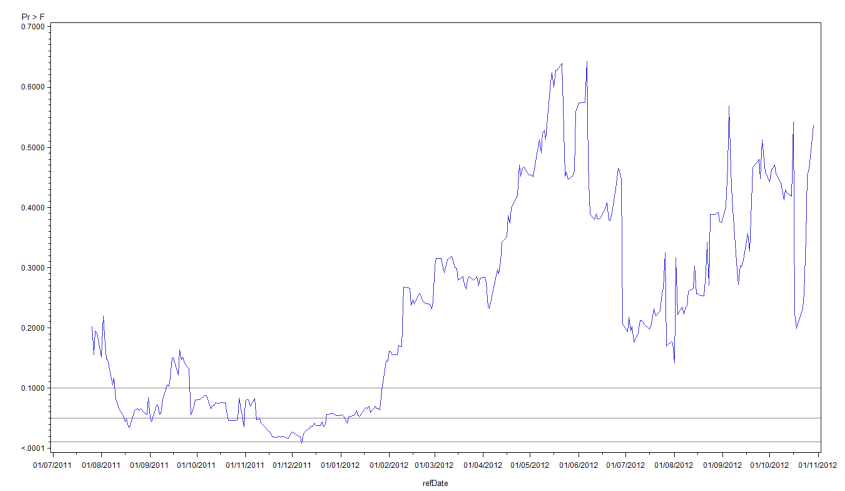

(d) Effective Spread: Structural Break

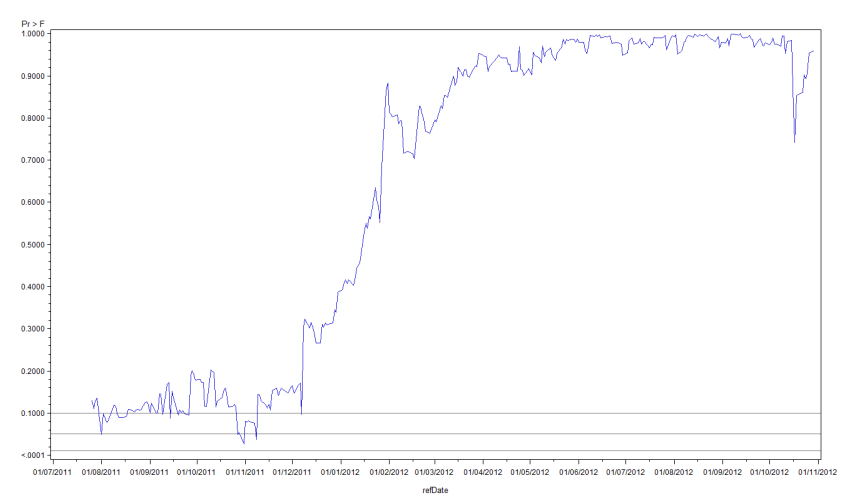

(f) Lambda: Structural Break

Figure 9: Test Statistic for CDS Threshold and Significance of the Chow Test for Structural Break for Different Liquidity Measures Panel a), c), and e) plot the test statistic for the regression $\Delta L M_{t}=\alpha_{0}+\alpha_{1} \Delta L M_{t-1}+$ $\alpha_{2} \Delta L M_{t-2}+\alpha_{3} \Delta L M_{t-3}+\beta_{0} \Delta C D S_{t}+\beta_{1} \Delta C D S_{t-1}$, estimated on the 2011 sub-samples for the liquidity measure Quoted Quantity, Effective Spread, and Lambda, respectively. The test statistic is normalized at 0 at the threshold which minimizes the sum of squared residuals for 2011 sub-sample for each liquidity measures. The horizontal line at 7.35 individuates the $5 \%$ confidence values for the threshold. Panel b), d), and f) plot the significance of the Chow test calculated by testing each day in our sample as a structural-break point for the specification $\Delta L M_{t}=\alpha+\Delta C D S_{t-q}$ in the overall sample, for the liquidity measure Quoted Quantity, Effective Spread, and Lambda, respectively. The horizontal lines individuates the $10 \%, 5 \%$, and $1 \%$ significance levels. 


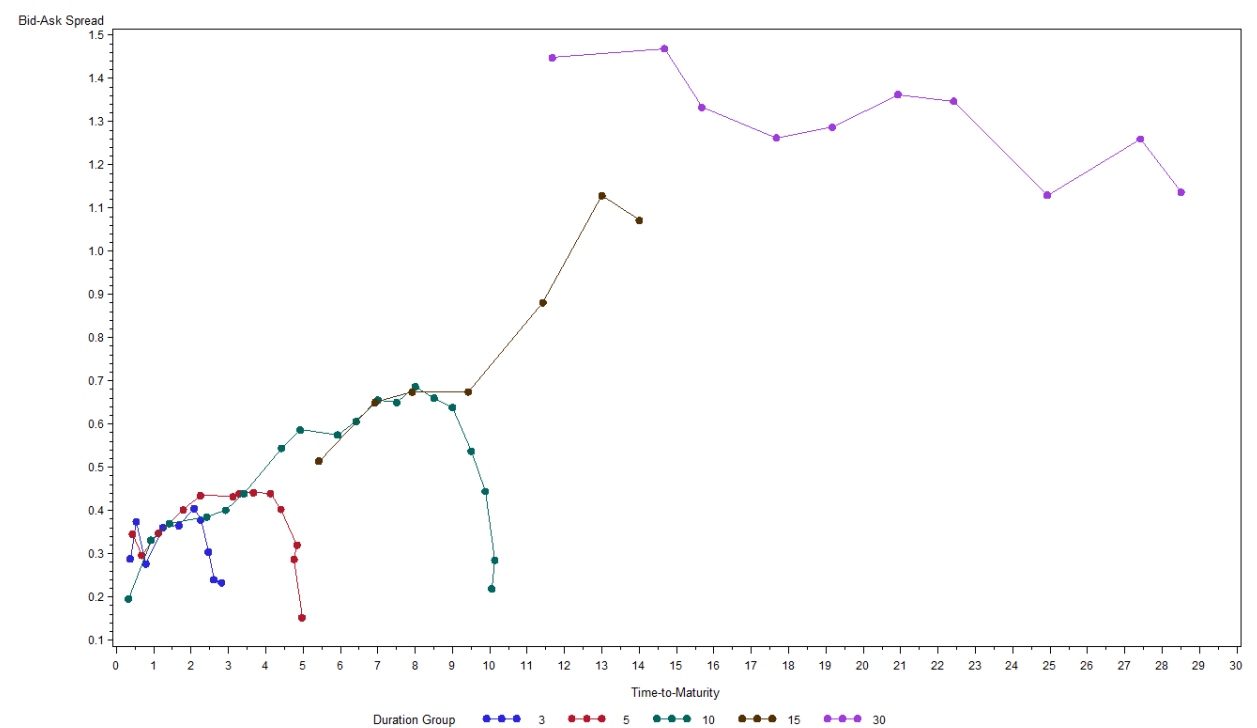

Figure 10: Cross-sectional Relationship between Bid-ask Spread and Time-to-Maturity. This figure shows the non-linear relationships between Age or Time-to-Maturity and Maturity in the cross-section. Every dot is one of the 58 coupon-bearing bonds in the sample. The y-axis is the Quoted Bid-Ask Spread, while the x-axis is the Time-toMaturity (i.e. the origin is the maturity date). Different colors correspond to different maturity groups. Our data set consists of transactions, quotes, and orders for all 152 fixed-rate and floating Italian government bonds (Buoni Ordinari del Tesoro (BOT) or Treasury Bills or Certificato del Tesoro Zero-coupon (CTZ) or Zero coupon bonds, Certificati di Credito del Tesoro (CCT) or Floating notes, and Buoni del Tesoro Poliennali (BTP) or Fixed-income Treasury Bonds) from June 1, 2011 to December 31, 2012. 


\section{References}

Acharya, V. V., Drechsler, I., and Schnabl, P., 2012, A Pyrrhic victory? Bank bailouts and sovereign credit risk. National Bureau of Economic Research Working Paper.

Acharya, V. V., and Pedersen, L. H., 2005, Asset pricing with liquidity risk. Journal of Financial Economics, 77(2), 375-410.

Amihud, Y., and Mendelson, H., 1980, Dealership market: Market-making with inventory. Journal of Financial Economics, 8(1), 31-53.

Bagehot, W.,1971, The only game in town. Financial Analysts Journal, 27(2), 12-14.

Bai, J., Julliard, C., and Yuan, K., 2012, Eurozone Sovereign Bond Crisis: Liquidity or Fundamental Contagion, Federal Reserve Bank of New York Working Paper.

Bao, J., Pan, J., and Wang, J., 2011, Liquidity and corporate bonds. Journal of Finance, 66, 911-946.

Beber, A., Brandt, M. W., and Kavajecz, K. A., 2009, Flight-to-quality or flight-to-liquidity? Evidence from the Euro-area bond market. Review of Financial Studies, 22(3).

Bessembinder, H., and Maxwell, M., 2008, Markets: Transparency and the corporate bond market. The Journal of Economic Perspectives, 22(2), 217-234.

Brunnermeier, M. K., 2009, Deciphering the liquidity and credit crunch 2007-08. National Bureau of Economic Research Working Paper.

Brunnermeier, M. K., and Pedersen, L. H., 2009, Market liquidity and funding liquidity. Review of Financial Studies, 22(6), 2201-2238.

Caner, M., Hansen, B. E., 2001, Threshold autoregression with a unit root. Econometrica, 69(6), $1555-1596$.

Caporale, G. M., and Girardi, A., 2011, Price formation on the EuroMTS platform. Applied Economics Letters, 18(3), 229-223.

Chakravarty, S., and Sarkar, A., 1999, Liquidity in U.S. fixed income markets: A comparison of the bid-ask spread in corporate, government and municipal bond markets. Federal Reserve Bank of New York Staff Report.

Cheung, Y. C., de Jong, F., and Rindi, B., 2005, Trading European Sovereign Bonds: The Microstructure of the MTS Trading Platforms. European Central Bank Working Paper.

Chow, G. C., 1960, Test of equality between sets of coefficients in two linear regressions. Econometrica, 28(2), 591-605.

Coluzzi, C., Ginebri, S., and Turco, M., 2008, Measuring and Analyzing the Liquidity of the Italian Treasury Security Wholesale Secondary Market, Working Paper, Università degli Studi del Molise Working Paper. 
Darbha, M., and Dufour, A., 2012, Measuring Euro Area Government Bond Market liquidity and its Asset Pricing Implications, Working Paper, University of Reading.

Davies, R. B., 1977, Hypothesis Testing when a Nuisance Parameter is Present Only under the Alternative, Biometrika, 64, 247-254.

Davies, R. B., 1987, Hypothesis Testing when a Nuisance Parameter is Present Only under the Alternative, Biometrika, 74, 33-43.

Dick-Nielsen, J., 2009, Liquidity biases in TRACE. Journal of Fixed Income, 19, 43-55.

Dick-Nielsen, J., Feldhütter, P., and Lando, D., 2012, Corporate bond liquidity before and after the onset of the subprime crisis. Journal of Financial Economics, 103, 471-492

Duffie, D., Garleanu, N., and Pedersen, L. H., 2007, Valuation in over-the-counter markets. Review of Financial Studies, 20(6), 1865-1900.

Dufour, A., and Nguyen, Minh, 2011, Permanent Trading Impacts and Bond Yields. University of Reading Working Paper.

Dufour, A., and Skinner, F., 2004, MTS Time Series: Market and Data Description for the European Bond and Repo Database. University of Reading Working Paper.

Easley, D., and O'Hara, M., 1987, Price, trade size, and information in securities markets. Journal of Financial Economics, 19(1), 69-90.

Engle, R., 2002, New frontiers for ARCH models. Journal of Applied Econometrics, 17, 425-446.

Engle, R., Fleming, M. J., Ghysels, E., and Nguyen, G., 2011, Liquidity and Volatility in the U.S. Treasury Market: Evidence From A New Class of Dynamic Order Book Models. Federal Reserve Bank of New York Working Paper.

Fama, E. F., French, K. R., 1993, Common risk factors in the returns on stocks and bonds. Journal of Financial Economics, 33(1), 3-56.

Favero, C., Pagano, M., and Von Thadden, E., 2010, How does liquidity affect government bond yields? Journal of Financial and Quantitative Analysis, 45.

Feldhütter, P., 2012, The same bond at different prices: Identifying search frictions and selling pressures. The Review of Financial Studies, 25(4), 1155-1206.

Fleming, M. J., 2003, Measuring Treasury Market Liquidity. Federal Reserve Bank of New York Economic Policy Review 2003.

Fleming, M. J., and Mizrach, B., 2009, The Microstructure of a U.S. Treasury ECN: The BrokerTec Platform. Federal Reserve Bank of New York Staff Report.

Fleming, M. J., and Remolona, E. M., 1999, Price formation and liquidity in the U.S. Treasury market: The response to public information. The Journal of Finance, 54(5). 
Friewald, N., Jankowitsch, R., and Subrahmanyam, M. G., 2012a, Illiquidity or credit deterioration: A study of liquidity in the U.S. corporate bond market during financial crises. Journal of Financial Economics, 105, 18-36.

Friewald, N., Jankowitsch, R., and Subrahmanyam, M. G., 2012b, Liquidity, Transparency and Disclosure in the Securitized Product Market, New York University Working Paper.

Garbade, K. D., and Silber, W. L., 1976, Price dispersion in the government securities market. The Journal of Political Economy, 721-740.

Garman, M. B., 1976, Market microstructure. Journal of Financial Economics, 3(3), 257-275.

Glosten, L. R., and Milgrom, P. R., 1985, Bid, ask and transaction prices in a specialist market with heterogeneously informed traders. Journal of Financial Economics, 14(1), 71-100.

Goyenko, R., Subrahmanyam, A., and Ukhov, A., 2011, The term structure of bond market liquidity and its implications for expected bond returns. Journal of Financial and Quantitative Analysis, 46, 1.

Hameed, A., Kang, W., and Viswanathan, S., 2010, Stock market declines and liquidity. The Journal of Finance, 65(1)

Hansen, B., 1996, Inference when a nuisance parameter is not identified under the null hypothesis, Econometrica, 64(2).

Hansen, B., 1999, Threshold e!ects in non-dynamic panels: Estimation, testing, and inference, Journal of Econometrics 93, 345-3680.

Hansen, B., 2000, Sample Splitting and Threshold Estimation, Econometrica 68(3).

He, Z., and Milbrandt, K., 2013, Endogenous liquidity and defaultable bonds. National Bureau of Economic Research Working Paper.

Ho, T., and Stoll, H. R., 1980, On dealer markets under competition. The Journal of Finance, 35(2), 259-267.

Hurvich, C. M., and Tsai, C.-L., 1989, Regression and time series model selection in small samples. Biometrika, 76, 297-307.

Jankowitsch, R., Nashikkar, A., and Subrahmanyam, M., 2011, Price dispersion in OTC markets: A new measure of liquidity. Journal of Banking and Finance, 35, 343-357.

Kyle, A. S., 1985, Continuous auctions and insider trading. Econometrica, 1315-1335.

Lin, H., Wang, J., and Wu, C., 2011, Liquidity risk and expected corporate bond returns. Journal of Financial Economics, 99, 628-650.

Longstaff, F. A., Pan, J., Pedersen, L. H., Singleton, K. J., 2010, How Sovereign is Sovereign Credit Risk?, American Economic Journal: Macroeconomics, 3(2), 75103. 
Longstaff, F.A., S. Mithal and E. Neis, 2005, Corporate yield spreads: default risk or liquidity? New evidence from the credit default swap market. Journal of Finance, 60(5), 2213-2253.

Mahanti, S., Nashikkar, A., Subrahmanyam, M., Chacko, G., and Mallik, G., 2008, Latent liquidity: A new measure of liquidity, with an application to corporate bonds. Journal of Financial Economics, $88,272-298$.

Nashikkar, A., Subrahmanyam, M., and Mahanti, S., 2011, Liquidity and arbitrage in the market for credit risk. Journal of Financial and Quantitative Analysis, 46, 627-656.

Pasquariello, P., Roush, J., and Vega, C., 2011, Government Intervention and Strategic Trading in the U.S. Treasury Market, University of Michigan Working Paper.

Pasquariello, P., and Vega, C., 2006, Informed and Strategic Order Flow in the Bond Markets. Board of Governors of the Federal Reserve System Working Paper.

Pelizzon, L., Subrahmanyam, M., Tomio, D., and Uno, J., 2013, The Microstructure of the European Sovereign Bond Market: A Study of the Euro-zone Crisis, New York University Working Paper.

Reiss, P., and Werner I., 1998, Does Risk Sharing Motivate Interdealer Trading?. Journal of Finance, $53,5,1657-1703$.

Ronen, T., and Zhou, X., 2009, Where Did All the Information Go? Trade in the Corporate Bond Market, Rutgers University Working Paper.

Roll, R., 1984, A simple implicit measure of the effective bid-ask spread in an efficient market. Journal of Finance, 39, 1127-1139.

Sadka, R., 2010, Liquidity risk and the cross-section of hedge-fund returns. Journal of Financial Economics, 98(1), 54-71.

Vickery, J. I., and Wright, J., TBA Trading and Liquidity in the Agency MBS Market, Federal Reserve Bank of New York. 